\title{
WestVirginiaUniversity
}

THE RESEARCH REPOSITORY @ WVU

Graduate Theses, Dissertations, and Problem Reports

2002

\section{Effects of high -dose chemotherapy on the bone marrow microenvironment}

Brett Matthew Hall

West Virginia University

Follow this and additional works at: https://researchrepository.wvu.edu/etd

\section{Recommended Citation}

Hall, Brett Matthew, "Effects of high -dose chemotherapy on the bone marrow microenvironment" (2002). Graduate Theses, Dissertations, and Problem Reports. 1627.

https://researchrepository.wvu.edu/etd/1627

This Dissertation is protected by copyright and/or related rights. It has been brought to you by the The Research Repository @ WVU with permission from the rights-holder(s). You are free to use this Dissertation in any way that is permitted by the copyright and related rights legislation that applies to your use. For other uses you must obtain permission from the rights-holder(s) directly, unless additional rights are indicated by a Creative Commons license in the record and/ or on the work itself. This Dissertation has been accepted for inclusion in WVU Graduate Theses, Dissertations, and Problem Reports collection by an authorized administrator of The Research Repository @ WVU.

For more information, please contact researchrepository@mail.wvu.edu. 


\title{
Effects of High Dose Chemotherapy on the Bone Marrow Microenvironment
}

\author{
Brett Matthew Hall \\ fulfillment of the requirements for the degree of \\ Doctor of Philosophy \\ in \\ Microbiology, Immunology and Cell Biology \\ Laura Gibson, Ph.D., Chair \\ Solveig Ericson, M.D., Ph.D. \\ Kenneth Landreth, Ph.D. \\ Jeannine Strobl, Ph.D. \\ David Weissman, M.D.
}

Dissertation submitted to the School of Medicine at West Virginia University in partial

Department of Microbiology, Immunology, and Cell Biology

Morgantown, WV

2002

Key Words: Microenvironment, VCAM-1, SDF-1, etoposide, VP-16, bone marrow, chemotherapy, hematopoiesis, stromal cell, transplant, cancer 


\title{
ABSTRACT \\ Effects of High Dose Chemotherapy on the Bone Marrow Microenvironment
}

\author{
Brett M. Hall
}

The bone marrow microenvironment composed in part of stromal cells provides the niche in which normal hematopoiesis occurs. Hematopoiesis generates cellular components of the immune system and blood through proliferation and differentiation of multipotent hematopoietic stem cells (HSC). In preparation for bone marrow transplantation, radiation or chemotherapy treatment temporarily disrupts the balance of hematopoiesis as many HSC and progenitor cells are destroyed. Following treatment cessation, transplanted HSC and progenitor cells migrate, or "home", back to the bone marrow microenvironment and initiate productive hematopoiesis. While the mechanism of bone marrow homing is not completely understood, several soluble factors and adhesion molecules are known to have specific roles in the process. The chemokine stromal derived factor-1 (SDF-1) and the adhesion molecule vascular cell adhesion molecule-1 (VCAM-1) are critical in mediating HSC chemotaxis and adhesion, respectively. In addition, both molecules have been demonstrated to be critical for maintenance of productive hematopoiesis.

We previously demonstrated and characterized stromal cell VCAM-1 protein down-regulation following in vitro exposure to the topoisomerase II inhibitor etoposide (VP-16). VP-16-induced VCAM-1 down-regulation is associated with an impairment of stromal cell layers to support early lymphoid and myeloid cell proliferation. More recently, we evaluated stromal cell SDF-1 protein production following exposure to several chemotherapeutic drugs, and we found that bone marrow stromal cell SDF-1 protein secretion is also disrupted following VP-16 or doxorubicin exposure. SDF-1 protein reductions correlated with a reduced capacity of B-cell progenitor lines to migrate toward chemotherapy-treated stromal cell layers. Finally, we have generated and characterized murine stromal cell lines that constitutively express human VCAM-1 protein. Human VCAM-1 expression is maintained following exposure to VP-16 and overall elevation of VCAM-1 protein offset diminished viabilities in B cell progenitors following removal of exogenous IL-7.

This research will contribute to better understanding mechanistic models that address the hypothesis that aggressive chemotherapy disrupts immune system reconstitution through bone marrow microenvironment damage and disruption of molecules that regulate homing. Ultimately, this work may improve our understanding of delayed immune system recovery following aggressive chemotherapy and lead to enhanced cancer treatment strategies. 


\section{DEDICATION}

This dissertation is dedicated to my wife, Terrie Hall, whose sacrifices at home and work have given me the opportunity to achieve my dreams. To my children, Tiffany and Ryan Hall, my greatest motivation to succeed is to provide you with the opportunities to pursue your dreams. 


\section{ACKNOWLEDGEMENTS}

I am deeply grateful to my mentor Dr. Laura Gibson, a truly exceptional person, scientist, and educator. Under Dr. Gibson's instruction, graduate school has been an outstanding learning experience for me in developing as a young scientist. I am thankful for all of her assistance, patience, and time these past four years of my training. My experiences here at West Virginia University will stay with me throughout my life.

I would also like to thank all of my committee members, past and present, for their enthusiasm, time, and advice. I have been privileged to have excellent committee members including Dr. Solveig Ericson, Dr. Kenneth Landreth, Dr. Jeannine Strobl, Dr. David Weissman, Dr. John Barnett, Dr. Marylin Evans, and Dr. Eric Westin.

I would like to thank Jim Fortney for his friendship and assistance during my graduate school tenure. Our interactions have enriched my lab experiences and enhanced my experimental productivity.

Finally, l'd like to thank all of those that have been instrumental in my educational process. To my father, Thomas Hall, I thank you for your encouragement, friendship, love, and support. You have always been there for me. In loving memory of my mother, Phyliss Hall, my life has felt your loss. You are deeply missed. To my sister, Julie Charlton, I cannot begin to list how wonderful you have been to have for a sister and a friend throughout the years. To the best educators that l've had the pleasure of learning from, including Mr. Dennis Gwirtz, Mr. Gary Cole, Dr. Janet Tarino, and Dr. Laura Gibson, I thank you all and hold all of you in the highest esteem. 


\section{TABLE OF CONTENTS}

Effects of High Dose Chemotherapy on the Bone Marrow

Microenvironment i

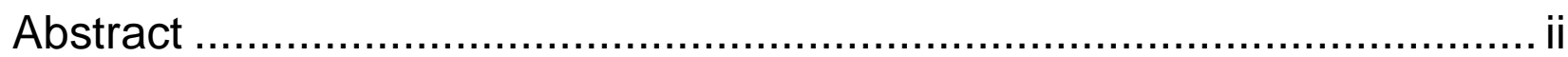

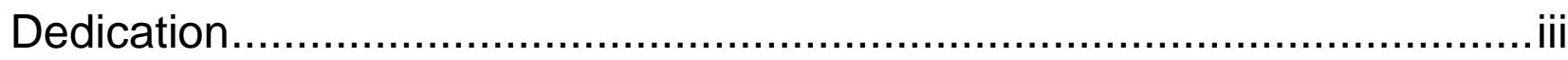

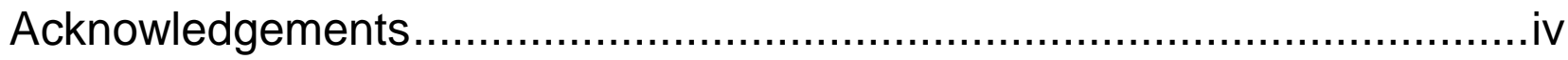

Table of Contents ...........................................................................

List of Figures ............................................................................. vii

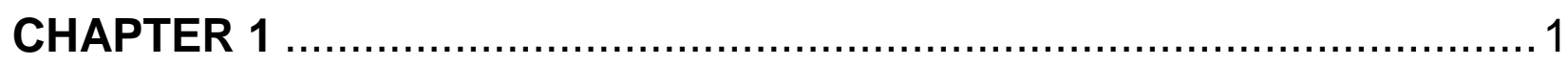

Introduction and Review of Literature................................................ 1

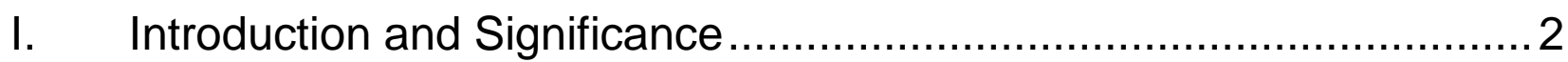

II. Hematopoiesis ........................................................................... 3

III. Bone Marrow Anatomy ........................................................... 10

IV. Bone Marrow Microenvironment .............................................. 12

V. Bone Marrow Homing ............................................................ 16

VI. Bone Marrow Mobilization...................................................... 19

VII. Bone Marrow Microenvironment Damage ......................................21

VIII. Corrective Medical Intervention Strategies.....................................23

IX. Summary and Goals ................................................................. 24

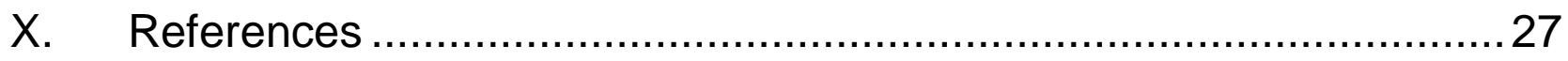

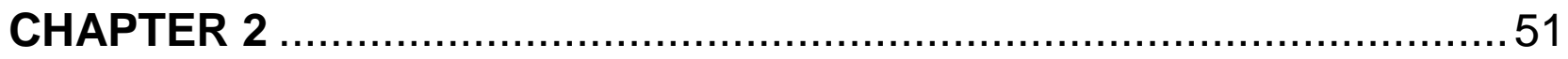

Human Bone Marrow Stromal Cell SDF-1 Production is Reduced Following exposure to Topoisomerase II Inhibitors, Etoposide or Doxorubicin............51

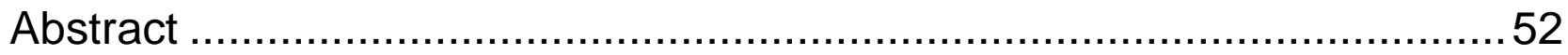

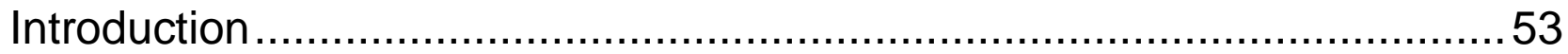




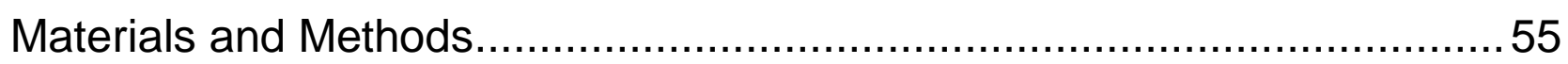

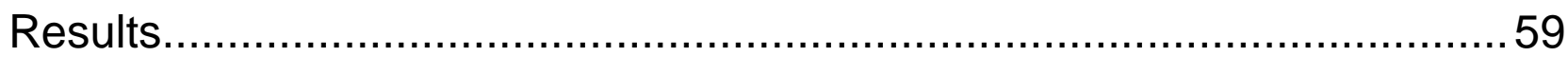

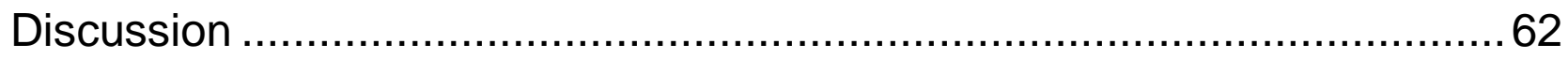

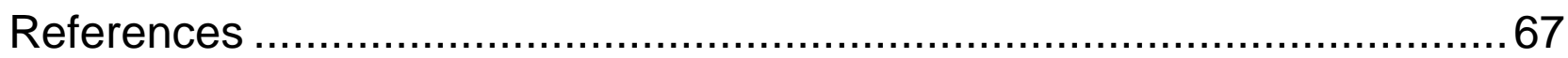

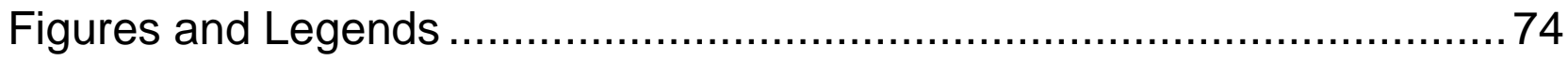

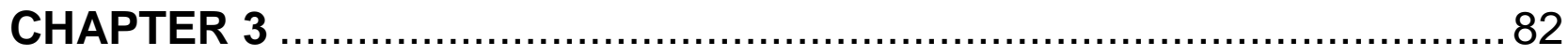

Alteration of nuclear factor- $\mathrm{kB}(\mathrm{NF}-\kappa \mathrm{B})$ Expressed in Bone Marrow Stromal

Cells Treated with Etoposide .......................................................... 82

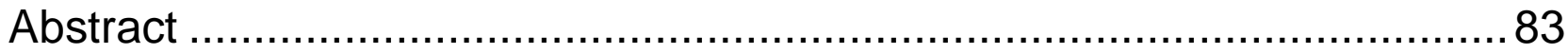

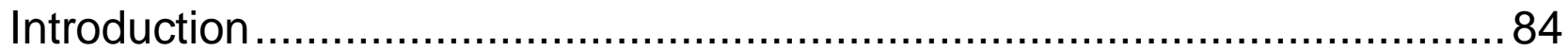

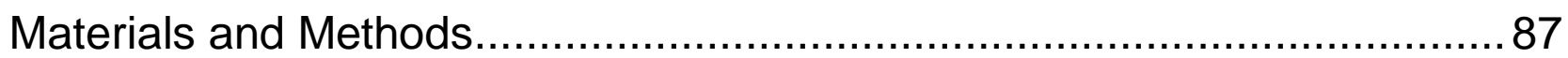

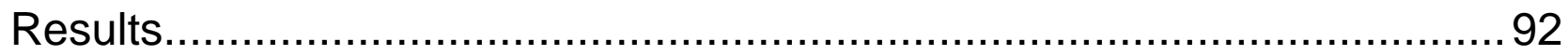

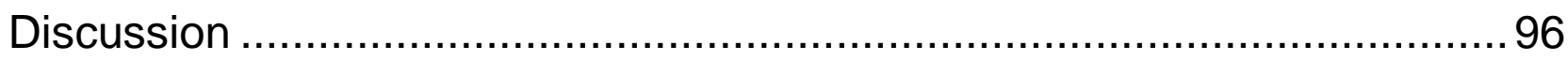

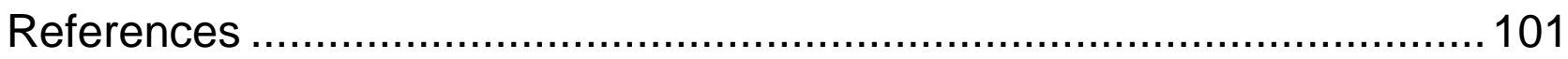

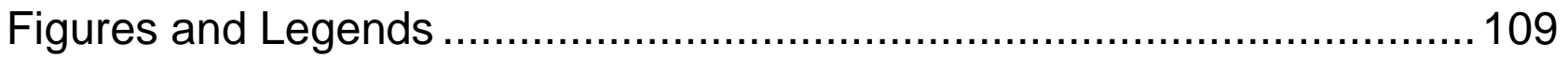

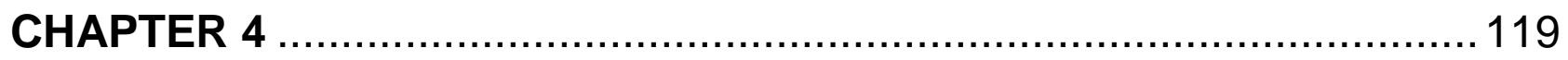

Characterization of Stromal Cell Lines Stably Transfected with Human

VCAM-1

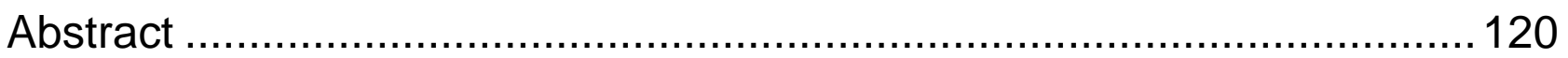

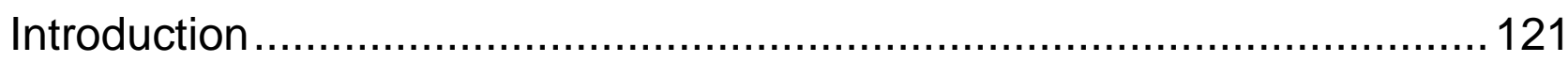

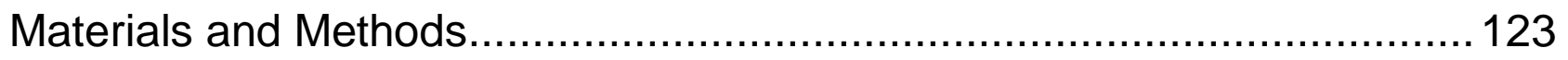

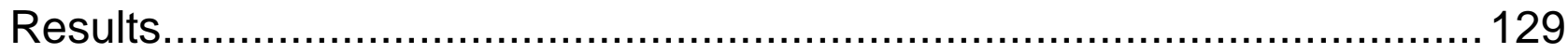

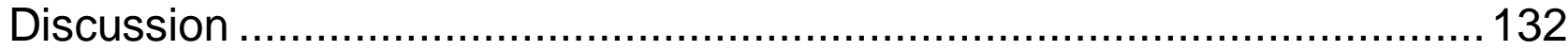

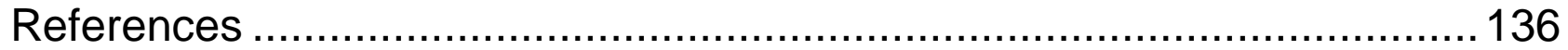

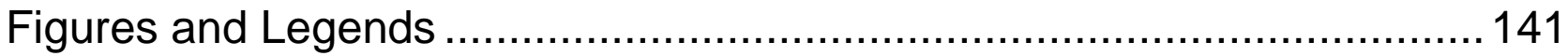

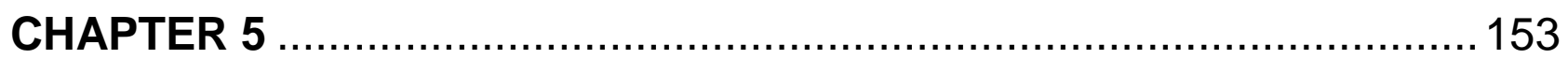

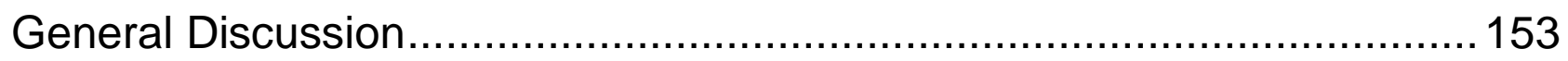




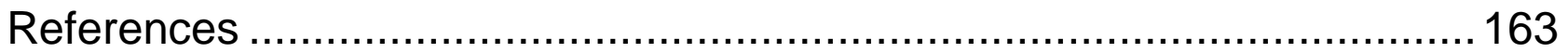

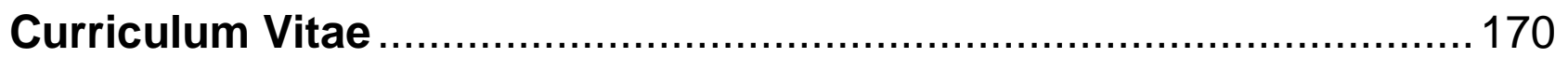

\section{LIST OF FIGURES}

\section{CHAPTER 1}

Figure 1. Anatomical locations of mammalian hematopoietic system during ontogeny . 4

Figure 2. Hardy Scheme: phenotypic characteristics of B-cell development..............7

Figure 3. Structure of murine and human VCAM-1 adhesion molecules ..................9

\section{CHAPTER 2}

Figure 1. VP-16 and doxorubicin reduce bone marrow stromal cell SDF-1 protein

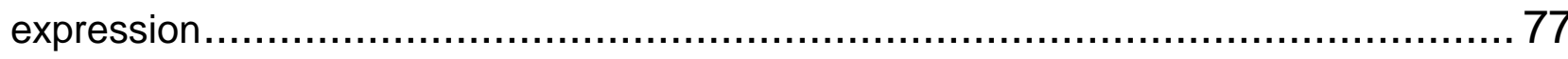

Figure 2. SDF-1 message is modestly reduced in bone marrow stromal cells following chemotherapy treatment 78

Figure 3. Stromal cell capacity to support JM-1 migration is restored by rSDF-1

following treatment

Figure 4. VP-16 treated stromal cells have sustained reductions in SDF-1 protein production

Figure 5. Stromal cell ability to support JM-1 chemotaxis does not recover for up to three days following removal of chemotherapy

\section{CHAPTER 3}

Figure 1. VCAM-1 transcripts in bone marrow stromal cells treated with VP-16.

Figure 2. Cellular localization of NF-kB p65 and p50 subunits following treatment of bone marrow stromal cells with VP-16.

Figure 3. Nuclear p65 and p50 protein in stromal cells following treatment withVP-16 
Figure 4. NF-kB binding to its consensus sequence in VP-16 treated stromal cells.... 115

Figure 5. $\mid \kappa-B \alpha$ protein expression in stromal cells exposed to VP-16 ..................... 116

Figure 6. VCAM-1 expression in (E)-Capsaicin treated stromal cells ....................117

Figure 7. Nuclear p65 and p50, and VCAM-1 protein expression return to baseline

levels following removal of chemotherapy.....

\section{CHAPTER 4}

Figure 1. Mammalian expression vector maps ( $\beta$-galactosidase and human VCAM-1)

Table 1. Qualitative expression of $\beta$-galactosidase in vector control cell lines (C3, C5,

C17, C27, C43, C48, C54, C64, and C73)

Figure 2. Human VCAM-1 (hVCAM-1) expression on selected $\mathrm{hVCAM}-1^{+}$and $\beta$-gal ${ }^{+}$ cell lines.

Figure 3. Murine VCAM-1 (mVCAM-1) expression on representative cell lines, C54 and V49

Figure 4. Human and murine VCAM-1 RNA expression in multiple cell lines 150

Figure 6. Pro-B cell clone C1.92 chemotaxis and binding associated with C54 and V49 stromal cell clones

Figure 7. Expression of VCAM-1 and fibronectin protein following exposure to $100 \mu \mathrm{M}$

Figure 8. Expansion and survival of the stromal cell-dependent pro-B cell line $\mathrm{C} 1.92$ on C54 or V49 in the absence of rlL-7 152

\section{CHAPTER 5}

Figure 1. Model of hematopoietic delays associated with altered stromal cell function

Figure 2. Corrective bone marrow environment following dose-escalated

chemotherapy 


\section{LIST OF ABBREVIATIONS}

extracellular matrix (ECM)

stromal derived factor-1 (SDF-1)

vascular cell adhesion molecule-1 (VCAM-1)

yolk sac (YS)

aorta, gonad, mesonephros region (AGM)

hematopoietic stem cell (HSC)

hematopoietic progenitor cell (HPC)

common lymphoid progenitor cell (CLP)

terminal deoxynucleotidyl transferase (TdT)

interleukin-7 (IL-7)

leukocyte inhibitory factor (LIF)

stem cell factor (SCF)

granulocyte macrophage-colony stimulating factor (GM-CSF)

insulin-like growth factor-1 (IGF-1)

macrophage inflammatory protein-1 $\alpha$ (MIP- $1 \alpha)$

glycol phosphatidylinositol (GPI)

very late antigen-4 (VLA-4)

very late antigen-5 (VLA-5)

colony forming unit - spleen $\left(\mathrm{CFU}_{\mathrm{S}}\right)$

colony forming unit - culture $\left(\mathrm{CFU}_{\mathrm{C}}\right)$

graft-versus-host disease (GVHD)

bone marrow endothelial cell (BMEC)

bone marrow transplantation (BMT)

granulocyte-colony stimulating factor (G-CSF)

colony forming unit-fibroblast (CFU-F) 


\title{
CHAPTER I
}

\author{
Introduction and Review of Literature
}




\section{Introduction and Significance}

Hematopoiesis is the production of blood cells through stem cell renewal, proliferation and differentiation $(1 ; 2)$. In postnatal mammals, hematopoiesis occurs in the extravascular spaces of red as "hematopoietic" bone marrow $(3 ; 4)$. Unique biological compositions of individual bone marrow microenvironments predictably favor B-lymphopoiesis, erythropoiesis, or granulopoiesis. Hematopoietic microenvironments are composed of extracellular matrix (ECM), growth factors, and supportive hematopoietic and non-hematopoietic cells (5-7).

Fibroblastic stromal cells (stromal cell) are best characterized as principle microenvironmental regulators of B-lymphopoiesis (8-16). Soluble chemokine stromal derived factor-1 (SDF-1) and surface adhesion molecule vascular cell adhesion molecule-1 (VCAM-1) are two of the key factors produced by stromal cells that influence B cell development. SDF-1 is essential for establishing bone marrow concentration gradients that aid in the retention and attraction of hematopoietic progenitor and stem cells to the bone marrow, as well as influencing the expansion of immature B-cells $(17 ; 18)$. VCAM-1 is a critical stromal cell adhesion molecule that maintains the viability of stem cells, retains hematopoietic stem and progenitor cells within the bone marrow, and supports productive B-lymphopoiesis (12;19-22).

Sustained dysregulation of either of these stromal cell proteins would have devastating effects on the capacity of the bone marrow to adequately support steady state B-lymphopoiesis or to restore B-lymphopoiesis following bone marrow transplantation. Delays in B-cell recovery following ablative chemo-radiotherapy and 
bone marrow transplantation are observed clinically, and at times, observed B-cell deficits do not respond to exogenous growth factor therapy, suggesting potential damage to the supportive bone marrow microenvironments that support Blymphopoiesis (23-27).

Bone marrow transplantation is a common treatment strategy for many advanced stages of metastatic cancer (28-31). As such, defining the impact of high dose chemotherapy on bone marrow stromal cell function, with particular focus on key regulatory factors such as VCAM-1 and SDF-1, is essential. These studies may better define our understanding of hematopoietic recovery following bone marrow transplantation and also to the development of intervention strategies that enhance Bcell recovery. Data in this dissertation may contribute to optimized chemotherapeutic treatments that may enhance bone marrow capacity to restore and maintain robust hematopoiesis following bone marrow transplantation.

\section{Hematopoiesis}

Hematopoietic development in mammals involves progressive maturation from early or primitive hematopoiesis to definitive postnatal hematopoiesis at birth (Figure 1) (32-35). Primitive hematopoiesis, as found in the yolk sac (YS), does not contribute to later stages of hematopoiesis including establishment of fetal liver hematopoiesis. In contrast, definitive hematopoiesis expands to other hematopoietic tissues in a coordinated movement observed sequentially at distinct anatomical locations during embryogenesis (Figure 1). Mammalian hematopoietic stem cells originate from the ventral mesoderm cell layer $(32 ; 34)$. The more dorsal regions of the mesoderm give rise to stem cells for mesenchyme, kidney, muscle, and notochord (32). Primitive 


\section{Mammalian Hematopoietic System Development}

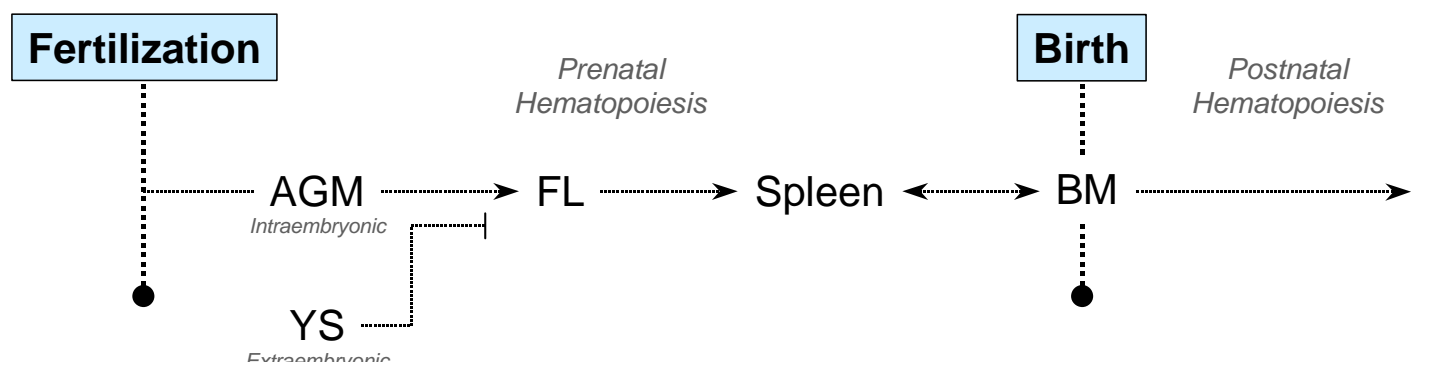

Figure 1. Anatomical locations of mammalian hematopoietic system during ontogeny 
hematopoiesis is first observed in the extraembryonic yolk sac and the intraembryonic AGM region (Aorta, Gonad, Mesonephros) (36-38). Embryonic vascularization allows for subsequent migration of primitive hematopoietic cells and colonization of sequential fetal tissues including the fetal liver, spleen and bone marrow (Figure 1) (39). Around birth, hematopoiesis predominantly shifts to the bone marrow $(40 ; 41)$.

Most mature blood cells have definitively short life spans (42-45). Therefore, hematopoiesis is a highly active process that is required to maintain blood cell numbers even during normal physiological states. Trilineage hematopoiesis (lymphopoiesis, myelopoiesis, and erythropoiesis) is regulated through environmental cues that act on primitive hematopoietic stem cells (HSC). Primitive hematopoietic stem cells are defined as a population of pluripotent cells that are able to self-renew and differentiate along each blood cell lineage $(2 ; 35 ; 45 ; 46)$. These stem cell characteristics can be determined through the use of multiple in vitro and in vivo assays described in detail elsewhere (47-49). As HSC differentiate, they become more committed to specific lineages and their capacity for self-renewal is diminished. Various stages of maturing HSC's are collectively referred to as hematopoietic progenitor cells (HPC). HPC have limited self-renewing capacities and are committed to either the lymphoid or myeloid lineages (50-54). Following bone marrow transplantation in humans, or experimentally in animals, the HSC and HPC populations contribute to long-term and short-term hematopoietic reconstitution respectively (55-57).

Further differentiation and maturation of HPC lead to lineage specific expansion and maintenance of the three blood cell lineages. The common lymphoid progenitor cell (CLP) is the most immature lymphoid cell committed to the B or T-cell 
developmental pathway. Phenotypic characterization of the CLP revealed that coexpression of CD34 and CXCR-4 represents the most immature CLP (i.e. precedes terminal deoxynucleotidyl transferase (TdT) and IL-7 receptor expression) (58). Even at this early progenitor cell stage, stromal cell influence, via SDF-1 production, is suggested from previous work that demonstrated that CXCR-4 activation induces myelosuppression (59). Regulation of stromal cell-dependent B-lymphopoiesis is central to work described in this thesis, and further discussion of hematopoiesis is focused on stromal cell regulation of B-cell development within the bone marrow. Detailed reviews on myeloid and erythroid cell development have been previously published (54;60-62).

Several groups have separately classified the stages of B-cell development based on germline DNA changes associated with B-cell receptor maturation, phenotypic expression of various proteins within the cytoplasm or on the cell membrane, growth factor and stromal cell dependence, or functional characteristics (63-67). For clarity, nomenclature for the stages of B-cell maturation in the current discussion corresponds to the phenotypic characteristics various surface cellular proteins as evaluated by flow cytometry (Figure 2) (63).

Development of B-lineage cells is tightly regulated by a complex interplay of soluble factors and adhesion molecules within microenvironmental niches $(4 ; 21 ; 68-70)$. A primary source of regulatory signals in the marrow microenvironment is bone marrow stromal cells. Bone marrow stromal cells produce proliferative, inhibitory, and chemotactic cytokines (e.g. IL-7, LIF, SCF, GM-CSF, IGF-1, Flt-3 ligand, MIP-1 $\alpha$, and SDF-1) that act on early hematopoietic progenitor cells. These factors function as either soluble or stromal anchored glycoproteins (12;71-75). 


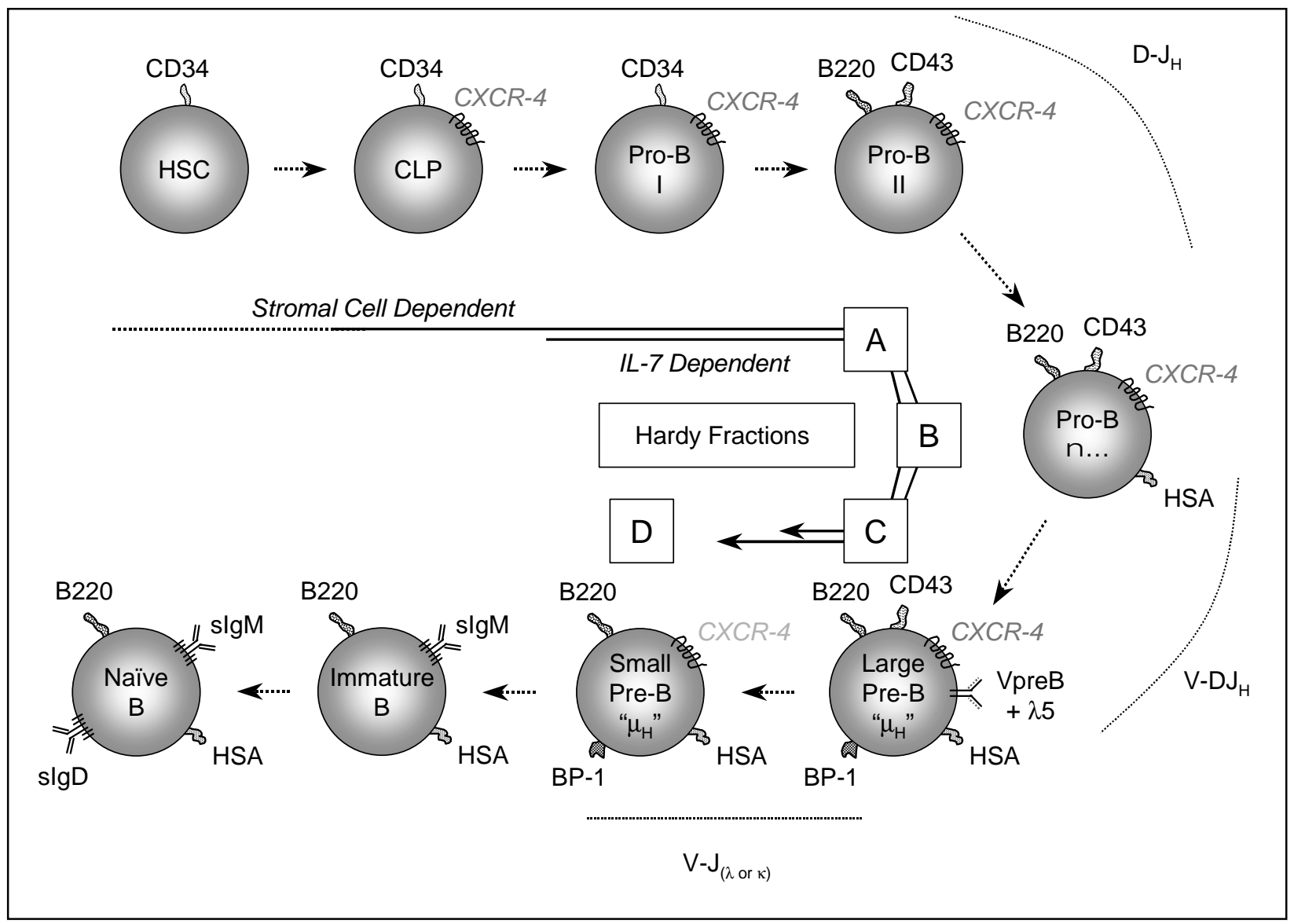

Figure 2. Hardy Scheme ${ }^{63}$ : phenotypic characteristics of B-cell development (CXCR-4 expression further defines the earliest lymphoid lineage commitment ${ }^{58}$ ) 
Bone marrow stromal cells also produce soluble and membrane anchored matrix proteins including collagen, fibronectin, and laminin that form a structural niche for productive hematopoiesis. Importantly, stromal cells express several types of cellular adhesion molecules including VCAM-1, fibronectin, and hyaluranate that have been shown to influence hematopoiesis (76-78). The necessity of physical interactions between stromal cells and developing B-cells through VCAM-1 and VLA-4 has been well characterized (76;79-84).

Cell surface expression of VCAM-1 was first identified on human umbilical vein endothelial cells following exposure to inflammatory cytokines $(85 ; 86)$. VCAM-1 was later identified as a cell surface adhesion molecule with the capacity to promote adherence of many cell types including basophils, eosinophils, neutrophils, monocytes, lymphocytes, CD34+ hematopoietic cells, and early B-lineage cells $(79 ; 82 ; 83 ; 87-91)$. Structural characterization identified VCAM-1 as a membrane anchored glycoprotein consisting of a 19 amino acid cytoplasmic tail and seven Ig-like extracellular domains $(85 ; 92 ; 93)$. Mice express an alternative form of VCAM-1 that is composed of the first three amino terminal immunoglobulin(lg)-like domains bound to the cell membrane using a glycol phospatidylinositol (GPI) anchor (94;95) (Figure 3).

VCAM-1's primary ligand is $\alpha_{4} \beta_{1}$ (VLA-4), which is predominantly expressed on stem cells and most lymphoid lineage cells. Several groups have demonstrated that blocking antibodies to VCAM-1 on stromal cells or VLA-4 on hematopoietic progenitor cells in vitro and in vivo inhibited B-lymphopoiesis and resulted in subsequent induction of apoptosis in CD34 ${ }^{+}$hematopoietic cells $(79-83 ; 89 ; 91 ; 96-98)$. Further support for the role of VLA-4 in B-lymphopoiesis was demonstrated by comparing $\alpha_{4}{ }^{-/-}$(VLA-4 $-\alpha_{4} \beta_{1}$ ) 


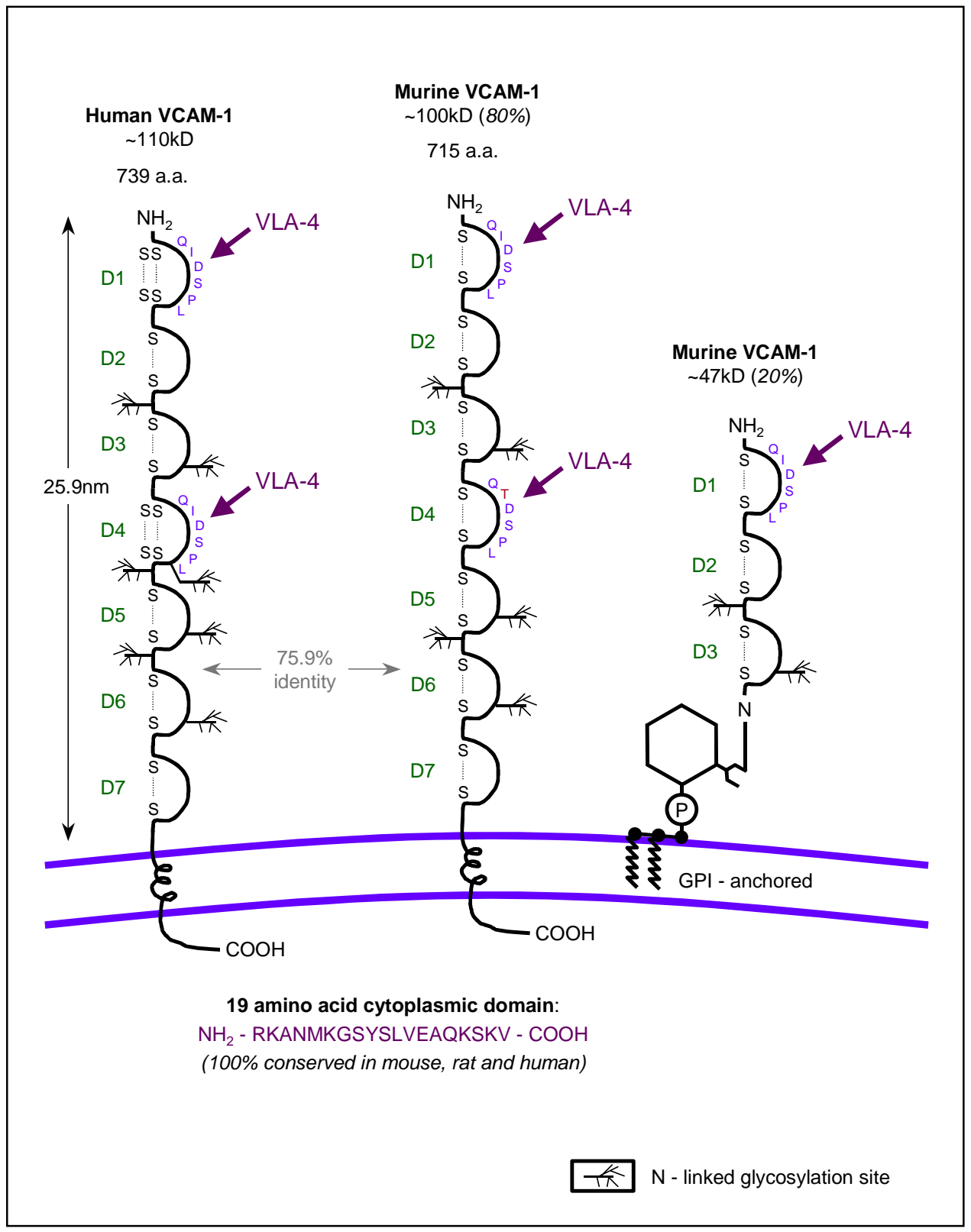

Figure 3. Structure of murine and human VCAM-1 adhesion molecules (adapted from references 85;92-95) 
or $\alpha_{5}^{-/-}$(VLA-5 $\left.-\alpha_{5} \beta_{1}\right)$ : RAG-2 ${ }^{-/-}$chimeric mice to wild type: RAG-2 ${ }^{-/-}$chimeric control mice (84). The $\alpha_{4}^{-/-}\left(\mathrm{VLA}-4-\alpha_{4} \beta_{1}\right)$ : RAG-2 ${ }^{-/-}$chimeric mice have both $\alpha_{4}^{-/-}$RAG-2 ${ }^{+/+}$ and $\alpha_{4}{ }^{+/+}$RAG $-2^{-/-}$hematopoietic stem cells. It had been previously demonstrated that loss of RAG-2 expression results in a stringent block from the pro-B to pre-B transition in B-lymphopoiesis (99). Therefore, only the genetically manipulated RAG-2 ${ }^{+/+}$ hematopoietic cells have the capacity to restore lymphopoiesis in RAG-2/- mice. While $\alpha_{4}^{-{ }^{--}}$chimeric mice failed to develop more mature bone marrow B-cells $\left(\mathrm{B}_{2} 20^{+} \lg \mathrm{M}^{+}\right)$, the

$\alpha_{5}^{-/-}$and the wild type control chimeric mice had normal restoration of bone marrow Blymphopoiesis (84).

Functional analysis of VCAM-1 ${ }^{-1-}$ knockout mice is not possible as these mice die during embryogenesis (100). Recently however, VCAM-1 conditional knockouts were generated and characterized (101). These mice had reduced immature and mature B cell numbers in the bone marrow, further demonstrating the requirement for VCAM-1 in B cell development (101). In addition, the same group established a definitive role for VCAM-1 in bone marrow lymphocyte homing, which will be discussed in further detail in section V.

\section{Bone Marrow Anatomy}

Hematopoietic bone marrow is an extensively vascularized organ system. In fact, all hematopoietic tissues (e.g. yolk sac, AGM region, fetal liver, spleen, and bone marrow) and those that will support hematopoiesis (e.g. kidney), provided the correct microenvironment, are extensively vascularized $(102 ; 103)$. Yellow "fatty" bone marrow receives only one-third the blood flow as compared to red "hematopoietic" marrow 
(104). These observations suggest that a complex vascular network and regulated blood flow are necessary, but not adequate, for productive hematopoiesis.

Bone marrow represents $1-2.5 \%$ of total body mass in humans. Of the total marrow, $25-75 \%$ is red "active hematopoietic" marrow versus yellow "fatty and nonhematopoietically active marrow". "Active hematopoietic" marrow receives $2-4 \%$ of cardiac output under normal physiological conditions (105-107). Unlike most organs, the bone marrow is unique as it is encased in non-flexible bone. This restricted isolation further enhances the dependence on vascular support for homeostasis of its physiological functions. Blood flow to and from the bone marrow must be tightly regulated in order to maintain hematopoietic cell egress, cytokine release, $\mathrm{O}_{2} / \mathrm{CO}_{2}$ exchange, cellular bone marrow homing, osmotic pressure, and nutrient/waste exchange.

Alterations in hematopoietic activity are typically associated with corresponding changes in bone marrow blood flow. A classic technique that enhances bone marrow erythropoiesis is the induction of anemia in animals through controlled blood loss (108). In animals with induced anemia, increased bone marrow erythropoiesis was accompanied by a corresponding increase in bone marrow blood flow by up to 3-fold (109-111). However, the bone marrow maintains similar blood flow and vascular resistance, as compared to severe changes seen in muscle tissues, associated with overall increases in arterial pressure and increased heart rate during moderate exercise (104). Hypovolaemia (reduced arterial blood pressure) induces immediate vasoconstriction in many organs to offset the reduced total arterial pressure (112). A $50 \%$ reduction of arterial blood pressure in dogs results in a five-fold reduction in bone 
marrow blood flow suggesting increased bone marrow vascular resistance (104). Finally, increases in bone marrow cellularity associated with several bone-harbored leukemias result in corresponding bone marrow blood flow increases (107). While many of the regulatory mechanisms are yet to be fully defined, these data demonstrate that the bone marrow vasculature is responsive to various physiological signals.

Regulation of bone marrow blood vessel tone and blood flow are not fully understood, but several factors are known to influence bone marrow blood vessel tension that ultimately influence blood flow. Bone marrow blood vessels, composed of endothelial cells and smooth muscle, are regulated by local cytokine levels, systemic factors and endothelial derived substances (111-116). Although the bone marrow vasculature is innervated, no functional alterations in bone marrow blood flow have been attributed directly to neuronal activity $(111 ; 117)$.

Hematopoietic bone marrow is a dynamic organ system that can be found throughout the mammalian skeletal system at various stages of life. In one study, Fliedner outlined a model in which peripheral blood stem cells are a transitory stem cell population (42). These transitory stem cells represent the peripheral stem cell population in a steady state exchange and balance of stem cells between all active hematopoietic bone marrow and the peripheral blood. In this way, mammals are able to maintain or restore stem cell pools equally between all supportive hematopoietic microenvironments following injury or under normal physiological states (42).

\section{Bone Marrow Microenvironment}

The term "hemopoietic inductive microenvironment (HIM)" (later shortened to hematopoietic microenvironment or microenvironment) was first coined to define 
microgeographical areas of the spleen and bone marrow that are capable of supporting specific hematopoietic colony growth (118). In this early work, Curry and Trentin observed that the macroscopic hematopoietic spleen colonies (originally described by Till and McCulloch (119)) were primarily composed of granulocytic, megakaryocytic and erythrocytic cells and that these colonies were found in discrete anatomical locations within the spleen. Additional microenvironmental specificity is suggested by the observation that while the spleen favors erythropoietic cell colony growth, the bone marrow favors granulocytic colony formation (120). While the lung is the first capillary bed that transplanted hematopoietic stem cells (HSC) encounter following intravenous injection, hematopoietic colonies are not readily observed in the lungs or other nonhematopoietic organs $(119 ; 121)$. Together these data suggest the existence of specific "microenvironments" that are unique within and between hematopoietic organs (118).

Further support for hematopoietic microenvironments was demonstrated in studies by Lord, et al. when they reported a spatial distribution of primitive hematopoietic progenitor cells (Colony Forming Unit - Spleen $\left(\mathrm{CFU}_{\mathrm{S}}\right)$ ) and more differentiated progenitor cells (Colony Forming Unit - Culture $\left(C F U_{C}\right)$ ) in murine bone marrow $(122 ; 123)$. In these studies, $\mathrm{CFU}_{\mathrm{S}}$-forming cells favored the marginal region of the bone marrow (closest to the bone) while the $\mathrm{CFU}_{\mathrm{C}}$-forming cells favored a more axial region (toward the center of the bone marrow cavity).

Bone marrow microenvironments are a complex organization of stroma including fibroblastic stromal cells, adipocytes, macrophages, and endothelial cells. In addition, accessory cells in the microenvironment include neurons, T-cells, monocytes, and differentiating hematopoietic cells. Finally, additional cell-derived proteins including 
growth factors, ECM, cytokines, chemokines, and neural peptides are located in the bone marrow spaces $(4 ; 70 ; 124)$. While the exact molecular and cellular compositions of in vivo bone marrow microenvironments that support B lymphopoiesis, myelopoiesis, or erythropoiesis are not precisely defined, bone marrow hematopoiesis is a process regulated through the local and dynamic effects of soluble molecules, extracellular matrix, and cell to cell interactions that take place within bone marrow microenvironments (7). Bone marrow hematopoietic conditions are difficult to evaluate in vivo, therefore more simplistic in vitro models and in vivo "knock-out" models have been used to dissect and evaluate specific mechanisms of hematopoiesis (125).

Bone marrow microenvironments regulate hematopoiesis through the coordinated activities of several cell types including fibroblastic stromal cells, fat cells, endothelial cells, and macrophages. Fibroblastic bone marrow stromal cells (referred to as "stromal cell" in this thesis) have been best characterized as the population that primarily directs hematopoiesis $(71 ; 89 ; 126-130)$. Stromal cells have the capacity to support both lymphopoiesis and myelopoiesis in vitro, are able to establish active sites of hematopoiesis in non-hematopoietic organs, and are essential for bone marrow hematopoietic recovery following ablative cytotoxic treatment $(103 ; 131 ; 132)$. Stromal cells regulate hematopoiesis through cell-to-cell adhesion, secretion of extracellular matrix proteins, and production of secreted and membrane bound cytokines. The molecular events by which bone marrow stromal cells specifically direct lymphopoiesis have been defined through the use of in vivo and in vitro models $(16 ; 19 ; 72 ; 76 ; 79 ; 128 ; 133 ; 134)$. It has been shown that direct interaction with stromal 
cells is essential in murine and human models for maximal support of immature lymphoid cells $(80-82 ; 90 ; 96 ; 130 ; 135 ; 136)$.

Vascular cell adhesion molecule-1 (VCAM-1), a surface bound stromal cell adhesion molecule, is an essential component of stromal cell capacity to support hematopoietic progenitor cells $(82 ; 83 ; 89 ; 91 ; 97 ; 98 ; 137 ; 138)$. Injection of anti-VCAM-1 antibody into mice disrupts stromal cell: hematopoietic progenitor cell associations (aggregates) and results in disrupted B-lymphopoiesis (83). In addition, hematopoietic progenitor cells were mobilized in primates following anti-VLA-4 $\left(\alpha_{4} \beta_{1}\right.$ integrin - VCAM1 ligand) antibody treatment (97). These observations support the essential role of VCAM-1 in regulation of the development of progenitor cells committed to the B cell lineage.

Bone marrow stromal cells also influence hematopoiesis through Stromal Derived Factor-1 (SDF-1)-regulated homing and migration of progenitor cells. SDF-1 is constitutively expressed by bone marrow stromal cells, and disruption of either SDF-1 protein or its receptor CXCR-4 results in diminished bone marrow hematopoiesis (139141). In addition to its role as a chemotactic factor, SDF-1 was also identified as a preB cell growth factor that induced pre-B cell proliferation (18).

Extracellular matrix $(\mathrm{ECM})$, predominantly derived from stromal cells, not only provides structural support for hematopoietic microenvironments but also acts to anchor, directly signal and indirectly signal hematopoietic cells (142-144). Several studies have demonstrated that growth factors such as IL-3, SCF, GM-CSF, and SDF-1 are able to bind to ECM in a "biologically active" fashion (145-147). In addition, the bone marrow ECM is involved in coordinating cellular interactions between bone 
marrow stromal cells and hematopoietic cells (144). However, it appears that the main function of the bone marrow ECM is in influencing proliferation, differentiation, and cell adhesion of developing myelopoietic, erythropoietic and more mature B-lineage cells $(148-151)$.

\section{Bone Marrow Homing}

Lethal doses of chemotherapy or irradiation result in the ablation of hematopoiesis and ultimately death. In 1951, Lorenz, et al. demonstrated that lethally irradiated mice could be rescued if these mice received a bone marrow transfusion from a genetically identical littermate (121). This was the first demonstration of successful bone marrow transplantation in animals and established proof for the concept of cellular hematopoietic recovery, as opposed to protective humoral factors $(121 ; 152)$. The first allogeneic bone marrow transplantation occurred in 1954 (153). Lorenz, et al. demonstrated that lethally irradiated mice could be rescued with intravenously injected rat bone marrow (153). These and other animal model studies eventually lead to clinical trials in humans by the late 1950's.

From 1958 to 1962, 154 patients had undergone bone marrow transplantation (154). The majority of these bone marrow transplants failed due to various causes including inadequate pretreatment of the patient, infection, or graft-versus-host disease (GVHD). Human bone marrow transplant studies were greatly reduced for the remainder of the 1960's. Of particular interest from these initial trials, was the observation that of the seven patients who underwent syngenic bone marrow transplantation, five patients $(71 \%)$ had displayed complete clinical recoveries. Less than $25 \%$ of other cases at this time survived and in those who survived transplantation 
disease progression continued (154). While the process of homing to, and engraftment within, the bone marrow was poorly understood, histocompatibility issues, GVHD, and other transplantation complications became major focal points at that time and research in these areas remains ongoing (154-156).

In 1993, Tashiro, et al. isolated the chemotactic factor SDF-1 and a heightened interest in characterizing the process of stem cell homing to the bone marrow began shortly after (140;157;158). Between 1996 and 2002, characterization of SDF-1 (CXCL12) and CXCR-4 and their relationship to homeostasis of bone marrow hematopoiesis, has been intensely studied.

Hematopoietic cell migration to and retention within hematopoietic bone marrow requires establishment of local SDF-1 concentration gradients $(7 ; 140 ; 159 ; 160)$. SDF$1 \alpha$, a member of the C-X-C chemokine family, is an 89 amino acid soluble protein that promotes $\mathrm{CXCR} 4^{+}$cell chemotaxis. SDF- $1 \beta$ is a minor isoform of SDF-1 generated by alternative splicing and contains 4 additional amino acids (161). SDF-1 is highly conserved in mice and humans, with only one amino acid difference between species. The only known endogenous ligand for SDF-1 is CXCR-4, which is predominantly expressed on $\mathrm{CD}_{3} 4^{+}$stem cells, pro- and pre-B cells, T-lymphocytes, monocytes, and some leukemic cells (162). Phenotypic manifestations of SDF- $1^{-1-}$ and CXCR-4 $4^{-1-}$ knockout mice are almost identical. Both homozygous mutant mice die during embryogenesis ( E18.5). They fail to establish bone marrow lymphopoiesis and myelopoiesis, display normal thymic T-cell development, and have reduced fetal liver myeloid cell development (139-141). 
The requirement for SDF-1 in bone marrow homing is well documented. However, the specific roles of various adhesion molecules in bone marrow homing are not as clear. There are only two known adhesion molecules uniquely found in the bone marrow. These include lectins found on stem cells (163) and hemonectin found in the bone marrow microenvironment (150). While unique addressins have not been identified that confer bone marrow homing specificity (as seen in homing to mucosal tissues (MadCAM-1 and $\alpha_{4} \beta_{7}$ ) (164)), other unique qualities of the bone marrow, including that of the bone marrow microvasculature, contribute to the specificity of homing. Data suggest that $18-20 \%$ of engrafted stem cells home to bone marrow (165). Bone marrow homing is specific as suggested from observations of $20 \%$ bone marrow homing versus bone marrow receiving only $2-4 \%$ of cardiac output (166)). Finally, given the correct microenvironment, engraftment (initiation of hematopoiesis) follows (167).

No single adhesion molecule has been demonstrated to be solely required for bone marrow homing to date. Instead, hematopoietic stem and progenitor cell homing specificities are the result of the coordinated effort of several adhesion molecules and their distinctive anatomical constitutive expression within the bone marrow microvasculature. Unlike other vascular endothelial cells, bone marrow endothelial cells (BMEC) constitutively express E-selectin and VCAM-1, and both have been shown to contribute to bone marrow homing specificity (168-171).

In the first stage of bone marrow homing hematopoietic progenitor and stem cells interact with bone marrow endothelial cells in specialized capillaries termed sinusoids. At the bone marrow sinusoids, cellular exchange is active between the vascular lumen and extravascular spaces. Hematopoietic progenitor and stem cell interactions with E- 
selectin (CD62E) and P-selectin (CD62P) result in rolling of hematopoietic cells along the vasculature (168-170). As the hematopoietic cells roll along the lumen of the bone marrow sinusoid, BMEC expression and presentation of SDF-1 induces progenitor and stem cells integrin activation (or clustering) and strong adherence (162;172-178). This is followed by arrest, mediated by BMEC VCAM-1 and hematopoietic progenitor and stem cell $\alpha_{4} \beta_{1}$ (VLA-4) interactions (168;179). In an E-selectin-mediated process, transendothelial cell migration from the lumen of the bone marrow sinusoid to the extravasculature space (bone marrow microenvironment) completes the homing phase $(168 ; 180)$.

Engraftment is defined by lodgment and expansion of hematopoietic cells within sustaining microenvironments. Once in the correct extravascular space, hematopoietic stem cell engraftment leads to hematopoietic recovery. Adhesion interactions within bone marrow microenvironments are unique and stem cell mobilization must overcome these adhesive interactions to allow reverse migration (egress) from the bone marrow microenvironment to the sinusoidal luminal spaces.

\section{Bone Marrow Mobilization}

Hematopoietic cell retention within the bone marrow microenvironment relies on a complex interplay of adhesion molecule interactions. Molecular and signaling alterations that result in the egress of hematopoietic progenitor and stem cells from the bone marrow to the periphery are not completely elucidated. Current mobilizing agents are characterized by their ability to mobilize stem cells to the periphery with minimal side effects, as opposed to an understanding of their underlying mechanisms (181). GCSF mobilization is the most widely utilized stem cell mobilizing strategy $(22 ; 181 ; 182)$. 
Other mobilizing agents have been evaluated including SCF, IL-11, IL-8, and Flt-3 ligand, but they have not been shown to better mobilize hematopoietic progenitor and stem cells than G-CSF (183).

G-CSF induced hematopoietic stem cell mobilization generates a 40 - to 80 -fold increase in peripheral hematopoietic progenitor and stem cells following 4 to 5 days of treatment $(184 ; 185)$. Optimal peripherilization is preceded by bone marrow neutrophil granulopoiesis (186). Until recently, the mechanism of G-CSF induced stem cell mobilization remained unknown. In late 2001, Lévesque, et al. proposed a model that detailed potential mechanisms underlying G-CSF-induced hematopoietic progenitor and stem cell mobilization. During G-CSF mobilization, bone marrow neutrophil accumulation and increased release of two serine proteases, neutrophil elastase and cathepsin G, was shown to result in stromal cell VCAM-1 cleavage and stem cell mobilization. While stromal cell VCAM-1 was reduced, bone marrow vascular VCAM-1 and VCAM-1 levels in the spleen remain unchanged, accounting for the observation of hematopoietic cell splenic homing and increased spleen mass (22). This work further supports a central role for bone marrow stromal cell VCAM-1 interactions with hematopoietic progenitor and stem cell $\alpha_{4} \beta_{1}(\mathrm{VLA}-4)$ in hematopoietic cell bone marrow extravascular space retention (22;82;84;97;169;187-190).

Given these data, it is tempting to attribute hematopoietic progenitor and stem cells retention within the bone marrow solely to VCAM-1 interactions with $\alpha_{4} \beta_{1}$ (VLA-4). However, the complex interplay of various other adhesion molecules, their activity, and signaling also impact hematopoietic cell bone marrow retention and mobilization. Several mobilizing strategies result in consistent reductions of hematopoietic stem cell 
LFA-1 and LFA-3 in addition to VLA-4. Negligible change has been observed in CD-31, CD-44, and CD-62L (L-selectin) expression (191-193). It is currently unknown how alterations in hematopoietic progenitor and stem cell adhesion molecule profiles are regulated following mobilizing strategies, but the central role of VCAM-1: $\alpha_{4} \beta_{1}$ (VLA-4) interactions in bone marrow hematopoietic cell retention are well established.

\section{Bone Marrow Microenvironment Damage}

Irradiation and/or chemotherapy are common treatment strategies associated with many forms of cancer. Irradiation in conjunction with high-dose chemotherapy is commonly utilized prior to bone marrow transplantation (BMT) to optimize residual tumor cell death. Many studies have shown that delays in immune system recovery are associated with different treatment regimes in preparation for BMT. Of interest is that functional recovery of specific blood cell lineages (e.g. myeloid, erythroid, and lymphoid) occur at distinct times following BMT, and a common observation involves prolonged deficits in the B-cell compartment $(19 ; 23 ; 194-198)$. Studies that evaluated enhanced restoration of B-lymphopoiesis by addition of exogenous lymphoid specific cytokines such as IL-7 have shown promise, but suboptimal microenvironmental support and tumor generation from excess exogenous IL-7 remain valid concerns (199-201). There have also been encouraging reports of lymphoid cell restoration when healthy stromal cells are co-infused with hematopoietic cells during bone marrow transplantation $(195 ; 196 ; 202)$. These observations suggest that specific bone marrow microenvironments (i.e. those that favor B-cell development) are altered or sustain prolonged damage following high dose chemotherapy and BMT. 
Bone marrow stromal cells are primarily non-cycling and relatively resistant to apoptosis induced by chemotherapy or irradiation $(119 ; 203 ; 204)$. However, stromal cell resistance to cytotoxic agents appears to vary depending on several factors including the specific cytotoxic agent, dose, and experimental method utilized to test for functional damage (205-209). Several groups have demonstrated that both chemotherapy and irradiation can damage stromal cells, leading to a reduced capacity to both support efficient hematopoiesis and to self-renew $(205 ; 207)$. Stromal cell damage was identified as altered production of cytokines (reduced G-CSF (210), increased TNF- $\alpha$ (211) and a reduced ability of self-renewal, quantitated by a decrease in the frequency of fibroblastic colonies formed in vitro (CFU-F) from treated subjects $(207 ; 208 ; 212)$.

Importantly, previous studies have not addressed the altered function of stromal cells related to individual drugs. One group reported that patients irradiated and treated with multi-drug chemotherapy had a reduced ability to establish CFU-F's for up to twelve years following treatment cessation (207). These data suggest an impaired capacity of stromal cell self-renewal, but they do not address alterations in the capacity of stromal cells to contribute to homing of progenitor cells or to support hematopoiesis.

A group of studies have specifically focused on disruption of stromal cell adhesion molecule expression as one component of treatment induced damage. Gibson, et al. demonstrated that stromal cell cultures treated in vitro with etoposide had reduced ability to support lymphoid cell proliferation and diminished VCAM-1 protein expression (213). Although data from several groups suggest the potential for chemotherapy-induced damage of the microenvironment, the molecular mechanisms that underlie reported damage remain to be determined. In addition, no reports provide 
description of how aggressive chemotherapy exposure may alter the signals that regulate homing of healthy progenitor cells, as in the transplantation setting.

A functional bone marrow microenvironment is essential not only during normal hematopoiesis, but also to facilitate recovery of hematopoietic populations following chemotherapy or irradiation (131). Recovery relies on both homing of healthy progenitors to the marrow and appropriate development once seeded in the correct microenvironmental niche. Long-term damage to the immune system following aggressive chemotherapy suggests that, in addition to stem cell damage, there is potential disruption of the bone marrow microenvironment $(23 ; 26 ; 27 ; 131 ; 194 ; 195 ; 211 ; 214 ; 215)$. This damage may result in both disruption of stromal cell directed homing of progenitor cells to the bone marrow and diminished support of those progenitor cells that do traffic to the marrow. While microenvironment damage is likely diverse, alterations in VCAM-1 and SDF-1 expression following chemotherapy are essential areas to investigate. VCAM-1 and SDF-1 define unique and specific stromal cell derived elements of the bone marrow microenvironment to which strategies to maintain or restore function following treatment could be applied.

\section{Corrective medical intervention strategies}

Myelosuppressive doses of chemotherapy and/or irradiation in preparation for bone marrow transplantation (BMT) ablate bone marrow hematopoiesis and leave patients in a fragile immunologic state until engrafted bone marrow reestablishes hematopoiesis. Following high dose chemotherapy, immediate corrective measures to counter anemia, thrombocytopenia and neutropenia are imperative for enhancing survival of patients. While blood transfusions are sufficient to offset anemia and 
thrombocytopenia, absolute neutrophil count (ANC) restoration requires bone marrow hematopoietic restoration. Attempts to enhance hematopoietic (myelopoietic) recovery in BMT patients include use of exogenous growth factors such as G-CSF, GM-CSF, SCF, IL-3, and IL-6. These growth factors enhance bone marrow myelopoiesis leading to improved patient ANC recovery times (216-227).

Immediate concerns following BMT are in restoration myelopoietic functions as delays in humoral (B-cell) and cell-mediated (T-cell) immunity can be offset using antifungal and antibacterial agents. However, long-term delays in humoral or cellmediated immunity increase the risk of pathogen resistance and infection. Some studies have demonstrated that recombinant IL-7 treatment following BMT and other chemotherapeutic treatment strategies leads to enhanced B and T-cell recoveries (228230). Variability in exogenous growth factor restoration of hematopoiesis may be explained by differential damage to the bone marrow microenvironment caused by different cytotoxic agents. In addition to exploring the ability of exogenous cytokines to

enhance B-lymphopoiesis, several recent studies have suggested that co-infusion of bone marrow stromal cells following high-dose chemotherapy enhances lymphopoiesis and B-cell recovery $(196 ; 202)$. These strategies may be better suited to B-cell restoration following BMT in conjunction with cytotoxic treatment strategies that severely damage the bone marrow microenvironment.

\section{Summary and Goals}

Numerous adhesion molecules, cytokines, chemokines, extracellular matrix proteins, and other soluble factors influence and regulate steady state hematopoiesis. Two proteins appear to be critical for successful homing of hematopoietic to the bone 
marrow, the stromal cell adhesion molecule VCAM-1 and the stromal cell-derived chemokine SDF-1. In addition to their roles in homing, VCAM-1 and SDF-1 have been shown to support B cell development and proliferation respectively. Following ablative therapies in preparation for bone marrow transplantation, reductions in stromal cell VCAM-1 and/or SDF-1 potentially have serious clinical consequences reflected as a patient's diminished ability to support bone marrow homing and restoration of hematopoiesis. Understanding the molecular mechanisms that underlie altered expression of VCAM-1 and SDF-1 could lead to treatment strategies that would restore efficient bone marrow homing and enhance the kinetics of hematopoietic recovery following bone marrow transplantation.

The focus of the current study was to begin to define bone marrow microenvironment damage following high dose chemotherapy that may contribute to prolonged immune system deficits. Characterization of bone marrow stromal cell damage following dose escalated chemotherapy in vitro may lend insight to the observed deficits in B-cell restoration following bone marrow transplantation. Using in vitro models, the impact of aggressive chemotherapy on stromal cell production of VCAM-1 and SDF-1 has been characterized. Dysregulation of these two critical stromal cell derived proteins following exposure to chemotherapy correlates with observed delays in immune system reconstitution documented clinically.

In this study, etoposide (VP-16) was chosen as a model chemotherapeutic drug due to common clinical use at escalated doses (26;231-234). In the first aim, alterations in stromal cell SDF-1 production following drug exposure were characterized. Experiments in the second aim evaluated molecular mechanisms that underlie down 
regulation of stromal cell VCAM-1 following chemotherapy exposure. Finally, experiments completed in the third aim established and characterized a model that may be beneficial in determining the impact of altered VCAM-1 expression on the ability of stromal cells to support hematopoiesis in vitro. 


\section{References}

1. Zhu,J. and Emerson,S.G. (2002): Hematopoietic cytokines, transcription factors and lineage commitment. Oncogene, 21:3295-3313.

2. Morrison,S.J., Uchida,N., and Weissman,I.L. (1995): The biology of hematopoietic stem cells. Annu.Rev.Cell Dev.Biol., 11:35-71.

3. Osmond,D.G. (1985): The ontogeny and organization of the lymphoid system. J.Invest Dermatol., 85:2s-9s.

4. Mayani,H., Guilbert,L.J., and Janowska-Wieczorek,A. (1992): Biology of the hemopoietic microenvironment. Eur.J.Haematol., 49:225-233.

5. Simmons,P.J., Levesque,J.P., and Haylock,D.N. (2001): Mucin-like molecules as modulators of the survival and proliferation of primitive hematopoietic cells. Ann.N.Y.Acad.Sci., 938:196-206.

6. Minguell,J.J., Erices,A., and Conget,P. (2001): Mesenchymal stem cells. Exp.Biol.Med.(Maywood.), 226:507-520.

7. Prosper,F. and Verfaillie,C.M. (2001): Regulation of hematopoiesis through adhesion receptors. J.Leukoc.Biol., 69:307-316.

8. Stoddart,A., Fleming,H.E., and Paige,C.J. (2001): The role of homotypic interactions in the differentiation of B cell precursors. Eur.J.Immunol., 31:11601172.

9. LeBien,T.W. (1998): B-cell lymphopoiesis in mouse and man. Curr.Opin.Immunol., 10:188-195.

10. Tang,J., Nuccie,B.L., Ritterman,I., Liesveld,J.L., Abboud,C.N., and Ryan,D.H. (1997): TGF-beta down-regulates stromal IL-7 secretion and inhibits proliferation of human B cell precursors. J.Immunol., 159:117-125.

11. Prieyl,J.A. and LeBien,T.W. (1996): Interleukin 7 independent development of human B cells. Proc.Natl.Acad.Sci.U.S.A, 93:10348-10353. 
12. Funk,P.E., Stephan,R.P., and Witte,P.L. (1995): Vascular cell adhesion molecule 1-positive reticular cells express interleukin-7 and stem cell factor in the bone marrow. Blood, 86:2661-2671.

13. Peault,B. (1995): In-vitro models of stroma-dependent lymphopoiesis. Semin.Immunol., 7:169-175.

14. Witte,P.L., Frantsve,L.M., Hergott,M., and Rahbe,S.M. (1993): Cytokine production and heterogeneity of primary stromal cells that support B lymphopoiesis. Eur.J.Immunol., 23:1809-1817.

15. Billips,L.G., Petitte,D., and Landreth,K.S. (1990): Bone marrow stromal cell regulation of $B$ lymphopoiesis: interleukin-1 (IL-1) and IL-4 regulate stromal cell support of pre-B cell production in vitro. Blood, 75:611-619.

16. Sudo,T., Ito,M., Ogawa,Y., lizuka,M., Kodama,H., Kunisada,T., Hayashi,S., Ogawa,M., Sakai,K., and Nishikawa,S. (1989): Interleukin 7 production and function in stromal cell-dependent B cell development. J.Exp.Med., 170:333-338.

17. Egawa,T., Kawabata,K., Kawamoto,H., Amada,K., Okamoto,R., Fujii,N., Kishimoto,T., Katsura,Y., and Nagasawa,T. (2001): The earliest stages of B cell development require a chemokine stromal cell-derived factor/pre-B cell growthstimulating factor. Immunity., 15:323-334.

18. Nagasawa,T., Kikutani,H., and Kishimoto,T. (1994): Molecular cloning and structure of a pre-B-cell growth-stimulating factor. Proc.Natl.Acad.Sci.U.S.A, 91:2305-2309.

19. Dittel,B.N. and LeBien,T.W. (1995): Reduced expression of vascular cell adhesion molecule-1 on bone marrow stromal cells isolated from marrow transplant recipients correlates with a reduced capacity to support human $B$ lymphopoiesis in vitro. Blood, 86:2833-2841.

20. Ryan,D.H. (1993): Adherence of normal and neoplastic human B cell precursors to the bone marrow microenvironment. Blood Cells, 19:225-241.

21. Kincade,P.W. (1992): Cell interaction molecules and cytokines which participate in B lymphopoiesis. Baillieres Clin. Haematol., 5:575-598. 
22. Levesque,J.P., Takamatsu,Y., Nilsson,S.K., Haylock,D.N., and Simmons,P.J. (2001): Vascular cell adhesion molecule-1 (CD106) is cleaved by neutrophil proteases in the bone marrow following hematopoietic progenitor cell mobilization by granulocyte colony-stimulating factor. Blood, 98:1289-1297.

23. Lum,L.G. (1987): The kinetics of immune reconstitution after human marrow transplantation. Blood, 69:369-380.

24. Ashihara,E., Shimazaki,C., Yamagata,N., Hirata,T., Okawa,K., Oku,N., Goto,H., Inaba,T., Fujita,N., and Nakagawa,M. (1994): Reconstitution of lymphocyte subsets after peripheral blood stem cell transplantation: two-color flow cytometric analysis. Bone Marrow Transplant., 13:377-381.

25. Small,T.N., Keever,C.A., Weiner-Fedus,S., Heller,G., O'Reilly,R.J., and Flomenberg,N. (1990): B-cell differentiation following autologous, conventional, or T-cell depleted bone marrow transplantation: a recapitulation of normal B-cell ontogeny. Blood, 76:1647-1656.

26. Herzig,R.H., Lynch,J., Christiansen,N.P., Fay,J.W., Davis,M.P., and Herzig,G.P. (1996): Dose-intensive chemotherapy with etoposide-cyclophosphamide for advanced breast cancer. North American Marrow Transplant Group. Semin.Oncol., 23:28-32.

27. Gardner,R.V. (1999): Long term hematopoietic damage after chemotherapy and cytokine. Front Biosci., 4:e47-e57

28. Montemurro,F., Ueno,N.T., Rondon,G., Aglietta,M., and Champlin,R.E. (2000): High-dose chemotherapy with hematopoietic stem-cell transplantation for breast cancer: current status, future trends. Clin.Breast Cancer, 1:197-209.

29. Huff,C.A. and Jones,R.J. (2002): Bone marrow transplantation for multiple myeloma: where we are today. Curr.Opin.Oncol., 14:147-151.

30. De Giorgi,U., Rosti,G., Papiani,G., and Marangolo,M. (2002): The status of highdose chemotherapy with hematopoietic stem cell transplantation in germ cell tumor patients. Haematologica, 87:95-104.

31. Kyle,R.A. (2001): Management of patients with multiple myeloma: emphasizing the role of high-dose therapy. Clin.Lymphoma, 2:21-28. 
32. Zon,L.I. (1995): Developmental biology of hematopoiesis. Blood, 86:2876-2891.

33. Nishikawa,M., Tahara,T., Hinohara,A., Miyajima,A., Nakahata,T., and Shimosaka,A. (2001): Role of the microenvironment of the embryonic aorta-gonadmesonephros region in hematopoiesis. Ann.N.Y.Acad.Sci., 938:109-116.

34. Dzierzak,E. and Medvinsky,A. (1995): Mouse embryonic hematopoiesis. Trends Genet., 11:359-366.

35. Medvinsky,A. and Dzierzak,E. (1999): Development of the hematopoietic stem cell: can we describe it? Blood, 94:3613-3614.

36. Medvinsky,A. and Dzierzak,E. (1996): Definitive hematopoiesis is autonomously initiated by the AGM region. Cell, 86:897-906.

37. Palis,J. and Yoder,M.C. (2001): Yolk-sac hematopoiesis: the first blood cells of mouse and man. Exp.Hematol., 29:927-936.

38. Medvinsky,A.L., Gan,O.I., Semenova,M.L., and Samoylina,N.L. (1996): Development of day-8 colony-forming unit-spleen hematopoietic progenitors during early murine embryogenesis: spatial and temporal mapping. Blood, 87:557-566.

39. de Bruijn,M.F., Speck,N.A., Peeters,M.C., and Dzierzak,E. (2000): Definitive hematopoietic stem cells first develop within the major arterial regions of the mouse embryo. EMBO J., 19:2465-2474.

40. Bessler,H. and Djaldetti,M. (1992): Ultrastructural studies on bone marrow development in embryonic mice. Biol.Neonate, 61:243-252.

41. Tavassoli,M. (1991): Embryonic and fetal hemopoiesis: an overview. Blood Cells, 17:269-281.

42. Fliedner,T.M. (1998): The role of blood stem cells in hematopoietic cell renewal. Stem Cells, 16 Suppl 1:13-29.

43. Osmond,D.G. (1993): The turnover of B-cell populations. Immunol.Today, 14:3437. 
44. Freitas,A.A. and Rocha,B.B. (1993): Lymphocyte lifespans: homeostasis, selection and competition. Immunol.Today, 14:25-29.

45. Domen,J. and Weissman,I.L. (1999): Self-renewal, differentiation or death: regulation and manipulation of hematopoietic stem cell fate. Mol.Med.Today, 5:201-208.

46. Metcalf,D. (1992): Hemopoietic regulators. Trends Biochem.Sci., 17:286-289.

47. Harrison,D.E., Jordan,C.T., Zhong,R.K., and Astle,C.M. (1993): Primitive hemopoietic stem cells: direct assay of most productive populations by competitive repopulation with simple binomial, correlation and covariance calculations. Exp.Hematol., 21:206-219.

48. Dick,J.E., Bhatia,M., Gan,O., Kapp,U., and Wang,J.C. (1997): Assay of human stem cells by repopulation of NOD/SCID mice. Stem Cells, 15 Suppl 1:199-203.

49. Ploemacher,R.E., Van der Loo,J.C., and Van der Sluijs,J.P. (1992): In vitro assays for primitive hematopoietic cells. Blood, 79:834-837.

50. Ohishi,K., Varnum-Finney,B., and Bernstein,I.D. (2002): The notch pathway: modulation of cell fate decisions in hematopoiesis. Int.J.Hematol., 75:449-459.

51. Stier,S., Cheng,T., Dombkowski,D., Carlesso,N., and Scadden,D.T. (2002): Notch1 activation increases hematopoietic stem cell self-renewal in vivo and favors lymphoid over myeloid lineage outcome. Blood, 99:2369-2378.

52. Lemischka,I. (1999): Searching for stem cell regulatory molecules. Some general thoughts and possible approaches. Ann.N.Y.Acad.Sci., 872:274-287.

53. Abramson,S., Miller,R.G., and Phillips,R.A. (1977): The identification in adult bone marrow of pluripotent and restricted stem cells of the myeloid and lymphoid systems. J.Exp.Med., 145:1567-1579.

54. Katsura,Y. and Kawamoto,H. (2001): Stepwise lineage restriction of progenitors in lympho-myelopoiesis. Int.Rev.Immunol., 20:1-20. 
55. Brecher,G., Neben,S., Yee,M., Bullis,J., and Cronkite,E.P. (1988): Pluripotent stem cells with normal or reduced self renewal survive lethal irradiation. Exp.Hematol., 16:627-630.

56. Jones,R.J., Celano,P., Sharkis,S.J., and Sensenbrenner,L.L. (1989): Two phases of engraftment established by serial bone marrow transplantation in mice. Blood, 73:397-401.

57. Keller,G. (1992): Hematopoietic stem cells. Curr.Opin.Immunol., 4:133-139.

58. Ishii,T., Nishihara,M., Ma,F., Ebihara,Y., Tsuji,K., Asano,S., Nakahata,T., and Maekawa,T. (1999): Expression of stromal cell-derived factor-1/pre-B cell growthstimulating factor receptor, CXC chemokine receptor 4, on CD34+ human bone marrow cells is a phenotypic alteration for committed lymphoid progenitors. J.Immunol., 163:3612-3620.

59. Sanchez,X., Cousins-Hodges,B., Aguilar,T., Gosselink,P., Lu,Z., and Navarro,J. (1997): Activation of HIV-1 coreceptor (CXCR4) mediates myelosuppression. J.Biol.Chem., 272:27529-27531.

60. Cantor,A.B. and Orkin,S.H. (2002): Transcriptional regulation of erythropoiesis: an affair involving multiple partners. Oncogene, 21:3368-3376.

61. Bender,J.G., Van Epps,D.E., and Stewart,C.C. (1987): Regulation of myelopoiesis. Comp Immunol.Microbiol.Infect.Dis., 10:79-91.

62. Friedman,A.D. (2002): Transcriptional regulation of myelopoiesis. Int.J.Hematol., 75:466-472.

63. Hardy,R.R., Carmack,C.E., Shinton,S.A., Kemp,J.D., and Hayakawa,K. (1991): Resolution and characterization of pro-B and pre-pro-B cell stages in normal mouse bone marrow. J.Exp.Med., 173:1213-1225.

64. Osmond,D.G. (1990): B cell development in the bone marrow. Semin.Immunol., 2:173-180.

65. Osmond,D.G., Rolink,A., and Melchers,F. (1998): Murine B lymphopoiesis: towards a unified model. Immunol.Today, 19:65-68. 
66. Ghia,P., ten Boekel,E., Rolink,A.G., and Melchers,F. (1998): B-cell development: a comparison between mouse and man. Immunol.Today, 19:480-485.

67. Burrows,P.D. and Cooper,M.D. (1993): B-cell development in man. Curr.Opin.Immunol., 5:201-206.

68. Kincade,P.W. (1994): B lymphopoiesis: global factors, local control. Proc.Natl.Acad.Sci.U.S.A, 91:2888-2889.

69. Verfaillie,C.M. (1998): Adhesion receptors as regulators of the hematopoietic process. Blood, 92:2609-2612.

70. Lichtman,M.A. (1981): The ultrastructure of the hemopoietic environment of the marrow: a review. Exp. Hematol., 9:391-410.

71. Dorshkind,K. (1990): Regulation of hemopoiesis by bone marrow stromal cells and their products. Annu.Rev.Immunol., 8:111-137.

72. Borghesi,L.A., Smithson,G., and Kincade,P.W. (1997): Stromal cell modulation of negative regulatory signals that influence apoptosis and proliferation of $B$ lineage lymphocytes. J.Immunol., 159:4171-4179.

73. Kodama,H., Nose,M., Niida,S., Nishikawa,S., and Nishikawa,S. (1994): Involvement of the c-kit receptor in the adhesion of hematopoietic stem cells to stromal cells. Exp.Hematol., 22:979-984.

74. Kittler,E.L., McGrath,H., Temeles,D., Crittenden,R.B., Kister,V.K., and Quesenberry,P.J. (1992): Biologic significance of constitutive and subliminal growth factor production by bone marrow stroma. Blood, 79:3168-3178.

75. Funk,P.E., Varas,A., and Witte,P.L. (1993): Activity of stem cell factor and IL-7 in combination on normal bone marrow B lineage cells. J.Immunol., 150:748-752.

76. Murti,K.G., Brown,P.S., Kumagai,M., and Campana,D. (1996): Molecular interactions between human B-cell progenitors and the bone marrow microenvironment. Exp.Cell Res., 226:47-58. 
77. Simmons,P.J., Levesque,J.P., and Zannettino,A.C. (1997): Adhesion molecules in haemopoiesis. Baillieres Clin.Haematol., 10:485-505.

78. Rougier,F., Dupuis,F., and Denizot,Y. (1996): Human bone marrow fibroblasts--an overview of their characterization, proliferation and inflammatory mediator production. Hematol.Cell Ther., 38:241-246.

79. Ryan,D.H., Nuccie,B.L., Abboud,C.N., and Winslow,J.M. (1991): Vascular cell adhesion molecule- 1 and the integrin VLA-4 mediate adhesion of human B cell precursors to cultured bone marrow adherent cells. J.Clin.Invest, 88:995-1004.

80. Kinashi,T. and Springer,T.A. (1994): Adhesion molecules in hematopoietic cells. Blood Cells, 20:25-44.

81. Miyake,K., Weissman,I.L., Greenberger,J.S., and Kincade,P.W. (1991): Evidence for a role of the integrin VLA-4 in lympho-hemopoiesis. J.Exp.Med., 173:599-607.

82. Miyake,K., Medina,K., Ishihara,K., Kimoto,M., Auerbach,R., and Kincade,P.W. (1991): A VCAM-like adhesion molecule on murine bone marrow stromal cells mediates binding of lymphocyte precursors in culture. J.Cell Biol., 114:557-565.

83. Funk,P.E., Kincade,P.W., and Witte,P.L. (1994): Native associations of early hematopoietic stem cells and stromal cells isolated in bone marrow cell aggregates. Blood, 83:361-369.

84. Arroyo,A.G., Taverna,D., Whittaker,C.A., Strauch,U.G., Bader,B.L., Rayburn,H., Crowley,D., Parker,C.M., and Hynes,R.O. (2000): In vivo roles of integrins during leukocyte development and traffic: insights from the analysis of mice chimeric for alpha 5, alpha v, and alpha 4 integrins. J.Immunol., 165:4667-4675.

85. Osborn,L., Hession,C., Tizard,R., Vassallo,C., Luhowskyj,S., Chi-Rosso,G., and Lobb,R. (1989): Direct expression cloning of vascular cell adhesion molecule 1, a cytokine-induced endothelial protein that binds to lymphocytes. Cell, 59:12031211.

86. Rice,G.E. and Bevilacqua,M.P. (1989): An inducible endothelial cell surface glycoprotein mediates melanoma adhesion. Science, 246:1303-1306. 
87. Bochner,B.S., Luscinskas,F.W., Gimbrone,M.A., Jr., Newman,W., Sterbinsky,S.A., Derse-Anthony,C.P., Klunk,D., and Schleimer,R.P. (1991): Adhesion of human basophils, eosinophils, and neutrophils to interleukin 1-activated human vascular endothelial cells: contributions of endothelial cell adhesion molecules. J.Exp.Med., 173:1553-1557.

88. Carlos,T., Kovach,N., Schwartz,B., Rosa,M., Newman,B., Wayner,E., Benjamin,C., Osborn,L., Lobb,R., and Harlan,J. (1991): Human monocytes bind to two cytokineinduced adhesive ligands on cultured human endothelial cells: endothelialleukocyte adhesion molecule-1 and vascular cell adhesion molecule-1. Blood, 77:2266-2271.

89. Oostendorp,R.A., Reisbach,G., Spitzer,E., Thalmeier,K., Dienemann,H., Mergenthaler,H.G., and Dormer,P. (1995): VLA-4 and VCAM-1 are the principal adhesion molecules involved in the interaction between blast colony-forming cells and bone marrow stromal cells. Br.J.Haematol., 91:275-284.

90. Dittel,B.N., McCarthy,J.B., Wayner,E.A., and LeBien,T.W. (1993): Regulation of human B-cell precursor adhesion to bone marrow stromal cells by cytokines that exert opposing effects on the expression of vascular cell adhesion molecule-1 (VCAM-1). Blood, 81:2272-2282.

91. Simmons,P.J., Masinovsky,B., Longenecker,B.M., Berenson,R., Torok-Storb,B., and Gallatin,W.M. (1992): Vascular cell adhesion molecule-1 expressed by bone marrow stromal cells mediates the binding of hematopoietic progenitor cells. Blood, 80:388-395.

92. Araki,M., Araki,K., and Vassalli,P. (1993): Cloning and sequencing of mouse VCAM-1 cDNA. Gene, 126:261-264.

93. Cybulsky,M.I., Fries,J.W., Williams,A.J., Sultan,P., Eddy,R., Byers,M., Shows,T., Gimbrone,M.A., Jr., and Collins,T. (1991): Gene structure, chromosomal location, and basis for alternative mRNA splicing of the human VCAM1 gene. Proc.Natl.Acad.Sci.U.S.A, 88:7859-7863.

94. Terry,R.W., Kwee,L., Levine,J.F., and Labow,M.A. (1993): Cytokine induction of an alternatively spliced murine vascular cell adhesion molecule (VCAM) mRNA encoding a glycosylphosphatidylinositol- anchored VCAM protein. Proc.Natl.Acad.Sci.U.S.A, 90:5919-5923. 
95. Kinashi,T., St Pierre,Y., and Springer,T.A. (1995): Expression of glycophosphatidylinositol-anchored and -non-anchored isoforms of vascular cell adhesion molecule 1 in murine stromal and endothelial cells. J.Leukoc.Biol., 57:168-173.

96. Kincade,P.W., Yamashita,Y., Borghesi,L., Medina,K., and Oritani,K. (1998): Blood cell precursors in context. Composition of the bone marrow microenvironment that supports B lymphopoiesis. Vox Sang. , 74 Suppl 2:265-268.

97. Papayannopoulou,T. and Nakamoto,B. (1993): Peripheralization of hemopoietic progenitors in primates treated with anti-VLA4 integrin. Proc.Natl.Acad.Sci.U.S.A, 90:9374-9378.

98. Wang,M.W., Consoli,U., Lane,C.M., Durett,A., Lauppe,M.J., Champlin,R., Andreeff,M., and Deisseroth,A.B. (1998): Rescue from apoptosis in early (CD34selected) versus late (non-CD34- selected) human hematopoietic cells by very late antig. Cell Growth Differ., 9:105-112.

99. Fischer,A. and Malissen,B. (1998): Natural and engineered disorders of lymphocyte development. Science, 280:237-243.

100. Kwee,L., Baldwin,H.S., Shen,H.M., Stewart,C.L., Buck,C., Buck,C.A., and Labow,M.A. (1995): Defective development of the embryonic and extraembryonic circulatory systems in vascular cell adhesion molecule (VCAM-1) deficient mice. Development, 121:489-503.

101. Koni,P.A., Joshi,S.K., Temann,U.A., Olson,D., Burkly,L., and Flavell,R.A. (2001): Conditional vascular cell adhesion molecule 1 deletion in mice: impaired lymphocyte migration to bone marrow. J.Exp.Med., 193:741-754.

102. Amsel,S., Maniatis,A., Tavassoli,M., and Crosby,W.H. (1969): The significance of intramedullary cancellous bone formation in the repair of bone marrow tissue. Anat.Rec., 164:101-111.

103. Friedenstein,A.J., Chailakhyan,R.K., Latsinik,N.V., Panasyuk,A.F., and KeilissBorok,I.V. (1974): Stromal cells responsible for transferring the microenvironment of the hemopoietic tissues. Cloning in vitro and retransplantation in vivo. Transplantation, 17:331-340. 
104. Gross,P.M., Heistad,D.D., and Marcus,M.L. (1979): Neurohumoral regulation of blood flow to bones and marrow. Am.J.Physiol, 237:H440-H448

105. Donohue DM, Gabrio BW, and Finch CA (1958): Quantitative Measurement of Hematopoietic Cells of the Marrow. J.Clin.Invest, 37:1564-1576.

106. Martiat,P., Ferrant,A., Cogneau,M., Bol,A., Michel,C., Rodhain,J., Michaux,J.L., and Sokal,G. (1987): Assessment of bone marrow blood flow using positron emission tomography: no relationship with bone marrow cellularity. Br.J.Haematol., 66:307-310.

107. Lahtinen,R., Lahtinen,T., and Romppanen,T. (1982): Bone and bone-marrow blood flow in chronic granulocytic leukemia and primary myelofibrosis. J.Nucl.Med., 23:218-224.

108. Michelsen,K. (1969): Hemodynamics in the bone marrow of anemic rabbits with increased hematopoiesis. Acta Physiol Scand., 77:52-57.

109. Chen,L.T., Chen,M.F., and Porter,V.L. (1986): Increased bone marrow blood flow in rabbits with acute hemolytic anemia. Am.J.Hematol., 22:35-41.

110. Schoutens,A., Verhas,M., Dourov,N., Verschaeren,A., Mone,M., and Heilporn,A. (1990): Anaemia and marrow blood flow in the rat. Br.J.Haematol., 74:514-518.

111. Iversen,P.O., Nicolaysen,G., and Benestad,H.B. (1992): Blood flow to bone marrow during development of anemia or polycythemia in the rat. Blood, 79:594601.

112. Schadt,J.C. and Ludbrook,J. (1991): Hemodynamic and neurohumoral responses to acute hypovolemia in conscious mammals. Am.J.Physiol, 260:H305-H318

113. Iversen,P.O., Nicolaysen,G., and Benestad,H.B. (1993): The leukopoietic cytokine granulocyte colony-stimulating factor increases blood flow to rat bone marrow. Exp.Hematol., 21:231-235.

114. Yanagisawa,M., Kurihara,H., Kimura,S., Tomobe,Y., Kobayashi,M., Mitsui,Y., Yazaki,Y., Goto,K., and Masaki,T. (1988): A novel potent vasoconstrictor peptide produced by vascular endothelial cells. Nature, 332:411-415. 
115. Furchgott,R.F. and Vanhoutte,P.M. (1989): Endothelium-derived relaxing and contracting factors. FASEB J., 3:2007-2018.

116. Iversen,P.O., Nicolaysen,G., and Benestad,H.B. (1994): Endogenous nitric oxide causes vasodilation in rat bone marrow, bone, and spleen during accelerated hematopoiesis. Exp.Hematol., 22:1297-1302.

117. Calvo,W. (1968): The innervation of the bone marrow in laboratory animals. Am.J.Anat., 123:315-328.

118. Curry,J.L. and Trentin,J.J. (1967): Hemopoietic spleen colony studies. I. Growth and differentiation. Dev.Biol., 15:395-413.

119. Till JE and McCulloch EA (1961): A Direct Measurement of the Radiation Sensitivity of Normal Mouse Bone Marrow Cells. Radiation Research, 14:213-222.

120. Wolf,N.S. and Trentin,J.J. (1968): Hemopoietic colony studies. V. Effect of hemopoietic organ stroma on differentiation of pluripotent stem cells. $J$ Exp.Med., 127:205-214.

121. Lorenz E, Uphoff D, Reid TR, and Shelton E (1951): Modification of Irradiation Injury in Mice and Guinea Pigs by Bone Marrow Injections. J Nat Cancer Inst, 12:197-201.

122. Lord,B.I. and Hendry,J.H. (1972): The distribution of haemopoietic colony-forming units in the mouse femur, and its modification by $x$ rays. Br.J.Radiol., 45:110-115.

123. Lord,B.I., Testa,N.G., and Hendry,J.H. (1975): The relative spatial distributions of CFUs and CFUc in the normal mouse femur. Blood, 46:65-72.

124. Janowska-Wieczorek,A., Majka,M., Ratajczak,J., and Ratajczak,M.Z. (2001): Autocrine/paracrine mechanisms in human hematopoiesis. Stem Cells, 19:99-107.

125. Metcalf,D. (1998): The molecular control of hematopoiesis: progress and problems with gene manipulation. Stem Cells, 16:314-321.

126. Whitlock,C.A. and Witte,O.N. (1982): Long-term culture of B lymphocytes and their precursors from murine bone marrow. Proc.Natl.Acad.Sci.U.S.A, 79:3608-3612. 
127. Kincade,P.W., Lee,G., Pietrangeli,C.E., Hayashi,S., and Gimble,J.M. (1989): Cells and molecules that regulate $B$ lymphopoiesis in bone marrow. Annu.Rev.Immunol., 7:111-143.

128. McGinnes,K., Quesniaux,V., Hitzler,J., and Paige,C. (1991): Human Blymphopoiesis is supported by bone marrow-derived stromal cells. Exp.Hematol., 19:294-303.

129. Wolf,M.L., Buckley,J.A., Goldfarb,A., Law,C.L., and LeBien,T.W. (1991): Development of a bone marrow culture for maintenance and growth of normal human B cell precursors. J.Immunol., 147:3324-3330.

130. Dittel,B.N. and LeBien,T.W. (1995): The growth response to IL-7 during normal human B cell ontogeny is restricted to B-lineage cells expressing CD34. J.Immunol., 154:58-67.

131. Knospe,W.H., Blom,J., and Crosby,W.H. (1966): Regeneration of locally irradiated bone marrow. I. Dose dependent, long- term changes in the rat, with particular emphasis upon vascular and stromal reaction. Blood, 28:398-415.

132. Tavassoli,M. and Crosby,W.H. (1968): Transplantation of marrow to extramedullary sites. Science, 161:54-56.

133. Dexter,T.M. (1982): Stromal cell associated haemopoiesis. J.Cell Physiol Suppl, $1: 87-94$.

134. Ryan,D.H., Nuccie,B.L., Abboud,C.N., and Liesveld,J.L. (1990): Maturationdependent adhesion of human $B$ cell precursors to the bone marrow microenvironment. J.Immunol., 145:477-484.

135. Manabe,A., Murti,K.G., Coustan-Smith,E., Kumagai,M., Behm,F.G., Raimondi,S.C., and Campana,D. (1994): Adhesion-dependent survival of normal and leukemic human B lymphoblasts on bone marrow stromal cells. Blood, 83:758-766.

136. Stephan,R.P., Reilly,C.R., and Witte,P.L. (1998): Impaired ability of bone marrow stromal cells to support B- lymphopoiesis with age. Blood, 91:75-88. 
137. Jacobsen,K., Kravitz,J., Kincade,P.W., and Osmond,D.G. (1996): Adhesion receptors on bone marrow stromal cells: in vivo expression of vascular cell adhesion molecule- 1 by reticular cells and sinusoidal endothelium in normal and gamma-irradiated mice. Blood, 87:73-82.

138. Arroyo,A.G., Yang,J.T., Rayburn,H., and Hynes,R.O. (1999): Alpha4 integrins regulate the proliferation/differentiation balance of multilineage hematopoietic progenitors in vivo. Immunity., 11:555-566.

139. Zou,Y.R., Kottmann,A.H., Kuroda,M., Taniuchi,I., and Littman,D.R. (1998): Function of the chemokine receptor CXCR4 in haematopoiesis and in cerebellar development. Nature, 393:595-599.

140. Nagasawa,T., Hirota,S., Tachibana,K., Takakura,N., Nishikawa,S., Kitamura,Y., Yoshida,N., Kikutani,H., and Kishimoto,T. (1996): Defects of B-cell lymphopoiesis and bone-marrow myelopoiesis in mice lacking the CXC chemokine PBSF/SDF-1. Nature, 382:635-638.

141. Ma,Q., Jones,D., Borghesani,P.R., Segal,R.A., Nagasawa,T., Kishimoto,T., Bronson,R.T., and Springer,T.A. (1998): Impaired B-lymphopoiesis, myelopoiesis, and derailed cerebellar neuron migration in CXCR-4-deficient mice. Proc.Natl.Acad.Sci.U.S.A, 95:9448-9453.

142. Adams,J.C. and Watt,F.M. (1993): Regulation of development and differentiation by the extracellular matrix. Development, 117:1183-1198.

143. Williams,D.A. (1993): Ex vivo expansion of hematopoietic stem and progenitor cells--robbing Peter to pay Paul? Blood, 81:3169-3172.

144. Yoder,M.C. and Williams,D.A. (1995): Matrix molecule interactions with hematopoietic stem cells. Exp.Hematol., 23:961-967.

145. Long,M.W., Briddell,R., Walter,A.W., Bruno,E., and Hoffman,R. (1992): Human hematopoietic stem cell adherence to cytokines and matrix molecules. J.Clin.Invest, 90:251-255.

146. Roberts,R., Gallagher,J., Spooncer,E., Allen,T.D., Bloomfield,F., and Dexter,T.M. (1988): Heparan sulphate bound growth factors: a mechanism for stromal cell mediated haemopoiesis. Nature, 332:376-378. 
147. Pelletier,A.J., van der Laan,L.J., Hildbrand,P., Siani,M.A., Thompson,D.A., Dawson,P.E., Torbett,B.E., and Salomon,D.R. (2000): Presentation of chemokine SDF-1 alpha by fibronectin mediates directed migration of T cells. Blood, 96:26822690.

148. Weinstein,R., Riordan,M.A., Wenc,K., Kreczko,S., Zhou,M., and Dainiak,N. (1989): Dual role of fibronectin in hematopoietic differentiation. Blood, 73:111-116.

149. Siler,U., Seiffert,M., Puch,S., Richards,A., Torok-Storb,B., Muller,C.A., Sorokin,L., and Klein,G. (2000): Characterization and functional analysis of laminin isoforms in human bone marrow. Blood, 96:4194-4203.

150. Campbell,A.D., Long,M.W., and Wicha,M.S. (1987): Haemonectin, a bone marrow adhesion protein specific for cells of granulocyte lineage. Nature, 329:744-746.

151. Hamilton,R. and Campbell,F.R. (1991): Immunochemical localization of extracellular materials in bone marrow of rats. Anat.Rec., 231:218-224.

152. Jacobson LO, Simmons EL, Marks EK, Gaston EO, Robson MJ, and Eldredge JH (1951): Recovery from Radiation Injury. Science, 113:510-511.

153. Lorenz E and Congdon C (1954): Modification of Lethal Irradiation Injury in Mice by Injection of Homologous or Heterologous Bone. J Nat Cancer Inst, 14:955-961.

154. Bortin,M.M. (1970): A compendium of reported human bone marrow transplants. Transplantation, 9:571-587.

155. Davies,S.M., Kollman,C., Anasetti,C., Antin,J.H., Gajewski,J., Casper,J.T., Nademanee,A., Noreen,H., King,R., Confer,D., and Kernan,N.A. (2000): Engraftment and survival after unrelated-donor bone marrow transplantation: a report from the national marrow donor program. Blood, 96:4096-4102.

156. Drobyski,W.R., Klein,J., Flomenberg,N., Pietryga,D., Vesole,D.H., Margolis,D.A., and Keever-Taylor,C.A. (2002): Superior survival associated with transplantation of matched unrelated versus one-antigen-mismatched unrelated or highly human leukocyte antigen-disparate haploidentical family donor marrow grafts for the treatment of hematologic malignancies: establishing a treatment algorithm for recipients of alternative donor grafts. Blood, 99:806-814. 
157. Tashiro,K., Tada,H., Heilker,R., Shirozu,M., Nakano,T., and Honjo,T. (1993): Signal sequence trap: a cloning strategy for secreted proteins and type I membrane proteins. Science, 261:600-603.

158. Bleul,C.C., Fuhlbrigge,R.C., Casasnovas,J.M., Aiuti,A., and Springer,T.A. (1996): A highly efficacious lymphocyte chemoattractant, stromal cell-derived factor 1 (SDF-1). J.Exp.Med., 184:1101-1109.

159. Kim,C.H. and Broxmeyer,H.E. (1998): In vitro behavior of hematopoietic progenitor cells under the influence of chemoattractants: stromal cell-derived factor-1, steel factor, and the bone marrow environment. Blood, 91:100-110.

160. Voermans,C., Anthony,E.C., Mul,E., van der,S.E., and Hordijk,P. (2001): SDF-1induced actin polymerization and migration in human hematopoietic progenitor cells. Exp.Hematol., 29:1456-1464.

161. Shirozu,M., Nakano,T., Inazawa,J., Tashiro,K., Tada,H., Shinohara,T., and Honjo,T. (1995): Structure and chromosomal localization of the human stromal cell- derived factor 1 (SDF1) gene. Genomics, 28:495-500.

162. Jo,D.Y., Rafii,S., Hamada,T., and Moore,M.A. (2000): Chemotaxis of primitive hematopoietic cells in response to stromal cell- derived factor-1. J.Clin.Invest, 105:101-111.

163. Hardy,C.L. (1995): The homing of hematopoietic stem cells to the bone marrow. Am.J.Med.Sci., 309:260-266.

164. Berlin,C., Berg,E.L., Briskin,M.J., Andrew,D.P., Kilshaw,P.J., Holzmann,B., Weissman,I.L., Hamann,A., and Butcher,E.C. (1993): Alpha 4 beta 7 integrin mediates lymphocyte binding to the mucosal vascular addressin MAdCAM-1. Cell, $74: 185$

165. Van der Loo,J.C. and Ploemacher,R.E. (1995): Marrow- and spleen-seeding efficiencies of all murine hematopoietic stem cell subsets are decreased by preincubation with hematopoietic growth factors. Blood, 85:2598-2606.

166. Iversen,P.O. (1997): Blood flow to the haemopoietic bone marrow. Acta Physiol Scand., 159:269-276. 
167. van Hennik,P.B., de Koning,A.E., and Ploemacher,R.E. (1999): Seeding efficiency of primitive human hematopoietic cells in nonobese diabetic/severe combined immune deficiency mice: implications for stem cell frequency assessment. Blood, 94:3055-3061.

168. Rood,P.M., Dercksen,M.W., Cazemier,H., Kerst,J.M., dem Borne,A.E., Gerritsen,W.R., and van der Schoot,C.E. (2000): E-selectin and very late activation antigen-4 mediate adhesion of hematopoietic progenitor cells to bone marrow endothelium. Ann. Hematol., 79:477-484.

169. Frenette,P.S., Subbarao,S., Mazo,I.B., von Andrian,U.H., and Wagner,D.D. (1998): Endothelial selectins and vascular cell adhesion molecule-1 promote hematopoietic progenitor homing to bone marrow. Proc.Natl.Acad.Sci.U.S.A, 95:14423-14428.

170. Mazo,I.B., Gutierrez-Ramos,J.C., Frenette,P.S., Hynes,R.O., Wagner,D.D., and von Andrian,U.H. (1998): Hematopoietic progenitor cell rolling in bone marrow microvessels: parallel contributions by endothelial selectins and vascular cell adhesion molecule 1. J.Exp.Med., 188:465-474.

171. Schweitzer,K.M., $\quad$ Drager,A.M., $\quad$ van,d., $\quad$ V, Thijsen,S.F., Zevenbergen,A., Theijsmeijer,A.P., van der Schoot,C.E., and Langenhuijsen,M.M. (1996): Constitutive expression of E-selectin and vascular cell adhesion molecule-1 on endothelial cells of hematopoietic tissues. Am.J.Pathol., 148:165-175.

172. Mohle,R., Rafii,S., and Moore,M.A. (1998): The role of endothelium in the regulation of hematopoietic stem cell migration. Stem Cells, 16 Suppl 1:159-165.

173. Mohle,R., Bautz,F., Rafii,S., Moore,M.A., Brugger,W., and Kanz,L. (1999): Regulation of transendothelial migration of hematopoietic progenitor cells. Ann.N.Y.Acad.Sci., 872:176-185.

174. Naiyer,A.J., Jo,D.Y., Ahn,J., Mohle,R., Peichev,M., Lam,G., Silverstein,R.L., Moore,M.A., and Rafii,S. (1999): Stromal derived factor-1-induced chemokinesis of cord blood CD34(+) cells (long-term culture-initiating cells) through endothelial cells is mediated by E-selectin. Blood, 94:4011-4019.

175. Voermans,C., Rood,P.M., Hordijk,P.L., Gerritsen,W.R., and van der Schoot,C.E. (2000): Adhesion molecules involved in transendothelial migration of human hematopoietic progenitor cells. Stem Cells, 18:435-443. 
176. Peled,A., Grabovsky,V., Habler,L., Sandbank,J., Arenzana-Seisdedos,F., Petit,I., Ben Hur,H., Lapidot,T., and Alon,R. (1999): The chemokine SDF-1 stimulates integrin-mediated arrest of CD34(+) cells on vascular endothelium under shear flow. J.Clin.Invest, 104:1199-1211.

177. Peled,A., Kollet,O., Ponomaryov,T., Petit,I., Franitza,S., Grabovsky,V., Slav,M.M., Nagler,A., Lider,O., Alon,R., Zipori,D., and Lapidot,T. (2000): The chemokine SDF1 activates the integrins LFA-1, VLA-4, and VLA-5 on immature human CD34(+) cells: role in transendothelial/stromal migration and engraftment of NOD/SCID mice. Blood, 95:3289-3296.

178. Shen,W., Bendall,L.J., Gottlieb,D.J., and Bradstock,K.F. (2001): The chemokine receptor CXCR4 enhances integrin-mediated in vitro adhesion and facilitates engraftment of leukemic precursor-B cells in the bone marrow. Exp.Hematol., 29:1439-1447.

179. Imai,K. and Kobayashi,M. (1998): Differences between bone marrow and lung endothelial cells. Semin.Thromb.Hemost., 24:275-277.

180. Dimitroff,C.J., Lee,J.Y., Rafii,S., Fuhlbrigge,R.C., and Sackstein,R. (2001): CD44 is a major E-selectin ligand on human hematopoietic progenitor cells. J.Cell Biol., 153:1277-1286.

181. To,L.B., Haylock,D.N., Simmons,P.J., and Juttner,C.A. (1997): The biology and clinical uses of blood stem cells. Blood, 89:2233-2258.

182. Papayannopoulou,T. (1999): Hematopoietic stem/progenitor cell mobilization. A continuing quest for etiologic mechanisms. Ann.N.Y.Acad.Sci., 872:187-197.

183. Kronenwett,R., Martin,S., and Haas,R. (2000): The role of cytokines and adhesion molecules for mobilization of peripheral blood stem cells. Stem Cells, 18:320-330.

184. DeLuca,E., Sheridan,W.P., Watson,D., Szer,J., and Begley,C.G. (1992): Prior chemotherapy does not prevent effective mobilisation by G-CSF of peripheral blood progenitor cells. Br.J.Cancer, 66:893-899.

185. Sheridan,W.P., $\quad$ Begley,C.G., Juttner,C.A., Szer,J., To,L.B., Maher,D., McGrath,K.M., Morstyn,G., and Fox,R.M. (1992): Effect of peripheral-blood progenitor cells mobilised by filgrastim (G- CSF) on platelet recovery after highdose chemotherapy. Lancet, 339:640-644. 
186. Duhrsen,U., Villeval,J.L., Boyd,J., Kannourakis,G., Morstyn,G., and Metcalf,D. (1988): Effects of recombinant human granulocyte colony-stimulating factor on hematopoietic progenitor cells in cancer patients. Blood, 72:2074-2081.

187. Craddock,C.F., Nakamoto,B., Andrews,R.G., Priestley,G.V., and Papayannopoulou,T. (1997): Antibodies to VLA4 integrin mobilize long-term repopulating cells and augment cytokine-induced mobilization in primates and mice. Blood, 90:4779-4788.

188. Kikuta,T., Shimazaki,C., Ashihara,E., Sudo,Y., Hirai,H., Sumikuma,T., Yamagata,N., Inaba,T., Fujita,N., Kina,T., and Nakagawa,M. (2000): Mobilization of hematopoietic primitive and committed progenitor cells into blood in mice by anti-vascular adhesion molecule-1 antibody alone or in combination with granulocyte colony-stimulating factor. Exp.Hematol., 28:311-317.

189. Prosper,F., Stroncek,D., McCarthy,J.B., and Verfaillie,C.M. (1998): Mobilization and homing of peripheral blood progenitors is related to reversible downregulation of alpha4 beta1 integrin expression and function. J.Clin.Invest, 101:2456-2467.

190. Levesque,J.P. and Simmons,P.J. (1999): Cytoskeleton and integrin-mediated adhesion signaling in human CD34+ hemopoietic progenitor cells. Exp. Hematol., 27:579-586.

191. Simmons,P.J., Leavesley,D.I., Levesque,J.P., Swart,B.W., Haylock,D.N., To,L.B., Ashman,L.K., and Juttner,C.A. (1994): The mobilization of primitive hemopoietic progenitors into the peripheral blood. Stem Cells, 12 Suppl 1:187-201.

192. Mohle,R., Haas,R., and Hunstein,W. (1993): Expression of adhesion molecules and c-kit on CD34+ hematopoietic progenitor cells: comparison of cytokinemobilized blood stem cells with normal bone marrow and peripheral blood. J.Hematother., 2:483-489.

193. Dercksen,M.W., $\quad$ Gerritsen,W.R., $\quad$ Rodenhuis,S., $\quad$ Dirkson,M.K., SlaperCortenbach,I.C., Schaasberg,W.P., Pinedo,H.M., dem Borne,A.E., and van der Schoot,C.E. (1995): Expression of adhesion molecules on CD34+ cells: CD34+ Lselectin+ cells predict a rapid platelet recovery after peripheral blood stem cell transplantation. Blood, 85:3313-3319.

194. Kagan,J.M., Champlin,R.E., and Saxon,A. (1989): B-cell dysfunction following human bone marrow transplantation: functional-phenotypic dissociation in the early posttransplant period. Blood, 74:777-785. 
195. Mauch,P., Constine,L., Greenberger,J., Knospe,W., Sullivan,J., Liesveld,J.L., and Deeg,H.J. (1995): Hematopoietic stem cell compartment: acute and late effects of radiation therapy and chemotherapy. Int.J.Radiat.Oncol.Biol.Phys., 31:1319-1339.

196. Janczewska,S., Ziolkowska,A., Durlik,M., Cybulska,E., Olszewski,W.L., and Lukomska,B. (1999): Requirement of stromal cells in the bone marrow transplant for rapid lymphoid replenishment. Transplant.Proc., 31:696-699.

197. Brandwein,J.M., Callum,J., Sutcliffe,S.B., Scott,J.G., and Keating,A. (1990): Analysis of factors affecting hematopoietic recovery after autologous bone marrow transplantation for lymphoma. Bone Marrow Transplant., 6:291-294.

198. Bentley,S.A., Brecher,M.E., Powell,E., Serody,J.S., Wiley,J.M., and Shea,T.C. (1997): Long-term engraftment failure after marrow ablation and autologous hematopoietic reconstitution: differences between peripheral blood stem cell and bone marrow recipients. Bone Marrow Transplant., 19:557-563.

199. Appasamy,P.M. (1999): Biological and clinical implications of interleukin-7 and lymphopoiesis. Cytokines Cell Mol.Ther., 5:25-39.

200. Komschlies,K.L., Grzegorzewski,K.J., and Wiltrout,R.H. (1995): Diverse immunological and hematological effects of interleukin 7: implications for clinical application. J.Leukoc.Biol., 58:623-633.

201. Mertsching,E., Meyer,V., Linares,J., Lombard-Platet,S., and Ceredig,R. (1998): Interleukin-7, a non-redundant potent cytokine whose over-expression massively perturbs B-lymphopoiesis. Int.Rev.Immunol., 16:285-308.

202. Koc,O.N., Gerson,S.L., Cooper,B.W., Dyhouse,S.M., Haynesworth,S.E., Caplan,A.I., and Lazarus,H.M. (2000): Rapid hematopoietic recovery after coinfusion of autologous-blood stem cells and culture-expanded marrow mesenchymal stem cells in advanced breast cancer patients receiving high-dose chemotherapy. J.Clin.Oncol., 18:307-316.

203. Song,Z.X. and Quesenberry,P.J. (1984): Radioresistant murine marrow stromal cells: a morphologic and functional characterization. Exp. Hematol., 12:523-533.

204. Osmond DG (1964): Radioautographic Studies of Bone Marrow Lymphocytes in vivo and in Diffusion Chamber Cultures. Blood, 23:1-17. 
205. Banfi,A., Bianchi,G., Galotto,M., Cancedda,R., and Quarto,R. (2001): Bone marrow stromal damage after chemo/radiotherapy: occurrence, consequences and possibilities of treatment. Leuk.Lymphoma, 42:863-870.

206. Testa,N.G. and Dexter,T.M. (1989): Long-term hematopoietic damage: concepts, approaches, and results relevant to the study of environmental toxins. Environ. Health Perspect., 82:51-56.

207. Galotto,M., Berisso,G., Delfino,L., Podesta,M., Ottaggio,L., Dallorso,S., Dufour,C., Ferrara,G.B., Abbondandolo,A., Dini,G., Bacigalupo,A., Cancedda,R., and Quarto,R. (1999): Stromal damage as consequence of high-dose chemo/radiotherapy in bone marrow transplant recipients. Exp. Hematol., 27:14601466.

208. Laver,J. (1989): Radiobiological properties of human hematopoietic and stromal marrow cells. Int.J.Cell Cloning, 7:203-212.

209. Greenberger,J.S., Anderson,J., Berry,L.A., Epperly,M., Cronkite,E.P., and Boggs,S.S. (1996): Effects of irradiation of CBA/CA mice on hematopoietic stem cells and stromal cells in long-term bone marrow cultures. Leukemia, 10:514-527.

210. Migliaccio,A.R., Migliaccio,G., Johnson,G., Adamson,J.W., and Torok-Storb,B. (1990): Comparative analysis of hematopoietic growth factors released by stromal cells from normal donors or transplanted patients. Blood, 75:305-312.

211. Schwartz,G.N., Warren,M.K., Rothwell,S.W., Zujewski,J., Halverson,D.C., Cowan,K.H., Tolcher,A., O'Shaughnessy,J., and Gress,R.E. (1998): Postchemotherapy and cytokine pretreated marrow stromal cell layers suppress hematopoiesis from normal donor CD34+ cells. Bone Marrow Transplant., 22:457468.

212. Piersma,A.H., Ploemacher,R.E., and Brockbank,K.G. (1983): Radiation damage to femoral hemopoietic stroma measured by implant regeneration and quantitation of fibroblastic progenitors. Exp.Hematol. , 11:884-890.

213. Gibson,L.F., Fortney,J., Landreth,K.S., Piktel,D., Ericson,S.G., and Lynch,J.P. (1997): Disruption of bone marrow stromal cell function by etoposide. Biol.Blood Marrow Transplant., 3:122-132. 
214. del Canizo,C., Lopez,N., Caballero,D., Fernandez,E., Brufau,A., Vazquez,L., Mateos,V., Gutierrez,N., and San Miguel,J.F. (1999): Haematopoietic damage persists 1 year after autologous peripheral blood stem cell transplantation. Bone Marrow Transplant., 23:901-905.

215. Fried,W. and Barone,J. (1980): Residual marrow damage following therapy with cyclophosphamide. Exp.Hematol., 8:610-614.

216. Lopez,A.F., Dyson,P.G., To,L.B., Elliott,M.J., Milton,S.E., Russell,J.A., Juttner,C.A., Yang,Y.C., Clark,S.C., and Vadas,M.A. (1988): Recombinant human interleukin-3 stimulation of hematopoiesis in humans: loss of responsiveness with differentiation in the neutrophilic myeloid series. Blood, 72:1797-1804.

217. Metcalf,D. and Nicola,N.A. (1991): Direct proliferative actions of stem cell factor on murine bone marrow cells in vitro: effects of combination with colony-stimulating factors. Proc.Natl.Acad.Sci.U.S.A, 88:6239-6243.

218. Molineux,G., Migdalska,A., Szmitkowski,M., Zsebo,K., and Dexter,T.M. (1991): The effects on hematopoiesis of recombinant stem cell factor (ligand for c-kit) administered in vivo to mice either alone or in combination with granulocyte colonystimulating factor. Blood, 78:961-966.

219. Suda,T., Yamaguchi,Y., Suda,J., Miura,Y., Okano,A., and Akiyama,Y. (1988): Effect of interleukin 6 (IL-6) on the differentiation and proliferation of murine and human hemopoietic progenitors. Exp.Hematol., 16:891-895.

220. Morstyn,G., Campbell,L., Souza,L.M., Alton,N.K., Keech,J., Green,M., Sheridan,W., Metcalf,D., and Fox,R. (1988): Effect of granulocyte colony stimulating factor on neutropenia induced by cytotoxic chemotherapy. Lancet, $1: 667-672$.

221. Gabrilove,J.L., Jakubowski,A., Scher,H., Sternberg,C., Wong,G., Grous,J., Yagoda,A., Fain,K., Moore,M.A., Clarkson,B., and . (1988): Effect of granulocyte colony-stimulating factor on neutropenia and associated morbidity due to chemotherapy for transitional-cell carcinoma of the urothelium. N.Engl.J.Med., 318:1414-1422.

222. Bronchud,M.H., Scarffe,J.H., Thatcher,N., Crowther,D., Souza,L.M., Alton,N.K., Testa,N.G., and Dexter,T.M. (1987): Phase I/II study of recombinant human granulocyte colony-stimulating factor in patients receiving intensive chemotherapy for small cell lung cancer. Br.J.Cancer, 56:809-813. 
223. Antman,K.S., Griffin,J.D., Elias,A., Socinski,M.A., Ryan,L., Cannistra,S.A., Oette,D., Whitley,M., Frei,E., III, and Schnipper,L.E. (1988): Effect of recombinant human granulocyte-macrophage colony-stimulating factor on chemotherapyinduced myelosuppression. N.Engl.J.Med., 319:593-598.

224. Brandt,S.J., Peters,W.P., Atwater,S.K., Kurtzberg,J., Borowitz,M.J., Jones,R.B., Shpall,E.J., Bast,R.C., Jr., Gilbert,C.J., and Oette,D.H. (1988): Effect of recombinant human granulocyte-macrophage colony-stimulating factor on hematopoietic reconstitution after high-dose chemotherapy and autologous bone marrow transplantation. N.Engl.J.Med., 318:869-876.

225. Sheridan,W.P., Morstyn,G., Wolf,M., Dodds,A., Lusk,J., Maher,D., Layton,J.E., Green,M.D., Souza,L., and Fox,R.M. (1989): Granulocyte colony-stimulating factor and neutrophil recovery after high-dose chemotherapy and autologous bone marrow transplantation. Lancet, 2:891-895.

226. Taylor,K.M., Jagannath,S., Spitzer,G., Spinolo,J.A., Tucker,S.L., Fogel,B., Cabanillas,F.F., Hagemeister,F.B., and Souza,L.M. (1989): Recombinant human granulocyte colony-stimulating factor hastens granulocyte recovery after high-dose chemotherapy and autologous bone marrow transplantation in Hodgkin's disease. J.Clin.Oncol., 7:1791-1799.

227. Stahel,R.A., Jost,L.M., Cerny,T., Pichert,G., Honegger,H., Tobler,A., Jacky,E., Fey,M., and Platzer,E. (1994): Randomized study of recombinant human granulocyte colony-stimulating factor after high-dose chemotherapy and autologous bone marrow transplantation for high-risk lymphoid malignancies. J.Clin.Oncol., 12:1931-1938.

228. Bolotin,E., Smogorzewska,M., Smith,S., Widmer,M., and Weinberg,K. (1996): Enhancement of thymopoiesis after bone marrow transplant by in vivo interleukin7. Blood, 88:1887-1894.

229. Abdul-Hai,A., Or,R., Slavin,S., Friedman,G., Weiss,L., Matsa,D., and Ben Yehuda,A. (1996): Stimulation of immune reconstitution by interleukin-7 after syngeneic bone marrow transplantation in mice. Exp. Hematol., 24:1416-1422.

230. Alpdogan,O., Schmaltz,C., Muriglan,S.J., Kappel,B.J., Perales,M.A., Rotolo,J.A., Halm,J.A., Rich,B.E., and van den Brink,M.R. (2001): Administration of interleukin7 after allogeneic bone marrow transplantation improves immune reconstitution without aggravating graft-versus-host disease. Blood, 98:2256-2265. 
231. Brown,R.A., Wolff,S.N., Fay,J.W., Pineiro,L., Collins,R.H., Jr., Lynch,J.P., Stevens,D., Greer,J., Herzig,R.H., and Herzig,G.P. (1996): High-dose etoposide, cyclophosphamide and total body irradiation with allogeneic bone marrow transplantation for resistant acute myeloid leukemia: a study by the North American Marrow Transplant Group. Leuk.Lymphoma, 22:271-277.

232. Schmitz,N., Pfistner,B., Sextro,M., Sieber,M., Carella,A.M., Haenel,M., Boissevain,F., Zschaber,R., Muller,P., Kirchner,H., Lohri,A., Decker,S., Koch,B., Hasenclever,D., Goldstone,A.H., and Diehl,V. (2002): Aggressive conventional chemotherapy compared with high-dose chemotherapy with autologous haemopoietic stem-cell transplantation for relapsed chemosensitive Hodgkin's disease: a randomised trial. Lancet, 359:2065-2071.

233. Kelly,K.M., Hutchinson,R.J., Sposto,R., Weiner,M.A., Lones,M.A., Perkins,S.L., and Massey,V. (2002): Feasibility of upfront dose-intensive chemotherapy in children with advanced-stage Hodgkin's lymphoma: preliminary results from the Children's Cancer Group Study CCG-59704. Ann.Oncol., 13 Suppl 1:107-111.

234. Rizzo,J.D., Elias,A.D., Stiff,P.J., Lazarus,H.M., Zhang,M.J., Oblon,D.J., Pecora,A.L., Hale,G.A., and Horowitz,M.M. (2002): Autologous stem cell transplantation for small cell lung cancer. Biol.Blood Marrow Transplant., 8:273280. 


\title{
Chapter II
}

Human Bone Marrow Stromal Cell SDF-1 Production Is Reduced Following exposure To Topoisomerase II Inhibitors, Etoposide Or Doxorubicin

\author{
Brett M. Hall', James E. Fortney ${ }^{2}$, and Laura F. Gibson ${ }^{1,2,3}$
}

Microbiology, Immunology, and Cell Biology ${ }^{1}$, Departments of Pediatrics ${ }^{2}$, and the Blood and Marrow Transplantation Program of the Mary Babb Randolph Cancer Center ${ }^{3}$ West Virginia University, Morgantown, WV 26506

This manuscript was published in the journal Analytical Pharmacology (in press 2002). 


\begin{abstract}
An essential component of successful bone marrow transplantation is the efficient chemotaxis of transplanted hematopoietic progenitor cells to the bone marrow. Stromal cell derived factor-1 (SDF-1) is a primary chemokine responsible for chemotaxis of hematopoietic cells to the marrow microenvironment. To determine whether aggressive chemotherapy reduces SDF-1 expression or the ability of stromal cells to support progenitor cell chemotaxis, we evaluated the effect of etoposide or doxorubicin on stromal cell SDF-1 production. SDF-1 protein was reduced following exposure of stromal cells to either topoisomerase II inhibitor. In addition, chemotherapy treated stromal cells failed to support leukemic cell or normal pro-B cell migration. These data suggest that specific chemotherapeutic agents may contribute to delayed hematopoietic recovery, in part, through reduction of stromal cell SDF-1 expression in the bone marrow microenvironment.
\end{abstract}




\section{INTRODUCTION}

Homing of hematopoietic progenitor cells to the bone marrow during normal development, or following transplantation, is a multi-step process $\{1 ; 2\}$. It is essential that progenitor cells marginate, transition from rolling to strong interaction with the luminal surface of the bone marrow endothelium, and undergo diapedesis. Following transit through the endothelium, hematopoietic cells migrate to stromal cell niches in the microenvironment that are capable of supporting their survival, proliferation, and differentiation. A cascade of interacting integrins, adhesion molecules, and extracellular matrix proteins regulate this complex process. The chemokine stromal cell derived factor-1 (SDF-1) has been shown to be essential for the directed movement of hematopoietic progenitor cells from the periphery to the bone marrow and for their subsequent migration through the extracellular matrix to the stromal cell surface $\{3-6\}$.

SDF-1 was originally identified in the stromal cell line PA6 as a soluble factor that synergized with IL-7 induced proliferation of pre-B DW34 cells $\{7\}$. The deduced nucleotide sequence for SDF-1 was homologous with a factor identified earlier as a secreted protein by signal sequence trapping $\{8\}$. The chemoattractant found in supernatants of murine stromal cell lines MS-5, PA-6, and ST-2, was identified as SDF1 based on amino acid identity $\{5 ; 7 ; 9\}$. SDF-1 is now known to play a definitive role in homing of hematopoietic progenitor cells to the bone marrow microenvironment. Knock-out mice that lack SDF-1 expression or its G-protein coupled receptor, CXCR4 $\{10-13\}$ suffer both cardiac and hematopoietic defects $\{14-16\}$. SDF-1 knockout mice 
have markedly reduced $B$ lymphopoiesis and complete absence of myelopoiesis in the bone marrow $\{15\}$. In CXCR4 defective mice, myeloid cell development in the fetal liver was demonstrated to be normal, but cellularity of the bone marrow was markedly reduced $\{14\}$. In addition, studies have shown that anti-CXCR4 antibody treated human CD $-34^{+}$stem cells failed to engraft in NOD/SCID mice recipients $\{17\}$. Reports based on in vivo models have been substantiated by in vitro studies that demonstrated a role for SDF-1 directed homing of progenitors to the marrow and direct effects on survival and proliferation of hematopoietic cells $\{18\}$. Importantly, hematologic recovery of patients following transplantation has recently been shown to be most efficient in patients who received CD $34^{+}$cells that responded efficiently to SDF-1 in vitro $\{19\}$.

We previously reported that VP-16 exposure disrupted stromal cell capacity to support lymphoid and myeloid cell expansion, and that this diminished capacity was correlated with reduced expression of the stromal cell adhesion molecule VCAM-1 $\{20\}$. In the present study, we investigated the effect of VP-16 and doxorubicin on stromal cells to determine whether their ability to support migration of a CXCR4 $4^{+}$leukemic cell line, JM-1, was also impaired by treatment. Both drugs impose DNA strand breaks using a Topoisomerase II dependent mechanism. Our data demonstrate that chemotherapy treated human bone marrow stromal cells secrete reduced amounts of SDF-1 protein and have an impaired capacity to support JM-1 cell migration compared to untreated cells. Reduced SDF-1 secretion was sustained for five days following removal of drug. Taken together, these observations support the hypothesis that delayed hematopoietic recovery following dose intensive chemotherapy may be due, in part, to diminished stromal cell SDF-1 production. 


\section{MATERIALS AND METHODS}

\section{Cell Lines}

Stromal cell cultures were initiated from human bone marrow from consenting donors, with approval by the West Virginia University Institutional Review Board, as previously described $\{20\}$. All stromal cell primary cultures were initiated from donors with no previous chemotherapy exposure. The JM-1 factor independent lymphoblastic leukemic cell line, (\#CRL-1873; HLA DR ${ }^{+}, \mathrm{CD} 10^{+}, \mathrm{CD} 19^{+}$, surface Ig ${ }^{-}, \mathrm{VLA}-4^{+}, \mathrm{VLA}-5^{-}$, CXCR-4 $4^{+}$) was purchased from the American Type Culture Collection (ATCC). JM-1 cells were maintained in Iscoves medium supplemented with $10 \%$ ATCC Fetal Bovine Serum, 2mM L-Glutamine (GibcoBRL; Rockville, MD), 100U/ml Penicillin (Sigma; St. Louis, MO), $100 \mu \mathrm{g} / \mathrm{ml}$ Streptomycin (Sigma), $5 \times 10^{-5} \mathrm{M} \beta$-mercaptoethanol (Sigma).

\section{Chemotherapeutic agents}

VP-16 (Sigma) was mixed at a stock concentration of $20 \mathrm{mg} / \mathrm{ml}$ (100mg VP-16, $650 \mathrm{mg}$ polyethylene glycol 300, $80 \mathrm{mg}$ Tween 80 (ultra pure), 30.5\% ethanol, $2 \mathrm{mg}$ citric acid, 30mg benzyl alcohol) and diluted to $0.1-100 \mu \mathrm{M}$ in culture medium immediately prior to use. We have previously determined that matched vehicle doses do not impact on stromal cell SDF-1 secretion (data not shown). $100 \mu \mathrm{M}$ VP-16 was chosen to approximate serum levels reported for patients on high dose therapy $\{23\}$. Doxorubicin (Gensia Laboratories; Irvine, $\mathrm{CA}$ ) was diluted to $0.1 \mu \mathrm{M}$ to $10 \mu \mathrm{M}$ in culture medium to approximate the range of serum concentrations found in patients receiving this drug \{24-26\}. Based on its association with cardiac toxicity when used at escalated doses 
\{30-31\}, a maximum dose of $1.0 \mu \mathrm{M}$ doxorubicin is used in most experiments as a clinically relevant level. Both chemotherapeutic drugs were stored at $4^{\circ} \mathrm{C}$ prior to use.

\section{SDF-1 ELISA}

Confluent stromal cells, in 96-well tissue culture dishes (Becton Dickinson; Franklin Lakes, NJ), were treated with $0.10 \mu \mathrm{M}-100 \mu \mathrm{M}$ VP-16 or $0.10 \mu \mathrm{M}-10 \mu \mathrm{M}$ doxorubicin for up to 24 hours. Following treatment, cells were rinsed three times with fresh medium, and $110 \mu \mathrm{l}$ of serum-free Iscoves medium placed in each well. Plates were returned to $37^{\circ}$ for 24 hours, and $100 \mu$ l of the 24 -hour stromal cell conditioned supernatant was collected from each well to evaluate SDF-1 protein by ELISA, following the recommendations of the manufacturer (R\&D Systems, Inc.; Minneapolis, MN). The limit of SDF-1 protein detection as stated by the manufacturer ranged from $1-47 \mathrm{pg} / \mathrm{ml}$, which fell well below our lowest stromal cell SDF-1 protein concentration. All treatment groups were evaluated in triplicate.

\section{RNA isolation}

Total RNA was isolated from confluent stromal cells treated with $100 \mu \mathrm{M}$ VP-16 or $1.0 \mu \mathrm{M}$ doxorubicin using the S.N.A.P. Total RNA Isolation kit following the recommendation of the manufacturer (Invitrogen; Carlsbad, CA). Pelleted stromal cells were lysed by centrifugation through QIAshredder Spin Columns (QIAGEN Inc.; Santa Clarita, CA). RNA was DNase treated and quantitated at 260nm (GENESYS-10uv; Spectronic Unicam; Rochester, NY).

\section{Reverse Transcriptase - Polymerase Chain Reaction (RT-PCR)}

To evaluate SDF-1 and $\beta$-actin RNA levels, "One-Step" RT-PCR (Qiagen Inc.; Valencia, CA) was completed using RNA isolated from untreated, VP-16 treated, and 
doxorubicin treated stromal cells. Reverse transcription and amplification cycles included $50^{\circ}-30 \mathrm{~min}, 95^{\circ}-15 \mathrm{~min}$, and 30 cycles of $94^{\circ}-30 \mathrm{sec}, 55^{\circ}-1 \mathrm{~min} 15 \mathrm{sec}, 72^{\circ}-$

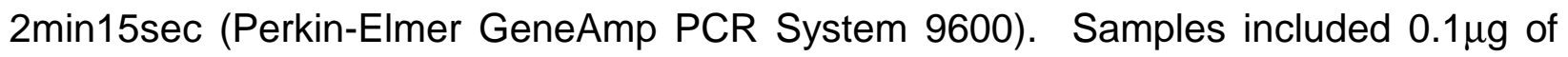
total RNA isolated from treated and untreated stromal cells as indicated above. Actin

primers were: 5'-TGACGGGGTCACCCACACTGTGCCCATCTA-3' and 5'CTAGAAGCATTTGCGGTGGACGATGGAGGG-3' (Stratagene; La Jolla, CA) at $0.1 \mu \mathrm{g} /$ reaction to generate an amplicon of 661 base pairs. SDF-1 primers: 5'GCCATGAACGCCAAGCTCGTGGT-3' and 5'-CCTCGAGTGGGTCTAGCGGAAAG-3', $(0.4 \mu \mathrm{g} /$ reaction) generated an amplicon of 317 base pairs $\{27\}$. As a negative control, samples that lacked RNA were included in all experiments. SDF-1:actin ratios were quantitated by EagleSight Version 3.21 (Stratagene; La Jolla, CA) densitometric analysis.

\section{Chemotaxis assay}

Migration of the CXCR- $4^{+}$cell line $\mathrm{JM}-1$ toward treated and control stromal cells across $5 \mu \mathrm{m}$ pores was determined using $6.5 \mathrm{~mm}$ diameter tissue culture treated transwells (Corning, Inc.; Corning, NY). Confluent stromal cell layers, grown in 24-well tissue culture plates (Becton Dickinson; Franklin Lakes, $\mathrm{NJ}$ ), were treated with $1.0 \mu \mathrm{M}$ or $100 \mu \mathrm{M}$ VP-16, $0.1 \mu \mathrm{M}$ or $1.0 \mu \mathrm{M}$ doxorubicin, or left untreated for 24 hours. As noted previously, the highest dose of each drug represents that typically used at the maximal level. Stromal cells were then rinsed three times with fresh medium and $350 \mu$ l of Iscoves medium was placed in each well. Following 24 hours, $5 \mu \mathrm{m}$ transwells were placed into each well and $80,000-120,000$ CXCR-4 $4^{+} \mathrm{JM}-1$ cells in a volume of $150 \mu \mathrm{l}$ Iscoves medium were placed in the top chamber. To evaluate the ability of SDF-1 to 
restore migration toward chemotherapy pretreated stromal cells, $5 \mathrm{ng} / \mathrm{ml}$ SDF-1 was added to matched wells in each treatment group. Transwells were incubated at $37^{\circ} \mathrm{C}$ for 4.5 hours. Cells migrating to the lower chamber were enumerated and percent JM-1 chemotaxis was determined as percent of control chemotaxis. Negative control samples included medium only in the lower chamber to evaluate spontaneous migration (less than $10 \%$ of positive controls at all times tested - data not shown), and positive control wells included $5 \mathrm{ng} / \mathrm{ml}$ recombinant human SDF-1 (rSDF-1) in the lower chamber.

\section{Recovery of stromal cell SDF-1 expression}

Stromal cells were exposed to $100 \mu \mathrm{M}$ VP-16 for up to 72 hours or cultured in medium alone. Following treatment, cells were rinsed, resuspended in fresh medium, and cultures maintained for up to 5 days. Supernatants were removed and replaced one day before SDF-1 ELISA analysis with serum-free Iscoves complete medium as previously described.

\section{Recovery of stromal cell ability to support JM-1 cell migration}

Stromal cell layers were treated for 24,48 , or 72 hours with $100 \mu \mathrm{M}$ VP-16. Cells were either evaluated immediately following treatment or following 3 days of recovery. 24 hours prior to initiation of assays, supernatants were replaced by $350 \mu$ fresh medium on all wells. Migration was evaluated as percent of control (untreated stromal cells), as previously described.

\section{Statistical analysis}

Statistical analysis was performed using One Way Analysis of Variance and Tukey Test to detect differences among means (SigmaStat Version 2.0 software, SPSS 
Inc.; Chicago, IL). All statistical comparisons represent treated samples as compared to control levels. All controls were matched to the longest treatment groups in each experiment.

\section{RESULTS}

VP-16 or doxorubicin exposure reduces bone marrow stromal cell SDF-1 protein expression

To determine whether topoisomerase II inhibitors VP-16 or doxorubicin alter stromal cell production of SDF-1, we evaluated several independent primary human stromal cell lines for SDF-1 protein production by ELISA following exposure to each drug. SDF-1 protein was reduced in stromal cell supernatants in a dose-dependent manner following exposure to either drug (Figure 1A). Secreted SDF-1 protein was reduced to approximately $70 \%$ of untreated control levels when stromal cells were treated with either $0.1 \mu \mathrm{M}$ doxorubicin or $1.0 \mu \mathrm{M}$ VP-16 for 24 hours. When cells were exposed to $1.0 \mu \mathrm{M}$ doxorubicin or $100 \mu \mathrm{M}$ VP-16 for 24 hours, greater reductions to 40 $50 \%$ of untreated control levels were observed (Figure 1A). SDF-1 protein reductions to $39 \%$ and $30 \%$ of baseline levels were observed when cells were exposed to the highest doses tested, $100 \mu \mathrm{M}$ VP-16 and $10 \mu \mathrm{M}$ doxorubicin respectively $(\mathrm{P}<0.05)$.

SDF-1 protein production by fifteen independent human stromal cell lines was evaluated in triplicate in two independent experiments. A mean stromal cell SDF-1 protein reduction of $63 \pm 2.1 \%$ (S.E.) $(\mathrm{P}<0.05$; each cell line), relative to untreated stromal cells, was observed following 24 hour exposure to $100 \mu \mathrm{M}$ VP-16 (Figure 1B). SDF-1 protein reduction was not due to decreased stromal cell viability in these 
experiments (data not shown). Consistent with our previously published report $\{20\}$, viability of treated stromal cells remained greater than 95\% (data not shown).

\section{Bone marrow stromal cell SDF-1 message level is reduced following chemotherapy treatment}

In contrast to SDF-1 protein, SDF-1 mRNA levels were only modestly decreased following stromal cell drug exposure. Bone marrow stromal cells were exposed to $1 \mu \mathrm{M}$ doxorubicin or $100 \mu \mathrm{M}$ VP-16 for up to 24 hours, and RT-PCR amplified SDF-1 RNA levels were compared to the housekeeping gene, actin, as previously described. Less than $30 \%$ reductions in SDF-1 transcript levels were observed following treatment with $100 \mu \mathrm{M}$ VP-16 (Figure $2 \mathrm{~A}$ ) or $1 \mu \mathrm{M}$ doxorubicin (Figure 2B) for up to 24 hours. SDF-1 message levels remained at $70-80 \%$ of control levels following up to 48 -hour doxorubicin or VP-16 exposures (data not shown).

\section{Chemotherapy diminishes stromal cell-induced migration of JM-1 cells}

To determine whether reduced stromal cell SDF-1 protein following drug exposure correlated with a reduced functional capacity of chemotherapy treated stromal cells, we evaluated JM-1 cell migration in vitro utilizing transwell assays. Consistent with reduced SDF-1 protein, chemotherapy treated stromal had reduced capacity to support JM-1 chemotaxis. When compared to $\mathrm{JM}-1$ cell migration toward untreated stromal cell layers, JM-1 migration toward stromal cells was reduced to $44.7 \%(\mathrm{P}<0.05)$, following $1 \mu \mathrm{M}$ VP-16 treatment of stromal cells and further reduced to $40.2 \%(\mathrm{P}<0.05)$ in response to $100 \mu \mathrm{M}$ VP-16 treated stromal cells (Figure 3A). JM-1 chemotaxis toward 
$0.1 \mu \mathrm{M}$ doxorubicin pre-treated stromal cells was $55.2 \%(\mathrm{P}<0.05)$ of the chemotaxis observed for $\mathrm{JM}-1$ cells toward untreated stromal cells. A further reduction in $\mathrm{JM}-1$ cell migration to $45.8 \%$ of untreated control levels $(P<0.05)$ was observed when stromal cells were treated with $1.0 \mu \mathrm{M}$ doxorubicin (Figure 3B). JM-1 cell movement toward medium alone was consistently less than $10 \%$ of that observed towards $5 \mathrm{ng} / \mathrm{ml} \mathrm{rSDF-1}$ or untreated stromal cell layers.

\section{Recombinant SDF-1 restores JM-1 movement toward chemotherapy damaged stromal cells}

To determine whether chemotherapy treated stromal cells produced factors that inhibit JM-1 cell chemotaxis, migration toward chemotherapy treated stromal cells, supplemented with recombinant SDF-1 was evaluated. Addition of exogenous rSDF-1 to the conditioned medium from treated stromal cells restored JM-1 cell chemotaxis to that of untreated stromal cell layers (Figures 3A and 3B).

SDF-1 protein expression does not recover for up to 5 days following removal of drug

Some high dose treatment strategies that include VP-16 include a 60-hour intravenous transfusion period $\{23\}$. To evaluate the effect of prolonged exposure on stromal cell SDF-1 protein levels, stromal cells were treated with VP-16 for up to 72 hours, rinsed, and allowed to recover for up to 5 days. All wells had fresh serum-free medium added 24 hours prior to SDF-1 protein evaluation by ELISA. VP-16 exposure for 72 hours resulted in decreased SDF-1 protein levels, with the decrease sustained 
during a 5 day recovery period (Figure 4). SDF-1 protein was reduced to approximately $40 \%$ of baseline $(P<0.05)$ when stromal cells were treated with $100 \mu \mathrm{M}$ VP-16 for 72 hours. Viability of confluent stromal cells treated with VP-16 for 72 hours consistently remained greater than 95\% (data not shown). Sustained SDF-1 reductions, $20-30 \%$ of untreated control stromal cells $(P<0.05)$, were maintained when cells were allowed to recover for up to 5 days following cessation of treatment (Figure 4).

\section{Sustained deficits in stromal cell SDF-1 protein expression by chemotherapy treated stromal cells correlate with impaired ability to support JM-1 cell migration}

To address the functional consequence of reduced stromal cell SDF-1 following VP-16 treatment and recovery, migration of $\mathrm{JM}-1$ cells toward treated and control adherent stromal cell layers was evaluated as described. The ability of VP-16 treated stromal cells to support JM-1 chemotaxis was diminished during exposure to VP-16 and did not recover for up to 3 days following removal of drug (Figure 5). JM-1 chemotaxis toward stromal cells was reduced to approximately $40 \%(\mathrm{P}<0.05)$ following $100 \mu \mathrm{M}$ VP16 treatment of stromal cells for up to 72 hours. Stromal cell deficits were sustained for up to 3 days following removal of the drug.

\section{DISCUSSION}

The role of SDF-1 as a major chemoattractant responsible for hematopoietic cell homing to the bone marrow has only recently been fully appreciated $\{3-6 ; 19\}$. Hematopoietic cell chemotaxis to, and retention within, the bone marrow relies in part on local and peripheral SDF-1 concentration gradients $\{28\}$. SDF-1's only known 
endogenous ligand is CXCR4, which is predominantly expressed on CD $34^{+}$stem cells, pro- and pre-B cells, T-lymphocytes, monocytes, and many leukemic cells $\{1 ; 3-6 ; 29\}$. In the current study, we tested the hypothesis that topoisomerase II inhibitors disrupt bone marrow stromal cell by reducing stromal cell SDF-1 protein production, using VP-16 and doxorubicin as model drugs. While a range of doses was tested for each drug, to evaluate their potential to reduce stromal cell SDF-1 expression, the maximal dose used most commonly in clinical settings was chosen as the focus of the migration assays. Our data demonstrate that both topoisomerase II inhibitors tested reduce stromal cell SDF-1 protein expression in all independent primary human stromal cell lines evaluated. In addition, the ability of stromal cells to support chemotaxis of JM-1 cells was markedly reduced by stromal cell exposure to either chemotherapeutic agent. These data suggest a functional alteration of bone marrow stromal cells by two agents that are commonly included in chemotherapy treatment regimens.

VP-16 may be the most clinically relevant drug in our in vitro transplantation model because it is tolerated by patients at escalated doses, while doxorubicin use at high levels is limited by cardiac toxicities $\{30 ; 31\}$. Interestingly however, both topoisomerase II inhibitors decreased SDF-1 production by stromal cells, while cytosine arabinoside (Ara-C) or 4-hydroxycyclophosphamide (4-HC; the primary active metabolite of cyclophosphamide) treatment had no effect (data not shown). These observations suggest that reduction of stromal cell SDF-1 production may be unique to specific drugs, or classes of drugs, such as topoisomerase II inhibitors. In a recent publication, increases in bone marrow SDF-1 expression were observed following irradiation or treatment with cyclophosphamide or $5-\mathrm{FU}$ in mice $\{32\}$. In the current 
study, no increase in stromal cell SDF-1 protein level resulted from 4-HC exposure. Discrepancy between our results and the previous report may stem from our use of the active metabolite, 4-HC, in contrast to the parental compound, cyclophosphamide.

Stromal cell exposure to the topoisomerase II inhibitors VP-16 or doxorubicin reduced SDF-1 protein production (Figure 1) without impacting on cell viability. In contrast to SDF-1, preliminary experiments indicated increased expression of secreted SCF and stable expression of MIP- $1 \alpha$ protein by VP-16 treated stromal cell layers compared to untreated controls (data not shown). These observations suggest that VP16 treatment does not result in a general reduction of protein synthesis or stability, but rather has specific effects on unique stromal cell derived factors. Reduced SDF-1 protein production following treatment correlated with impaired ability of bone marrow stromal cells to support directional JM-1 cell movement (Figure 3A). Primary human stromal cell production of SDF-1 protein ranged from $1300-3600 \mathrm{pg} / \mathrm{ml}$. When exposed to VP-16 or doxorubicin, primary human stromal cell lines consistently demonstrated reduced SDF-1 production and diminished ability to promote $\mathrm{JM}-1$ cell migration. In addition to $\mathrm{JM}-1$ cells, we evaluated chemotaxis of the CXCR4 ${ }^{+}$, SDF-1 responsive cell lines SUP-B15 (human pre-B ALL) and C1.92 (nontransformed murine pro-B cell clone $\{22\})$, as indicators of stromal cell mediated chemotaxis. A consistent trend of reduced migration of these additional lines toward chemotherapy treated stromal cells was observed (data not shown).

Decreases in stromal cell SDF-1 protein following exposure to VP-16 or doxorubicin were not reflected at the SDF-1 RNA level (Figure 2). These data suggest alteration of SDF-1 may be due to post-transcriptional mechanisms. Protein transport or 
general translational alterations are unlikely responsible for this observation based, in part, on the observed increases in secreted SCF and maintenance of MIP- $1 \alpha$ following VP-16 exposure noted earlier.

Previous studies have shown that stromal cells established from chemotherapy treated patients inhibit generation of CFU-GM from $\mathrm{CD} 34^{+}$progenitor cells in vitro $\{33\}$. To determine whether VP-16 or doxorubicin induced stromal cell factors that inhibit JM1 cell chemotaxis, exogenous rSDF-1 was added to the supernatants of chemotherapy pre-treated stromal cells and evaluated restoration of migration. Addition of rSDF-1 to chemotherapy damaged stroma resulted in restoration of hematopoietic cell migration suggesting that SDF-1 protein reduction, in contrast to chemotherapy induced inhibitors, is a key factor in decreased stromal cell support of JM-1 cell chemotaxis following treatment (Figure 3B).

In some experiments, JM-1 cell migration toward stromal cell monolayers exceeded that of chemotaxis towards rSDF-1 alone. This observation is potentially explained by the combination of endogenous stromal cell SDF-1 and stem cell factor (SCF). SCF has been previously demonstrated to enhance hematopoietic cell chemotaxis in the presence of SDF-1 $\{3\}$. However, a previous report has demonstrated that even high levels of SCF cannot support chemotaxis of CXCR4 positive cells when SDF-1 availability is limited $\{3\}$.

Sustained deficits in hematopoietic recovery have been noted following high dose chemotherapy and bone marrow transplantation in many studies $\{34-36\}$. Consistent with delays in hematopoietic recovery following chemotherapy treatment, we did not observe restoration of SDF-1 protein levels from chemotherapy treated stromal 
cells for up to 5 days of recovery (Figure 4). This correlated with a functional impairment of chemotherapy treated stromal cells as well (Figure 5). Additional experiments will be necessary to evaluate extended periods of recovery, however, the current experiments are limited by the finite amount of time a confluent layer of stromal cells can be maintained in vitro.

The appropriate expression of stromal cell chemokines, adhesion molecules, and cytokines define the ability of the microenvironment to support hematopoiesis. Previously, we have reported that human stromal cells exposed to VP-16 have reduced VCAM-1 protein $\{20\}$. In addition, we have found that doxorubicin also disrupts stromal cell VCAM-1 protein (unpublished data). In the current report, we demonstrate that these same chemotherapeutic agents also reduce stromal cell SDF-1 production. Taken together, these observations suggest that specific chemotherapeutic agents may blunt hematopoietic reconstitution by disrupting factors that underlie progenitor cell chemotaxis to, or retention within, appropriate stromal cell niches of the marrow microenvironment.

\section{ACKNOWLEDGMENTS}

This work supported in part by the National Institutes of Health $(\mathrm{NIH})$ grant number HL56888 (LFG) and the WVU Department of Pediatrics Oncology Research Fund. The authors thank Drs. Kenneth Landreth, John Barnett, Jeannine Strobl, and Solveig Ericson for critique of this manuscript. 


\section{REFERENCES}

1. R Mohle, F Bautz, S Rafii, MA Moore, W Brugger, and L Kanz (1999): Regulation of transendothelial chemotaxis of hematopoietic progenitor cells. Ann.N.Y.Acad.Sci. 872:176.

2. IB Mazo and UH von Andrian (1999): Adhesion and homing of blood-borne cells in bone marrow microvessels. J.Leukoc.Biol. 66:25.

3. CH Kim and HE Broxmeyer (1998): In vitro behavior of hematopoietic progenitor cells under the influence of chemoattractants: stromal cell-derived factor-1, steel factor, and the bone marrow environment. Blood 91:100.

4. A Aiuti, IJ Webb, C Bleul, T Springer, and JC Gutierrez-Ramos (1997): The chemokine SDF-1 is a chemoattractant for human CD34+ hematopoietic progenitor cells and provides a new mechanism to explain the mobilization of CD34+ progenitors to peripheral blood. J.Exp.Med. 185:111.

5. CC Bleul, RC Fuhlbrigge, JM Casasnovas, A Aiuti, and TA Springer (1996): A highly efficacious lymphocyte chemoattractant, stromal cell-derived factor 1 (SDF-1). J.Exp.Med. 184:1101.

6. M D'Apuzzo, A Rolink, M Loetscher, JA Hoxie, I Clark-Lewis, F Melchers, M Baggiolini, and B Moser (1997): The chemokine SDF-1, stromal cell-derived factor 1, 
attracts early stage B cell precursors via the chemokine receptor CXCR4. Eur.J.Immunol. 27:1788.

7. T Nagasawa, H Kikutani, and T Kishimoto (1994): Molecular cloning and structure of a pre-B-cell growth-stimulating factor. Proc.Natl.Acad.Sci.U.S.A 91:2305.

8. K Tashiro, H Tada, R Heilker, M Shirozu, T Nakano, and T Honjo (1993): Signal sequence trap: a cloning strategy for secreted proteins and type I membrane proteins. Science 261:600.

9. S Nishikawa, M Ogawa, S Nishikawa, T Kunisada, and H Kodama (1988): B lymphopoiesis on stromal cell clone: stromal cell clones acting on different stages of B cell differentiation. Eur.J.Immunol. 18:1767.

10. EE Jazin, H Yoo, AG Blomqvist, F Yee, G Weng, MW Walker, J Salon, D Larhammar, and C Wahlestedt (1993): A proposed bovine neuropeptide Y (NPY) receptor cDNA clone, or its human homologue, confers neither NPY binding sites nor NPY responsiveness on transfected cells. Regul.Pept. 47:247.

11. H Nomura, BW Nielsen, and K Matsushima (1993): Molecular cloning of cDNAs encoding a LD78 receptor and putative leukocyte chemotactic peptide receptors. Int.Immunol. 5:1239. 
12. H Herzog, YJ Hort, J Shine, and LA Selbie (1993): Molecular cloning, characterization, and localization of the human homolog to the reported bovine NPY Y3 receptor: lack of NPY binding and activation. DNA Cell Biol. 12:465.

13. B Federsppiel, IG Melhado, AM Duncan, A Delaney, K Schappert, I Clark-Lewis, and FR Jirik (1993): Molecular cloning of the cDNA and chromosomal localization of the gene for a putative seven-transmembrane segment (7-TMS) receptor isolated from human spleen. Genomics 16:707.

14. YR Zou, AH Kottmann, M Kuroda, I Taniuchi, and DR Littman (1998): Function of the chemokine receptor CXCR4 in haematopoiesis and in cerebellar development. Nature 393:595.

15. T Nagasawa, S Hirota, K Tachibana, N Takakura, S Nishikawa, Y Kitamura, N Yoshida, H Kikutani, and T Kishimoto (1996): Defects of B-cell lymphopoiesis and bone-marrow myelopoiesis in mice lacking the CXC chemokine PBSF/SDF-1. Nature 382:635.

16. Q Ma, D Jones, PR Borghesani, RA Segal, T Nagasawa, T Kishimoto, RT Bronson, and TA Springer (1998): Impaired B-lymphopoiesis, myelopoiesis, and derailed cerebellar neuron chemotaxis in CXCR4- and SDF-1-deficient mice. Proc.Natl.Acad.Sci.U.S.A 95:9448. 
17. A Peled, I Petit, O Kollet, M Magid, T Ponomaryov, T Byk, A Nagler, H Ben Hur, A Many, L Shultz, O Lider, R Alon, D Zipori, and T Lapidot (1999): Dependence of human stem cell engraftment and repopulation of NOD/SCID mice on CXCR4. Science 283:845.

18. JJ Lataillade, D Clay, C Dupuy, S Rigal, C Jasmin, P Bourin, and MC BousseKerdiles (2000): Chemokine SDF-1 enhances circulating CD34(+) cell proliferation in synergy with cytokines: possible role in progenitor survival. Blood 95:756.

19. C Voermans, ML Kooi, S Rodenhuis, LH van der, CE van der Schoot, and WR Gerritsen (2001): In vitro migratory capacity of CD34+ cells is related to hematopoietic recovery after autologous stem cell transplantation. Blood 97:799.

20. LF Gibson, J Fortney, KS Landreth, D Piktel, SG Ericson, and JP Lynch (1997): Disruption of bone marrow stromal cell function by etoposide. Biol.Blood Marrow Transplant. 3:122.

21. LS Collins and K Dorshkind (1987): A stromal cell line from myeloid long-term bone marrow cultures can support myelopoiesis and B lymphopoiesis. J.Immunol. 138:1082.

22. LF Gibson, D Piktel, and KS Landreth (1993): Insulin-like growth factor-1 potentiates expansion of interleukin-7- dependent pro-B cells. Blood 82:3005. 
23. Herzig RH, Lynch F, Christiansen NP, Fay FW, Davis MP, Stevens DA, Pineiro SL, and Herzig GP (1994): Dose intensive chemotherapy with etoposide cyclophosphamide without stem cell support for advanced breast cancer: preliminary results. Presented at the Autologous Marrow and Blood Transplantation Society's Seventh International Symposium

24. CJ Twelves, NA Dobbs, HC Gillies, CA James, RD Rubens, and PG Harper (1998): Doxorubicin pharmacokinetics: the effect of abnormal liver biochemistry tests. Cancer Chemother.Pharmacol. 42:229.

25. CM Camaggi, R Comparsi, E Strocchi, F Testoni, B Angelelli, and F Pannuti (1988): Epirubicin and doxorubicin comparative metabolism and pharmacokinetics. A crossover study. Cancer Chemother.Pharmacol. 21:221.

26. B Neri, G Cini-Neri, M Bandinelli, P Pacini, S Bartalucci, and A Ciapini (1989): Doxorubicin and epirubicin cardiotoxicity: experimental and clinical aspects. Int.J.Clin.Pharmacol.Ther.Toxicol. 27:217.

27. J Arai, M Yasukawa, Y Yakushijin, T Miyazaki, and S Fujita (2000): Stromal cells in lymph nodes attract B-lymphoma cells via production of stromal cell-derived factor-1. Eur.J.Haematol. 64:323.

28. K Hattori, B Heissig, K Tashiro, T Honjo, M Tateno, JH Shieh, NR Hackett, MS Quitoriano, RG Crystal, S Rafii, and MA Moore (2001): Plasma elevation of stromal 
cell-derived factor-1 induces mobilization of mature and immature hematopoietic progenitor and stem cells. Blood 97:3354.

29. DY Jo, S Rafii, T Hamada, and MA Moore (2000): Chemotaxis of primitive hematopoietic cells in response to stromal cell- derived factor-1. J.Clin.Invest 105:101.

30. SS Legha, RS Benjamin, B Mackay, M Ewer, S Wallace, M Valdivieso, SL Rasmussen, GR Blumenschein, and EJ Freireich (1982): Reduction of doxorubicin cardiotoxicity by prolonged continuous intravenous infusion. Ann.Intern.Med. $96: 133$.

31. MM Haq, SS Legha, J Choksi, GN Hortobagyi, RS Benjamin, M Ewer, and M Ali (1985): Doxorubicin-induced congestive heart failure in adults. Cancer 56:1361.

32. T Ponomaryov, A Peled, I Petit, RS Taichman, L Habler, J Sandbank, F ArenzanaSeisdedos, A Magerus, A Caruz, N Fujii, A Nagler, M Lahav, M Szyper-Kravitz, D Zipori, and T Lapidot (2000): Induction of the chemokine stromal-derived factor-1 following DNA damage improves human stem cell function. J.Clin.Invest 106:1331.

33. GN Schwartz, MK Warren, SW Rothwell, J Zujewski, DC Halverson, KH Cowan, A Tolcher, J O'Shaughnessy, and RE Gress (1998): Post-chemotherapy and cytokine pretreated marrow stromal cell layers suppress hematopoiesis from normal donor CD34+ cells. Bone Marrow Transplant. 22:457. 
34. MR Thomas, WA Robinson, TI Mughal, N Morton, and LM Glode (1986): Recovery of blood and bone marrow stem cells following intense chemotherapy and autologous bone marrow transplantation. Oncology 43:273.

35. C del Canizo, N Lopez, D Caballero, E Fernandez, A Brufau, L Vazquez, V Mateos, N Gutierrez, and JF San Miguel (1999): Haematopoietic damage persists 1 year after autologous peripheral blood stem cell transplantation. Bone Marrow Transplant. 23:901.

36. W Fried and J Barone (1980): Residual marrow damage following therapy with cyclophosphamide. Exp.Hematol. 8:610. 


\section{FIGURE LEGENDS}

Figure 1. VP-16 and doxorubicin reduce bone marrow stromal cell SDF-1 protein expression. To quantitate stromal cell SDF-1 protein expression following chemotherapy treatment, confluent stromal cell layers were treated with (A) $0.10 \mu \mathrm{M}$ to $100 \mu \mathrm{M}$ VP-16 or $0.10 \mu \mathrm{M}$ to $10 \mu \mathrm{M}$ doxorubicin for up to 24 hours or (B) $100 \mu \mathrm{M}$ VP-16 for 24 hours. Following treatment, cells were rinsed, and $110 \mu \mathrm{l}$ of serum-free medium placed in each well. Following 24 hours incubation, $100 \mu$ l of conditioned supernatant was collected from each well for evaluation by ELISA. All treatment groups were evaluated in triplicate. Means $\pm S E$ are shown at each point. Data shown represents $(A)$ a minimum of 3 independent experiments (cell lines: Ped299, P156, P159, P160) and (B) two independent experiments in triplicate for each cell line exposure evaluated.

Figure 2. SDF-1 message is modestly reduced in bone marrow stromal cells following chemotherapy treatment. Total RNA was isolated from confluent stromal cells that were treated with (A) $100 \mu \mathrm{M}$ VP-16 or (B) $1.0 \mu \mathrm{M}$ doxorubicin for 8-24 hours. "OneStep" RT-PCR was completed using $0.1 \mu \mathrm{g}$ total RNA isolated from untreated, VP-16 treated, and doxorubicin treated stromal cells. SDF-1 and actin specific PCR products were separated on $1.5 \%$ ethidium bromide stained gels, and ratios were quantitated by densitometric analysis. Negative controls, containing no RNA template, were included for all samples (cell lines: Ped299, P156, P159, P160).

Figure 3. Stromal cell capacity to support JM-1 migration is restored by rSDF-1 following treatment. (A) Confluent stromal cell layers were treated with $1.0 \mu \mathrm{M}$ or $100 \mu \mathrm{M}$ VP-16, $0.1 \mu \mathrm{M}$ or $1.0 \mu \mathrm{M}$ doxorubicin, or left untreated for 24 hours. Cells were rinsed 
thoroughly and $350 \mu \mathrm{l}$ of Iscoves complete was placed in each well. Following 24 hours, 80,000-120,000 JM-1 cells were placed in the top chamber. Following a 4.5-hour incubation, JM-1 cells that had migrated to the lower chamber were enumerated and percent chemotaxis relative to untreated stromal cells was determined. Negative and positive control samples included medium only or $5 \mathrm{ng} / \mathrm{ml}$ recombinant human SDF-1, respectively, in the lower chamber. Mean percent migration is shown with SE. Data shown represents 3 independent experiments (cell lines: Ped299, P156, P159, P160). (B) Confluent stromal cell layers were treated with $1.0 \mu \mathrm{M}$ or $100 \mu \mathrm{M}$ VP-16, $0.1 \mu \mathrm{M}$ or $1.0 \mu \mathrm{M}$ doxorubicin, or left untreated for 24 hours. Stromal cells were rinsed thoroughly and medium with $5 \mathrm{ng} / \mathrm{ml}$ rSDF-1 protein was placed in each well. Following a 4.5-hour incubation, JM-1 cells that had migrated to the lower chamber were enumerated and percent chemotaxis was determined. Negative and positive control samples included medium only or rSDF-1, respectively, in the lower chamber. JM-1 migration towards medium only was less than $10 \%$ of that observed for medium plus $5 \mathrm{ng} / \mathrm{ml}$ rSDF- 1 in each case (data not shown). Mean percent JM-1 chemotaxis is shown with SE. Data shown represents 3 independent experiments (cell lines: Ped299, P159, P160).

Figure 4. VP-16 treated stromal cells have sustained reductions in SDF-1 protein production. Stromal cells were treated with VP-16 for up to 72 hours and allowed to recover for up to 5 days following removal of drug. ELISAs were completed to quantitate SDF-1 protein level as described in Materials and Methods. All samples were evaluated in triplicate. Mean $\pm \mathrm{SE}$, as $\%$ of control, are shown at each point. Data represent 3 independent experiments. 
Figure 5. Stromal cell ability to support JM-1 chemotaxis does not recover for up to three days following removal of chemotherapy. Stromal cell layers were treated for up to 72 hours with $100 \mu \mathrm{M}$ VP-16. Following treatment, stromal cells were rinsed thoroughly and $1 \mathrm{ml}$ of fresh medium was placed in each well for 72 hours. Following 72 hours of recovery, the supernatants were removed and replaced with fresh Iscoves complete medium. Chemotaxis assays were completed 24 hours later using JM-1 cells. All samples were evaluated in triplicate. Mean percent JM-1 chemotaxis is shown \pm SE. Data shown represent 3 independent experiments. 
Figure 1. VP-16 and doxorubicin reduce bone marrow stromal cell SDF-1 protein expression

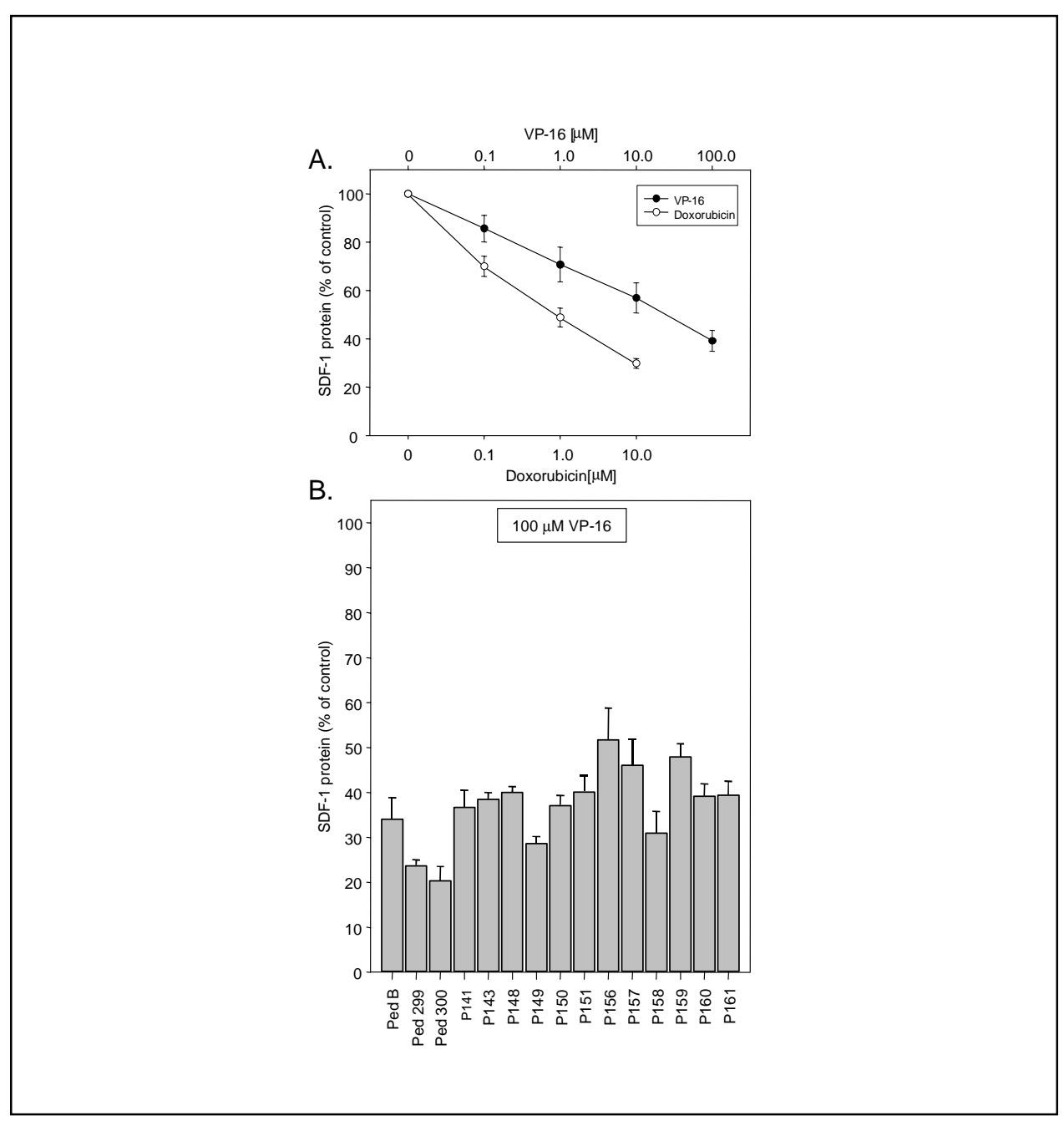


Figure 2. SDF-1 message is modestly reduced in bone marrow stromal cells following chemotherapy treatment

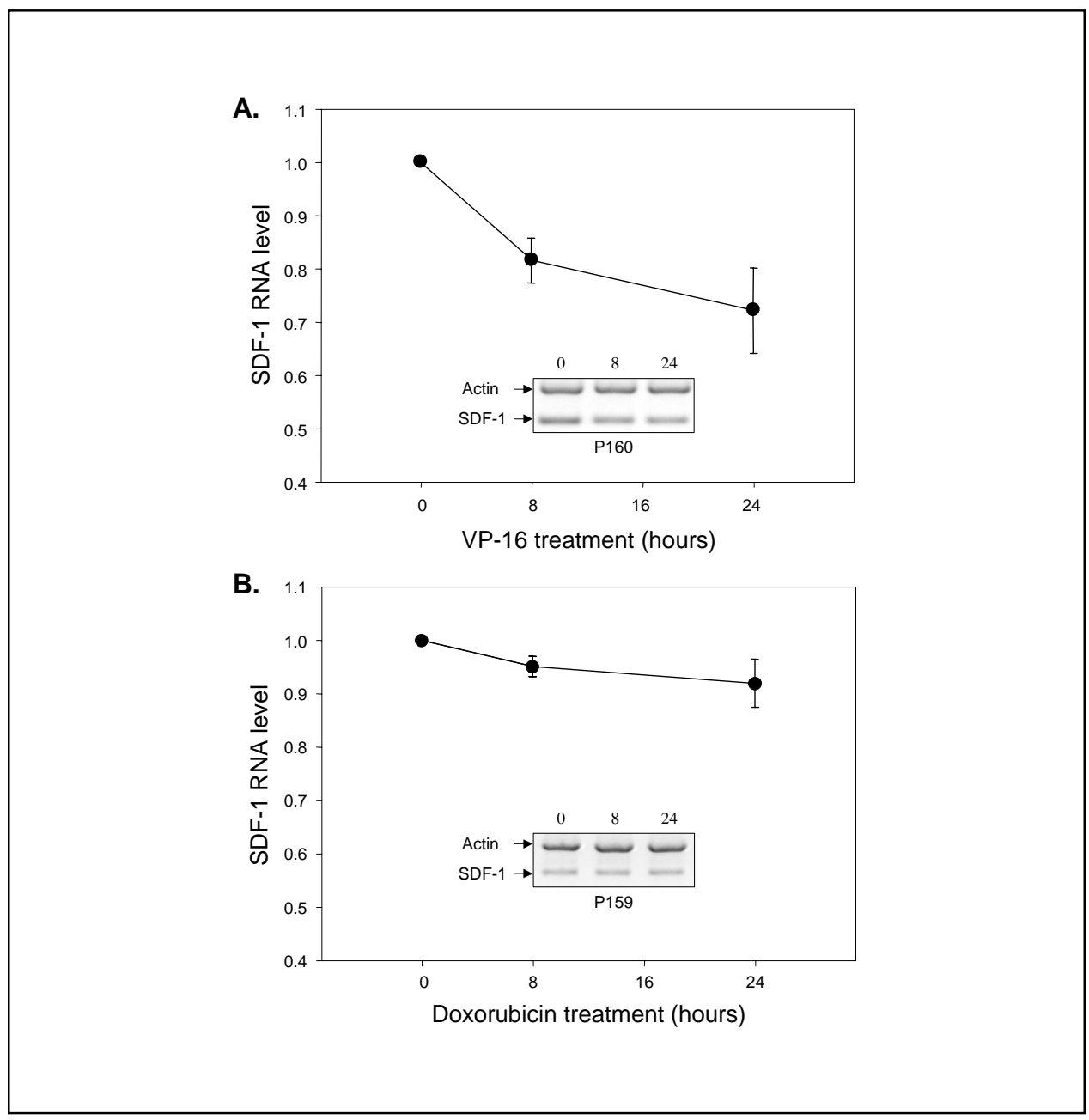


Figure 3. Stromal cell capacity to support $\mathrm{JM}-1$ migration is restored by rSDF-1 following treatment

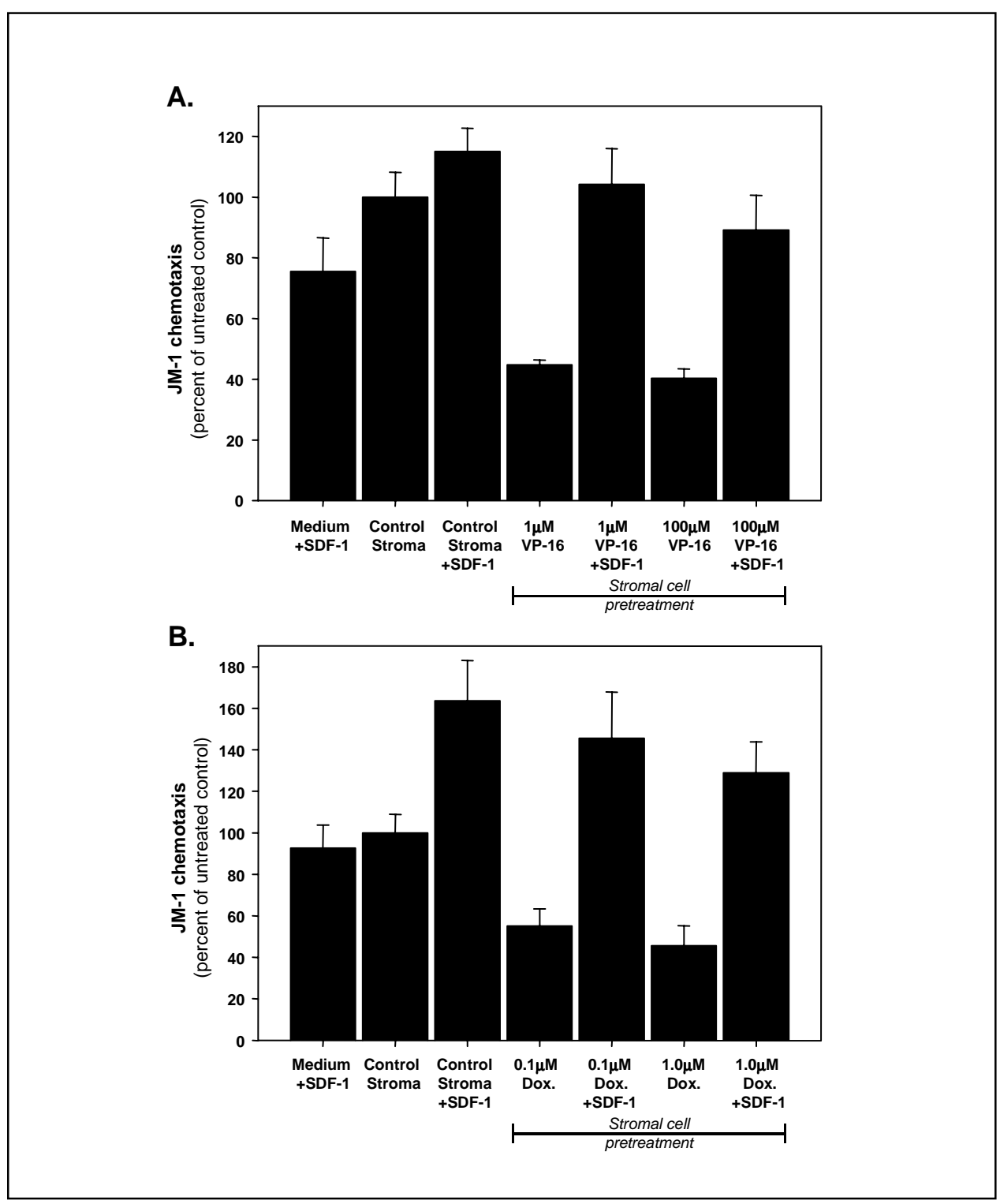


Figure 4. VP-16 treated stromal cells have sustained reductions in SDF-1 protein production

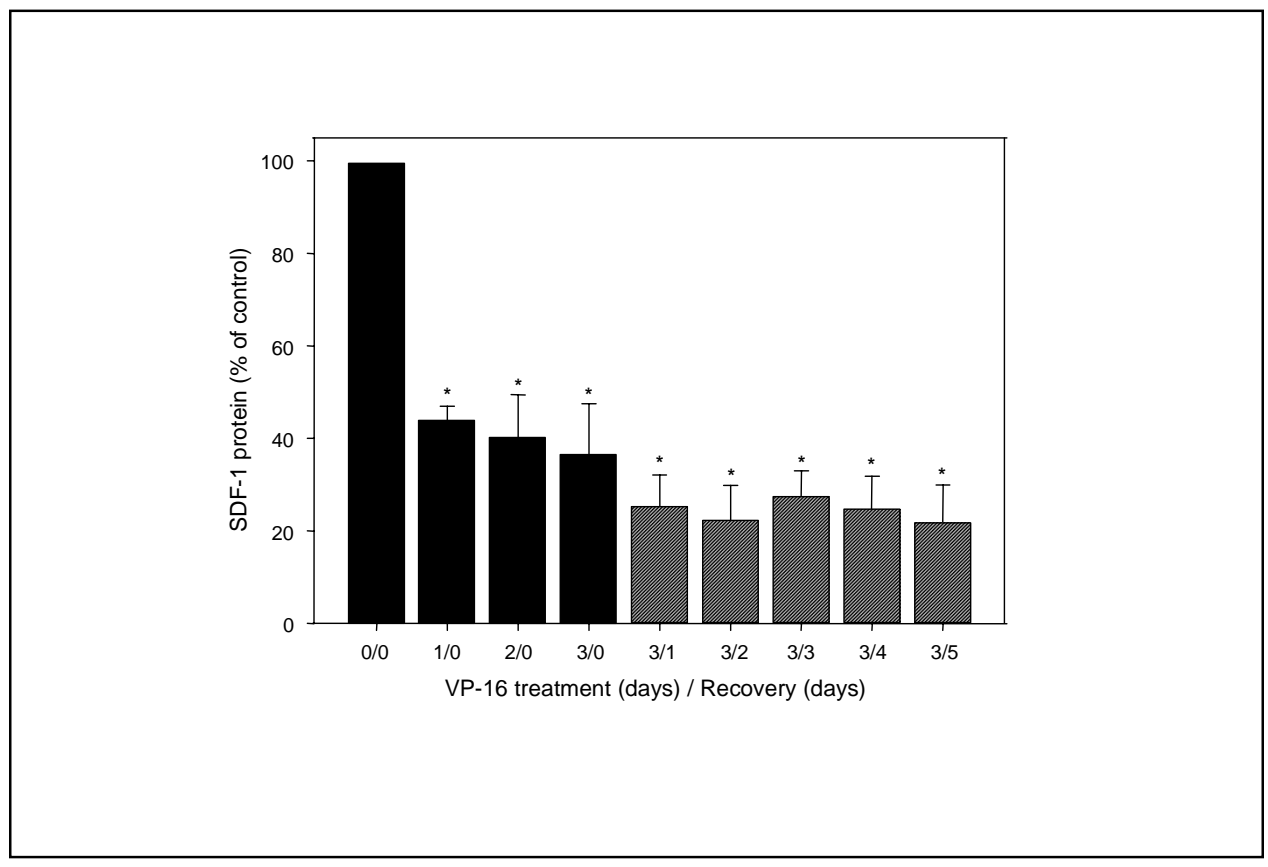


Figure 5. Stromal cell ability to support JM-1 chemotaxis does not recover for up to three days following removal of chemotherapy

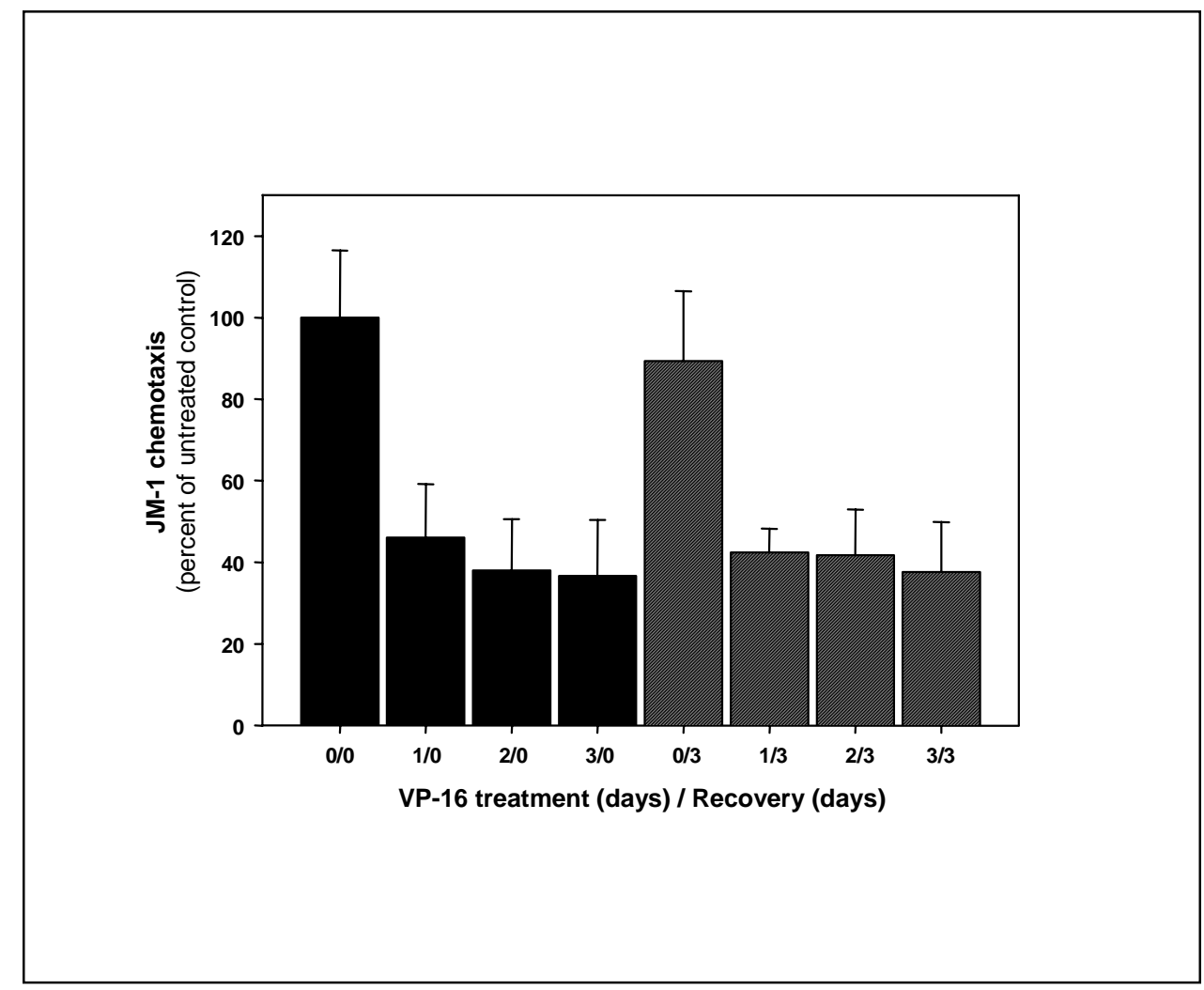




\title{
Chapter III
}

\section{Alteration of nuclear factor- $\mathrm{kB}$ (NF-kB) Expression in Bone Marrow Stromal Cells Treated with Etoposide}

\author{
Brett M. Hall ${ }^{1}$, James E. Fortney ${ }^{2}$, and Laura F. Gibson ${ }^{1,2,3}$
}

Departments of Microbiology, Immunology and Cell Biology ${ }^{1}$, Pediatrics $^{2}$, and the Blood and Marrow Transplantation Program of the Mary Babb Randolph Cancer Center ${ }^{3}$.

West Virginia University, Morgantown, WV 26506

This manuscript was published in the journal Biochemical Pharmacology, Vol 61 (2001) 1243-1252. 


\section{ABSTRACT}

Bone marrow stromal cells are an essential regulatory component in the hematopoietic microenvironment. Regulation of hematopoietic cell development is mediated, in part, through interaction of progenitor cells with stromal cell vascular cell adhesion molecule-1 (VCAM-1). VCAM-1 expression has been shown to be primarily driven by binding of NF- $\mathrm{\kappa B}$ to two consensus binding sites in the promoter region. In this study we show that down regulation of VCAM-1 by the chemotherapeutic agent etoposide (VP-16) is associated with altered cellular localization of NF-kB.

We demonstrate that VCAM-1 was diminished at the transcriptional level following stromal cell VP-16 treatment, without alteration of VCAM-1 stability. Culture of bone marrow stromal cells in VP-16 resulted in reduced nuclear RelA (p65), a modest increase in nuclear NF-kB1 (p50), and reduced NF-kB binding to its DNA consensus

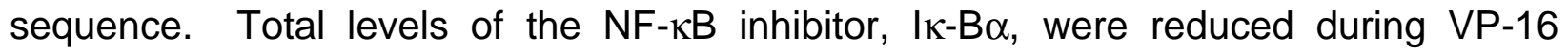
exposure. Following removal of VP-16 from culture, p65 and p50 nuclear profiles approximated those of untreated stromal cells, and VCAM-1 protein expression was restored.

The current study indicates NF-KB as a target molecule that is responsive to VP16 induced damage in bone marrow stromal cells. As the primary transcription factor that promotes VCAM-1 expression, the observed changes in p65 and p50 cellular localization during treatment have direct consequence for stromal cell function. The myriad of genes regulated by NF-kB, including both adhesion molecules and cytokines that contribute to stromal cell function, make chemotherapy induced disruption of NF-kB biologically significant. Alterations in NF-kB activity may provide one measure by which 
the effects of aggressive treatment strategies on the bone marrow microenvironment can be evaluated.

\section{INTRODUCTION}

The bone marrow microenvironment is the primary site of normal postnatal hematopoiesis, and the location of hematopoietic recovery following chemotherapy or irradiation induced injury to the immune system. Bone marrow stromal cells are critical components of the marrow microenvironment that regulate hematopoietic cell survival, proliferation, and differentiation $\{1-6\}$. As such, they insure appropriate development of mature lymphoid and myeloid cells. Therefore, appropriate stromal cell function is a central regulatory component of hematopoiesis.

As treatments for many malignancies become increasingly aggressive, it has become clear that targets for damage include not only malignant cells, and frequently their normal counterparts, but also the supportive bone marrow stroma $\{1-6\}$. Stromal cell damage is implicated by delays in hematopoietic recovery, even when healthy progenitor cells are provided, as in the bone marrow transplantation setting $\{7-11\}$. While delays in reconstitution of the hematopoietic system are an expected consequence of aggressive chemotherapy, the extent to which a damaged microenvironment contributes to such delays requires further investigation. We have previously reported, using an in vitro model, that VP-16 treated bone marrow stromal cells have diminished capability to support proliferation and survival of lymphoid and myeloid progenitor cells $\{7\}$. This altered support capacity is associated with reduced VCAM-1 protein expression $\{12 ; 13\}$. Altered capacity to support hematopoietic cells was not due to initiation of stromal cell apoptosis. No laddering of DNA was detected following treatment, and stromal cells proliferated following 
removal of VP-16 $\{7\}$. Other investigators have also noted reduced VCAM-1 expression on bone marrow stromal cells derived from patients treated with a variety of chemotherapeutic agents $\{12\}$. Interestingly, previous reports have indicated a specific decrease in VCAM-1 expression in human umbilical vein endothelial cells following exposure to topoisomerase II inhibitors, including VP-16 $\{13\}$. These previous observations, combined with the frequent use of VP-16 in several treatment regimens $\{14 ; 15\}$ make it a clinically relevant drug for further investigation.

Several studies have demonstrated that physical interaction between stromal cells and hematopoietic progenitors is essential during hematopoiesis $\{16-21\}$. Co-culture of human hematopoietic progenitors with stromal cells separated by transwell membranes resulted in reduced viability of progenitor cells compared to those in direct co-culture $\{4\}$. VCAM-1 has been identified as a critical molecule that mediates adhesion of progenitors to stromal cells in both murine and human in vitro models $\{20 ; 22-27\}$. Murine in vivo models have indicated that interaction of VLA-4 on immature progenitor cells with stromal cell VCAM-1, engages signaling pathways essential to hematopoietic cell development \{28\}. Stromal cell cultures established from patients treated with a variety of chemotherapeutic regimens have diminished adhesion of immature $B$ lineage progenitor cells, reduced capacity to support expansion of this same population, and lower levels of VCAM-1 than stromal cells from untreated control patients $\{12\}$. These combined observations suggest that disrupted stromal cell VCAM-1 during chemotherapy may contribute to delayed hematopoietic recovery following cessation of treatment.

It is well documented that transcription of VCAM-1 is regulated, in part, by binding of NF-kB to consensus binding sites in the VCAM-1 promoter $\{29-31\}$. In some cell types, 
binding of homodimeric p65 has also been shown to enhance VCAM-1 transcription $\{29 ; 30\}$. While the contribution of NF-kB and/or p65 homodimers appears largely cell type specific, a consistent model prevails in which p65 activates VCAM-1 transcription $\{30 ; 32\}$. Binding of the trans-activating factors Sp-1 and IRF-1 to their recognition sequences in the VCAM-1 promoter further enhances NF-אB gene transcription $\{31 ; 33\}$. In contrast to p65, dramatic increases in level of p50, favoring the generation of p50 homodimers, has been reported to repress VCAM-1 expression $\{30 ; 31\}$.

$\mathrm{NF}-\mathrm{KB}$ heterodimers can be retained in the cytoplasm by masking of the nuclear localization signal. This is mediated primarily through interaction with inhibitory proteins of the $\mid \kappa-B$ family $\{34 ; 35\}$. Signals that result in degradation of $I \kappa B$ molecules reveals the NF-kB nuclear localization signal, allowing transit to the nucleus and DNA binding. Inhibition of NF-kB activity can be mediated by sequestering the active heterodimer in the cytoplasm complexed with $\mathrm{I}-\mathrm{B}$, or through displacement of $\mathrm{p50/p65}$ heterodimers by repressive p50 homodimers $\{30 ; 31\}$.

NF-kB expression and cellular localization have been shown to respond to a variety of stimuli including chemotherapy, radiation and cytokine stimulation $\{36-38\}$. However, the response of NF-kB to chemotherapy in bone marrow stromal cells has not been characterized. Data presented in the current study reveal altered NF-KB cellular localization following exposure of stromal cells to VP-16, consistent with reduced stromal cell VCAM-1. Diminished nuclear localization of NF-kB in bone marrow stromal cells following VP-16 exposure may be central to the mechanism by which chemotherapy disrupts the bone marrow microenvironment. 


\section{MATERIALS AND METHODS}

\section{Establishment of fibroblastic bone marrow-derived stromal cell cultures.}

Stromal cell cultures were initiated from $200 \mu \mathrm{L}$ of unfiltered human bone marrow from consenting donors, with approval by the WVU Institutional Review Board, as previously described $\{7\}$.

\section{Chemotherapy treatment of bone marrow cells.}

VP-16 was obtained at a stock concentration of $20 \mathrm{mg} / \mathrm{ml}$ (Bristol-Myers Squibb, Princeton, $\mathrm{NJ}$ ) and diluted in culture medium to $100 \mu \mathrm{M}$ prior to use to approximate serum levels reported for patients on high dose therapy $\{15\}$. Stromal cells were grown to confluence prior to treatment. For experiments that evaluated NF- $\mathrm{kB}$ recovery, cells were treated with $100 \mu \mathrm{M}$ VP-16 for 3 hours, rinsed four times with fresh $\alpha-\mathrm{MEM}$, and cultured for 24-72 hours in fresh media.

\section{RNA isolation.}

Total RNA was isolated from stromal cells using the Invitrogen S.N.A.P. Total RNA Isolation kit (Invitrogen; Carlsbad, CA) following the recommendations of the manufacturer. Pelleted stromal cells were lysed by centrifugation through QIAshredder Spin Columns (QIAGEN Inc.; Santa Clarita, CA). RNA was DNase treated and

quantitated at 260nm (Perkin-Elmer Lambda 5 UV/VIS Spectrophotometer; PE Corporation; Norwalk, CN).

\section{Polymerase Chain Reaction.}

To evaluate changes in VCAM-1 mRNA following VP-16 treatment, semiquantitative PCR was performed. The linear ranges of amplification for actin and VCAM-1 were determined to be 25 and 30 cycles respectively. Amplification cycles 
included denaturation at $94^{\circ} \mathrm{C}$ for 30 seconds, primer annealing at $55^{\circ} \mathrm{C}$ for 1.5 minutes, and extension at $72^{\circ} \mathrm{C}$ for 2 minutes and15seconds (Perkin-Elmer GeneAmp PCR System 9600). cDNA's were generated by random priming of $1 \mu \mathrm{g}$ total RNA. Actin primer sets were: 5'-TGACGGGGTCACCCACACTGTGCCCATCTA-3' and 5'CTAGAAGCATTTGCGGTGGA CGATGGAGGG-3'(Stratagene; La Jolla, CA) at $0.4 \mu \mathrm{g} /$ reaction to generate an amplicon of 661 base pairs. VCAM-1 primers: 5'CATCCACAAAGCTGCAAGAA-3' and 5'-GCCACCACTC ATCTCGATTT-3' $\{39\}$, $(0.5 \mu \mathrm{g} /$ reaction) generated a 563 base pair product. Controls that lacked reverse transcriptase or cDNA template were included in all experiments. VCAM-1:actin ratios were quantitated by EagleSight Version 3.21 (Stratagene) densitometric analysis.

\section{RNase Protection Assay (RPA).}

To evaluate VCAM-1 mRNA, RPA's were performed using the RPAlll kit according to the manufacturer's protocol (Ambion, Austin, TX). Confluent stromal cell layers were treated with $5 \mu \mathrm{g} / \mathrm{mL}$ actinomycin D (Sigma Chemical Co.; St. Louis, MO) with and without $100 \mu \mathrm{M}$ VP-16. $10 \mu \mathrm{g}$ of RNA from each sample were hybridized to ${ }^{32} \mathrm{P}$ labelled VCAM-1 and GAPDH-specific complementary RNA probes. Anti-sense ${ }^{32} \mathrm{P}$ RNA probes were generated using T7 RNA polymerase-directed synthesis from RiboQuant DNA templates (PharMingen; San Diego, CA). Nucleic acids were treated with RNase A \& 11 to digest unhybridized sequences. RNA corresponding to VCAM-1 (288bp) and GAPDH (96bp) were visualized by exposure to Phospho-Imager cassettes (Molecular Dynamics; Sunnyvale, CA). VCAM-1 band intensities were normalized to GAPDH controls in each treatment group.

\section{Intracellular protein staining.}


Bone marrow stromal cells were cultured on coverslips (Corning Inc.; Corning, NY) for 24 hours prior to treatment with $100 \mu \mathrm{M}$ VP-16 for 3-6 hours. Following treatment, cells were fixed in methanol:acetone (1:1) for 20 minutes at room temperature then rinsed in autoclaved PBS. Non-specific antibody binding was blocked by incubation of stromal cells with $\mathrm{PBS} / 5 \% \mathrm{BSA}$ for 30 minutes at room temperature.

Cellular localization of p50 or p65 protein was evaluated by incubation of stromal cells with $10 \mu \mathrm{g}$ rabbit anti-human p50 or p65 (Santa Cruz Biotechnology, Inc.; Santa Cruz, CA) for 1 hour at room temperature. Coverslips were then rinsed in autoclaved PBS and subsequently incubated with goat anti-rabbit IgG-FITC (Santa Cruz Biotechnology). Fluoromount-G (Southern Biotechnology Associates, Inc.; Birmingham, AL) was added and coverslips were inverted onto slides for evaluation by fluorescent microscopy (Zeiss LSM 510, Germany).

\section{Isolation of stromal cell nuclei.}

Isolation of nuclear proteins was completed as described by Andrews, et al. $\{40\}$. Briefly, $0.5 \times 10^{5}-2.0 \times 10^{6}$ stromal cells were re-suspended in $400 \mu \mathrm{L}$ of $4^{0} \mathrm{C}$ Buffer A (10mM HEPES-KOH pH 7.9, 1.5mM MgCl $2,10 \mathrm{mM} \mathrm{KCl,} \mathrm{0.5mM} \mathrm{DTT,} \mathrm{0.2mM} \mathrm{PMSF).}$ Following incubation on ice for 10 minutes, samples were vortexed for 10 seconds and pelleted to isolate nuclei. Nuclei were then resuspended in Buffer C (20mM HEPES$\mathrm{KOH} \mathrm{pH} 7.9,25 \%$ v/v Glycerol, $420 \mathrm{mM} \mathrm{NaCl}, 1.5 \mathrm{mM} \mathrm{MgCl} 2,0.2 \mathrm{mM}$ EDTA, $0.5 \mathrm{mM}$ DTT, $0.2 \mathrm{mM}$ PMSF) and incubated on ice for 20 minutes. Following centrifugation to remove debris, supernatants containing nuclear proteins were stored at $-70^{\circ} \mathrm{C}$ until use. Protein concentrations were determined using the BCA Protein Assay kit (Pierce, Rockford, IL). 


\section{Western blot analysis.}

Western blot analysis was performed following the method described by Laemmli, et al. $\{41\}$. For evaluation of $p 65$ or p50, nuclear proteins $\{10 \mu \mathrm{g} / \mathrm{lane}\}$ were separated by SDS-PAGE and transferred to PVDF-Plus nylon membranes (MSI, Westborough, MA). Membranes were probed with $0.5 \mu \mathrm{g} / \mathrm{ml}$ polyclonal rabbit anti-human p65 (Santa Cruz Biotechnology) or a 1:2000 dilution of polyclonal rabbit anti-human p50 (generously provided by Dr. Nancy Rice, National Cancer Institute, Frederick Cancer Research and Development Center, Frederick, MD). Membranes were incubated with goat anti-rabbit-HRP (Santa Cruz Biotechnology). Bands were visualized by ECL (Amersham International; Buckinghamshire, England). Densitometric analysis using Eagle Eye II (Stratagene) or Optimus (Optimus Corp.; Bothell, WA) was completed for quantitation. Isotype matched controls were included for all experiments. Protein from $5 \times 10^{4}$ stromal cells was evaluated by PAGE to determine total I $\mathrm{KB} \alpha$ protein expression. Membranes were probed with $1.5 \mu \mathrm{g} / \mathrm{ml}$ monoclonal mouse anti-human I $\mathrm{kB} \alpha$ (Santa Cruz Biotechnology) followed by 1:2000 dilution of goat anti-mouse-HRP (Santa Cruz Biotechnology) for visualization.

Membranes were re-probed with polyclonal rabbit anti-human TFIIF-RAP30 $(0.5 \mu \mathrm{g} / \mathrm{ml}$, Santa Cruz Biotechnology) as an internal lane loading control. To establish ratios of p65 to p50 subunits, protein levels were compared within individual nuclear samples, and normalized to untreated controls set to 1.0. Statistical analysis was performed using the Dunnett's test (SigmaStat Version 2.0 software, SPSS Inc.; Chicago, IL).

\section{Electrophoretic mobility shift assay (EMSA).}


To determine if VP-16 altered NF-kB binding to its consensus sequence, EMSA's were performed. NF-kB consensus oligonucleotides (Santa Cruz Biotechnology) were end labeled with ${ }^{32}$ P- $\gamma$ ATP using "Ready•To•Go" T4 Polynucleotide Kinase (Pharmacia Biotech; Piscataway, NJ). Reactions included $2 \mu \mathrm{g}$ nuclear protein, $2 \mu \mathrm{g}$ poly $\mathrm{dl}: \mathrm{dC}$, $1 \mathrm{mM}$ spermidine, 1X Promega buffer (10mM HEPES $(\mathrm{pH} 7.9), 50 \mathrm{mM} \mathrm{KCl}, 0.2 \mathrm{mM}$ EDTA, 2.5mM DTT, 10\% glycerol, and 0.05\% NP-40). Supershifts were completed by the addition of rabbit anti-p50 or p65 (kindly provided by Dr. Nancy Rice) to indicated samples. Following incubation on ice for two hours, 50,000 CPM $(0.05-0.20 \mathrm{ng})$ labeled NF- $\mathrm{KB}$ consensus probe was added to all reaction mixtures. A 30-fold excess (2.08.0ng) of unlabeled specific (NF-kB) or non-specific (NF-AT) probe was added to indicated samples to evaluate binding specificity. Samples were then incubated at room temperature 30 additional minutes.

Complexes were separated through $5 \%$ polyacrylamide/1X TGE gels which were dried for 2.5 hours at $80^{\circ} \mathrm{C}$ with vacuum (Bio-Rad Model 583 gel dryer; Richmond, CA) and exposed to BioMax MR-1 film overnight (Kodak; Rochester, NY). Relative band intensities were determined using Eagle Eye II (Stratagene).

\section{(E)-Capsaicin treatment of stromal cells.}

To determine if reduced p65 in stromal cell nuclei was sufficient to reduce VCAM-1 expression, confluent stromal cells were treated for 4 or 8 hours (4 hour exposures on two consecutive days) with $200 \mu \mathrm{M}$ (E)-Capsaicin (Alexis Biochemicals; San Diego, CA). (E)-Capsaicin has been previously shown to reduce nuclear p65 levels \{42\}. Stromal cell VCAM-1 protein was evaluated 24 and 48 hours later by ELISA as described above. 


\section{VCAM-1 ELISA.}

To determine whether stromal cell VCAM-1 protein expression is restored following removal of VP-16 from culture, confluent stromal cells were treated with $100 \mu \mathrm{M}$ VP-16 for $24-72$ hours. Following treatment, cells were trypsinized, rinsed three times in medium, counted, and replated into 96 -well plates $(10,000$ cells/well) to allow recovery for up to 72 hours following the 24 hour VP-16 exposure, or up to 5 days following 72 hour chemotherapy treatment. Mouse anti human-VCAM-1 $(2 \mu \mathrm{g} / \mathrm{ml}$; Santa Cruz Biotechnology) and a matched isotype $\lg _{1}$ control (Southern Biotechnology Associates; Birmingham, $\mathrm{AL}$ ) were incubated on stromal cell layers at $37^{\circ} \mathrm{C}$ for 1 hour. Following incubation, layers were rinsed 5 times (PBS/0.5\% Tween 20). Sheep anti mouse-HRP (1 $\mu \mathrm{g} / \mathrm{ml}$; Amersham Life Science; Piscataway, NJ) was then incubated on stromal cell layers at $37^{\circ} \mathrm{C}$ for 1 hour and rinsed as above. The TMB Microwell Peroxidase Substrate System (Kirkegaard \& Perry Laboratories; Gaithersburg, MD) was used for quantitation of VCAM-1 protein. Isotype matched controls were included for all treatment groups to evaluate non-specific antibody binding.

\section{RESULTS}

\section{VCAM-1 transcripts in VP-16 treated stromal cells.}

To determine whether VP-16 reduced the amount of VCAM-1 transcripts in bone marrow stromal cells, their relative abundance was evaluated following 4-24 hours of $100 \mu \mathrm{M}$ VP-16 treatment. At 4 hours, message levels were approximately $65 \%$ of untreated control values, and the abundance of VCAM-1 transcripts continued to 
diminish out to 24 hours of exposure (Fig. 1A). Controls that lacked template or reverse transcriptase did not yield any product (data not shown).

\section{VCAM-1 message stability.}

To determine if reduced levels of VCAM-1 message following treatment of bone marrow stromal cells with VP-16 were due to altered stability in the presence of chemotherapy, confluent stromal cells were treated with actinomycin-D or both actinomycin-D and VP-16 as described. Following 3-24 hours of treatment, no significant differences were observed between the half-life of VCAM-1 specific transcripts in the presence and absence of VP-16. The half-life of VCAM-1 transcripts in both treatment groups was approximately 12 hours (Fig. 1B).

\section{NF- $\kappa B$ subunit cellular localization in stromal cells exposed to VP-16.}

Intracellular localization of p65 and p50 in treated and control stromal cells were evaluated by fluorescent microscopy as described. Untreated stromal cells expressed a significant level of nuclear p65, while nuclei of VP-16 treated bone marrow stromal cells had diminished to undetectable nuclear p65 expression (Fig. 2). In contrast, modestly increased nuclear expression of p50 was observed following treatment (Fig. 2).

To quantitate the changes in nuclear profiles of p65 and p50 in stromal cells treated with VP-16, Western blot analysis was completed. Following treatment with VP16 for 30 minutes to 3 hours, consistent decreases in nuclear p65 (Fig. 3A) and slight increases in p50 (Fig. 3B) were observed. Statistically significant decreases in nuclear p65 protein were observed after 1.5 and 3 hours of VP-16 exposure $(\mathrm{P}<0.05)$.

NF- $k B$ binding to a $\mathrm{kB}$ consensus sequence. 
To investigate whether VP-16 altered binding of NF-KB to its consensus site, EMSAs were completed as described in Materials and Methods. DNA binding of NF-kB was reduced to approximately $50 \%$ after 6 hours of VP-16 exposure compared to untreated stromal cells (Fig 4). A single complex was observed that could be shifted with antibody specific for p50 or p65. A 30 fold excess of unlabeled NF-kB oligonucleotide reduced the NF-KB binding by approximately $80 \%$, with negligible reduction of binding observed by inclusion of 30 fold excess NF-AT oligonucleotide (Fig. $4)$.

\section{$I K-B \alpha$ expression in VP-16 treated stromal cells.}

To determine if elevated $\mathrm{I} \kappa-\mathrm{B} \alpha$ was a potential mechanism by which $\mathrm{p} 65$ was reduced in the nucleus of VP-16 treated stromal cells, total I $\kappa-B \alpha$ protein was evaluated in treated and control stromal cells. A consistent reduction IK-B $\alpha$ protein was observed in VP-16 treated stromal cells (Fig. 5).

\section{VCAM-1 expression in (E)-Capsaicin treated stromal cell VCAM-1.}

To determine whether reduced nuclear p65 was sufficient to down regulate VCAM-1 expression, confluent stromal cell layers were treated with (E)-Capsaicin as described. VCAM-1 protein was consistently reduced following (E)-Capsaicin exposure (Fig. 6).

\section{Nuclear p65:p50 ratios following cessation of short term chemotherapy.}

To evaluate recovery of nuclear p65 and p50 following short term exposure to VP-16, stromal cells were treated with VP-16 for 3 hours, then allowed to recover for up to 72 hours (Fig. 7A). After 24 hours of recovery, nuclear p65:p50 ratios began to 
approximate the untreated control ratio, and after 72 hours the p65:p50 ratio was significantly higher than that immediately post-treatment (Tukey test; $\mathrm{P}<0.05$ ).

\section{VCAM-1 protein expression recovery following VP-16 treatment.}

To determine if VCAM-1 protein recovered following treatment with VP-16, stromal cell cultures were treated for $24-72$ hours followed by $1-5$ days recovery in fresh medium. Following a short (24 hour) VP-16 exposure, VCAM-1 protein levels increased at 24 hours, and reached control levels after 48 hours of recovery (Fig. 7B). In contrast, when stromal cells were treated for 72 hours with VP-16, reduced VCAM-1 protein expression was observed for up to 5 days (Fig. 7C).

\section{DISCUSSION}

We previously reported functional alteration of bone marrow stromal cells treated with VP-16 $\{7\}$. Specifically, treated stromal cells exposed to VP-16 had reduced capacity to support survival and proliferation of lymphoid and myeloid progenitor cells, and reduced levels of VCAM-1 protein expression $\{7\}$. Because interaction of hematopoietic progenitor cells with VCAM-1 on stromal cells has been shown to be important for development of progenitor cells $\{21-23 ; 28\}$, we investigated a potential mechanism by which VP-16 exposure results in dysregulated VCAM-1 expression.

Consistent with our previous report of reduced VCAM-1 protein in stromal cells treated with VP-16 $\{7\}$, VCAM-1 mRNA was reduced following treatment (Fig. 1A). This observation suggests that VP-16 either reduced the stability of VCAM-1 mRNA, or resulted in diminished transcription of VCAM-1 in stromal cells. The reduction in VCAM1 RNA in the presence of VP-16 was not due to altered stability (Fig. 1B). This 
observation prompted investigation of transcription factors that potentially mediated diminished expression.

We have previously reported that while VCAM-1 expression is reduced by treatment of stromal cells with VP-16, fibronectin is not altered $\{7\}$, suggesting VP-16 modulation of transcription factors that bind to the VCAM-1 promoter and not fibronectin. Two NF-kB consensus binding sites have been identified in the VCAM-1 promoter region $\{43\}$ while fibronectin is activated primarily by $\mathrm{Sp}-1$ binding $\{44 ; 45\}$. NF-kB or p65 homodimeric molecules have been reported to enhance transcriptional activity of the VCAM-1 gene in a variety of systems through binding to these sites $\{43 ; 46-48\}$.

Evaluation of stromal cell nuclear profiles of p65 and p50 indicated reduced levels of nuclear p65 following treatment with VP-16 (Fig. 2 and 3A). This observation is consistent with reduced availability of p65 to maintain VCAM-1 transcription during VP16 exposure. Ratios of p65:p50 were not significantly different in whole cell lysates of treated stromal cells compared to matched controls (data not shown). These data suggest that VP-16 primarily results in signals that alter cellular localization of NF-kB subunits, but does not impact total expression levels of p65 or p50. One direct means by which VP-16 may alter nuclear translocation of p65 is through physical interaction that either masks the nuclear localization signal, or alters nuclear pore permeability. However, while VP-16 has been shown to directly bind various proteins $\{49 ; 50\}$, no binding of ${ }^{3} \mathrm{H}-\mathrm{VP}-16$ to immunoprecipitated stromal cell p65 was observed (data not shown). To address the possibility that VP-16 masked the protein sites necessary for antibody interaction, immunoprecipitations were completed with nuclear protein, 
unlabeled VP-16, and $\alpha-p 65$ antibody. Subsequent Western blot analysis readily detected p65 (data not shown).

The prototypic molecule reported to detain p65 in the cytoplasm is Iא-B $\alpha$ through either increased expression or stability $\{34 ; 35\}$. However, I $\mathrm{k}-\mathrm{B} \alpha$ did not play an obvious role in sequestering p65 in the cytoplasm of stromal cells following VP-16 exposure. Total Iк-B $\alpha$ protein levels were diminished following treatment (Fig. 5). The reduction of $\mid \kappa-B \alpha$ protein was consistent with previous reports of $\kappa B$ binding sites in the $\mid \kappa-B \alpha$ promoter $\{35 ; 51\}$.

The observation that $\mathrm{I} \kappa-\mathrm{B} \alpha$ did not play a clear role in retention of $\mathrm{p} 65$ in the cytoplasm following VP-16 treatment did not rule out the possibility that another inhibitory molecule may have enhanced expression following treatment with VP-16. To investigate this possibility, levels of p100 and p105 proteins, which can also detain p65 in the cytoplasm, were evaluated as potential regulatory molecules that may respond to chemotherapy exposure. No consistent increase in either protein was observed following VP-16 exposure in three stromal cell lines examined (data not shown). In combination, these observations suggest a mechanism, other than interaction of p65 with an obvious inhibitory protein, that accounts for reduced p65 levels in the nucleus following treatment. Alteration of the nuclear pore complex seems unlikely as p50 entrance to the nucleus was not disrupted in VP-16 treated stromal cells.

In contrast to p65, modest increases in nuclear p50 were noted in VP-16 treated stromal cells (Fig. 2 and 3B). Homodimers of p50 have been previously reported to repress VCAM-1 transcription in cells lines generated to over express p50 $\{30 ; 31\}$. However, p50 homodimer complexes were not discerned by EMSA in our model (Fig. 
4). Homodimeric p50 may have been present at a level below our sensitivity of detection. However, a modest increase in stromal cell nuclear p50, combined with a consistent decrease in nuclear p65 in cells treated with VP-16, results in a ratio less conducive to NF-kB driven VCAM-1 expression.

Treatment of stromal cells layers with (E)-Capsaicin reduced VCAM-1 expression at 24 and 48 hours (Fig. 6). We have previously determined that the half life of stromal cell VCAM-1 is approximately 24 hours (unpublished data), providing the rationale for evaluation of VCAM-1 protein 24 and 48 hours after disruption of nuclear p65 by (E)Capsaicin. This observation supports the premise that reduced nuclear p65 is sufficient to diminish VCAM-1 expression, and suggests that chemotherapeutic agents that modulate cellular localization of p65 potentially alter stromal cell VCAM-1 expression through this mechanism.

The recovery of p65 and p50 nuclear levels to baseline following removal of VP16 following a 3 hour exposure suggests an absence of permanent damage to stromal cells following short term exposure (Fig. 7A). In addition, restoration of VCAM-1 protein expression following removal of drug occurred following 24 hour treatment (Fig. 7B), but not following 72 VP-16 exposure (Fig. 7C). This observation suggests a potential link between duration of drug exposure and severity of damage that may be as critical as drug dose. We have previously reported that while VP-16 disrupted the ability of confluent stromal cell layers to support hematopoiesis, it did not induce stromal cell apoptosis, confirmed by an absence of DNA laddering or PI staining $\{7\}$. The inability of VP-16 to initiate apoptosis in non-cycling confluent stromal cell cultures is in marked 
contrast to its ability to efficiently induce death in dividing cells. This suggests unique NF-KB mediated signaling pathways in cycling versus quiescent cells.

The relevance of the current study may not be in designing strategies to prevent damage to the microenvironment, but rather in understanding the kinetics of stromal cell recovery following chemotherapy. Attempts at maintaining nuclear levels of p65 during treatment to sustain VCAM-1 expression on stromal cells would likely prove detrimental. NF-kB has been shown to be a critical component of the apoptotic pathway in various model systems $\{37\}$, therefore, blocking translocation of p65 or p50 subunits in response to chemotherapy would likely diminish the efficacy of treatment in many circumstances

The rationale for investigating the response of NF- $\mathrm{kB}$ to chemotherapeutic agents rests in its ability to regulate several stromal cell genes. In addition to altered VCAM-1 expression, we have observed reduced transcription of stromal cell GM-CSF (unpublished data) in VP-16 treated cells. Like VCAM-1, GM-CSF expression has been shown to be regulated, in part, by NF-KB binding $\{52\}$. In combination, the appropriate expression of stromal cell adhesion molecules and cytokines define the ability of the microenvironment to support hematopoiesis. The response of stromal cell NF-kB to specific chemotherapeutic agents may provide insight into mechanisms that contribute to a disrupted bone marrow microenvironment, and the delayed hematopoietic recovery that is associated with specific chemotherapeutic agents. 


\section{ACKNOWLEDGMENTS}

The authors thank Drs. Kenneth Landreth, John Barnett, and Bonita Stanton for critique of this manuscript, and Dr. Solveig Ericson for assistance in obtaining bone marrow samples. This work supported in part by the National Institutes of Health $(\mathrm{NIH})$ grant number HL56888 (LFG) and the WVU Department of Pediatrics Oncology Research Fund. 


\section{REFERENCES}

1. Kincade,P.W., Lee,G., Pietrangeli,C.E., Hayashi,S., and Gimble,J.M. (1989) Cells and molecules that regulate B lymphopoiesis in bone marrow Annu.Rev.Immunol. 7: 111-143.

2. Dorshkind,K. (1990) Regulation of hemopoiesis by bone marrow stromal cells and their products Annu.Rev.Immunol. 8: 111-137.

3. McGinnes,K., Quesniaux,V., Hitzler,J., and Paige,C. (1991) Human B-lymphopoiesis is supported by bone marrow-derived stromal cells Exp.Hematol. 19: 294-303.

4. Dittel,B.N., LeBien,T.W. (1995) The growth response to IL-7 during normal human B cell ontogeny is restricted to B-lineage cells expressing CD34 J.Immunol. 154: 58-67.

5. Wolf,M.L., Buckley,J.A., Goldfarb,A., Law,C.L., and LeBien,T.W. (1991) Development of a bone marrow culture for maintenance and growth of normal human B cell precursors J.Immunol. 147: 3324-3330.

6. Whitlock,C.A., Witte,O.N. (1982) Long-term culture of B lymphocytes and their precursors from murine bone marrow Proc.Natl.Acad.Sci.U.S.A 79: 3608-3612.

7. Gibson,L.F., Fortney,J., Landreth,K.S., Piktel,D., Ericson,S.G., and Lynch,J.P. (1997) Disruption of bone marrow stromal cell function by etoposide Biol.Blood Marrow Transplant. 3: 122-132. 
8. Schwartz,G.N., Warren,M.K., $\quad$ Rothwell,S.W., Zujewski,J., Halverson,D.C., Cowan,K.H., Tolcher,A., O'Shaughnessy,J., and Gress,R.E. (1998) Post-chemotherapy and cytokine pretreated marrow stromal cell layers suppress hematopoiesis from normal donor CD34+ cells Bone Marrow Transplant. 22: 457-468.

9. Mauch,P., Constine,L., Greenberger,J., Knospe,W., Sullivan,J., Liesveld,J.L., and Deeg,H.J. (1995) Hematopoietic stem cell compartment: acute and late effects of radiation therapy and chemotherapy Int.J.Radiat.Oncol.Biol.Phys. 31: 1319-1339.

10. Greenberger,J.S., Epperly,M.W., Jahroudi,N., Pogue-Geile,K.L., Berry,L., Bray,J., and Goltry,K.L. (1996) Role of bone marrow stromal cells in irradiation leukemogenesis Acta Haematol. 96: 1-15.

11. Greenberger,J.S., Anderson,J., Berry,L.A., Epperly,M., Cronkite,E.P., and Boggs,S.S. (1996) Effects of irradiation of CBA/CA mice on hematopoietic stem cells and stromal cells in long-term bone marrow cultures Leukemia 10: 514-527.

12. Dittel,B.N., LeBien,T.W. (1995) Reduced expression of vascular cell adhesion molecule- 1 on bone marrow stromal cells isolated from marrow transplant recipients correlates with a reduced capacity to support human B lymphopoiesis in vitro Blood 86: 2833-2841.

13. Deisher,T.A., Kaushansky,K., and Harlan,J.M. (1993) Inhibitors of topoisomerase II prevent cytokine-induced expression of vascular cell adhesion molecule-1, while augmenting the expression of endothelial leukocyte adhesion molecule-1 on human umbilical vein endothelial cells Cell Adhes.Commun. 1: 133-142. 
14. Weisdorf,D., Katsanis,E., Verfaillie,C., Ramsay,N.K., Haake,R., Garrison,L., and Blazar,B.R. (1994) Interleukin-1 alpha administered after autologous transplantation: a phase I/II clinical trial Blood 84: 2044-2049.

15. Herzig,R.H., Lynch,J., Christiansen,N.P., Fay,J.W., Davis,M.P., and Herzig,G.P. (1996) Dose-intensive chemotherapy with etoposide-cyclophosphamide for advanced breast cancer. North American Marrow Transplant Group Semin.Oncol. 23: 28-32.

16. Dexter,T.M. (1982) Stromal cell associated haemopoiesis J.Cell Physiol Suppl 1: 87-94.

17. Allen,T.D., Dexter,T.M. (1984) The essential cells of the hemopoietic microenvironment Exp.Hematol. 12: 517-521.

18. Bentley,S.A. (1982) Bone marrow connective tissue and the haemopoietic microenvironment Br.J.Haematol. 50: 1-6.

19. Mayani,H., Guilbert,L.J., and Janowska-Wieczorek,A. (1992) Biology of the hemopoietic microenvironment Eur.J.Haematol. 49: 225-233.

20. Verfaillie,C.M. (1998) Adhesion receptors as regulators of the hematopoietic process Blood 92: 2609-2612.

21. Jacobsen,K., Kravitz,J., Kincade,P.W., and Osmond,D.G. (1996) Adhesion receptors on bone marrow stromal cells: in vivo expression of vascular cell adhesion molecule- 1 by reticular cells and sinusoidal endothelium in normal and gammairradiated mice Blood 87: 73-82. 
22. Kincade,P.W., Yamashita,Y., Borghesi,L., Medina,K., and Oritani,K. (1998) Blood cell precursors in context. Composition of the bone marrow microenvironment that supports B lymphopoiesis Vox Sang. 74 Suppl 2: 265-268.

23. Miyake,K., Medina,K., Ishihara,K., Kimoto,M., Auerbach,R., and Kincade,P.W. (1991) A VCAM-like adhesion molecule on murine bone marrow stromal cells mediates binding of lymphocyte precursors in culture J.Cell Biol. 114: 557-565.

24. Dittel,B.N., McCarthy,J.B., Wayner,E.A., and LeBien,T.W. (1993) Regulation of human B-cell precursor adhesion to bone marrow stromal cells by cytokines that exert opposing effects on the expression of vascular cell adhesion molecule-1 (VCAM-1) Blood 81: 2272-2282.

25. Stephan,R.P., Reilly,C.R., and Witte,P.L. (1998) Impaired ability of bone marrow stromal cells to support B- lymphopoiesis with age Blood 91: 75-88.

26. Ryan,D.H., Nuccie,B.L., Abboud,C.N., and Winslow,J.M. (1991) Vascular cell adhesion molecule-1 and the integrin VLA-4 mediate adhesion of human B cell precursors to cultured bone marrow adherent cells J.Clin.Invest 88: 995-1004.

27. Ryan,D.H., Nuccie,B.L., Abboud,C.N., and Liesveld,J.L. (1990) Maturationdependent adhesion of human B cell precursors to the bone marrow microenvironment J.Immunol. 145: 477-484.

28. Miyake,K., Weissman,I.L., Greenberger,J.S., and Kincade,P.W. (1991) Evidence for a role of the integrin VLA-4 in lympho-hemopoiesis J.Exp.Med. 173: 599-607. 
29. Shu,H.B., Agranoff,A.B., Nabel,E.G., Leung,K., Duckett,C.S., Neish,A.S., Collins,T., and Nabel,G.J. (1993) Differential regulation of vascular cell adhesion molecule 1 gene expression by specific NF-kappa B subunits in endothelial and epithelial cells Mol.Cell Biol. 13: 6283-6289.

30. Ahmad,M., Marui,N., Alexander,R.W., and Medford,R.M. (1995) Cell type-specific transactivation of the VCAM-1 promoter through an NF- kappa B enhancer motif J.Biol.Chem. 270: 8976-8983.

31. Neish,A.S., Read,M.A., Thanos,D., Pine,R., Maniatis,T., and Collins,T. (1995) Endothelial interferon regulatory factor 1 cooperates with NF-kappa B as a transcriptional activator of vascular cell adhesion molecule 1 Mol.Cell Biol. 15: 25582569.

32. Fujita,T., Nolan,G.P., Ghosh,S., and Baltimore,D. (1992) Independent modes of transcriptional activation by the p50 and p65 subunits of NF-kappa B Genes Dev. 6: 775-787.

33. Neish,A.S., Khachigian,L.M., Park,A., Baichwal,V.R., and Collins,T. (1995) Sp1 is a component of the cytokine-inducible enhancer in the promoter of vascular cell adhesion molecule-1 J.Biol.Chem. 270: 28903-28909.

34. Rice,N.R., Ernst,M.K. (1993) In vivo control of NF-kappa B activation by I kappa B alpha $E M B O$ J. 12: 4685-4695. 
35. Sun,S.C., Ganchi,P.A., Ballard,D.W., and Greene,W.C. (1993) NF-kappa B controls expression of inhibitor I kappa B alpha: evidence for an inducible autoregulatory pathway Science 259: 1912-1915.

36. Lee,J.I., Burckart,G.J. (1998) Nuclear factor kappa B: important transcription factor and therapeutic target J.Clin.Pharmacol. 38: 981-993.

37. Wang,C.Y., Mayo,M.W., and Baldwin,A.S., Jr. (1996) TNF- and cancer therapyinduced apoptosis: potentiation by inhibition of NF-kappaB Science 274: 784-787.

38. Kang,S.M., Tran,A.C., Grilli,M., and Lenardo,M.J. (1992) NF-kappa B subunit regulation in nontransformed CD4+ T lymphocytes Science 256: 1452-1456.

39. Pietersma,A., Tilly,B.C., Gaestel,M., de Jong,N., Lee,J.C., Koster,J.F., and Sluiter,W. (1997) p38 mitogen activated protein kinase regulates endothelial VCAM-1 expression at the post-transcriptional level Biochem.Biophys.Res.Commun. 230: 44-48.

40. Andrews,N.C., Faller,D.V. (1991) A rapid micropreparation technique for extraction of DNA-binding proteins from limiting numbers of mammalian cells Nucleic Acids Res. 19: 2499.

41. Laemmli,U.K. (1970) Cleavage of structural proteins during the assembly of the head of bacteriophage T4 Nature 227: 680-685.

42. Singh,S., Natarajan,K., and Aggarwal,B.B. (1996) Capsaicin (8-methyl-N-vanillyl-6nonenamide) is a potent inhibitor of nuclear transcription factor-kappa B activation by diverse agents J.Immunol. 157: 4412-4420. 
43. Neish,A.S., Williams,A.J., Palmer,H.J., Whitley,M.Z., and Collins,T. (1992) Functional analysis of the human vascular cell adhesion molecule 1 promoter J.Exp.Med. 176: 1583-1593.

44. Suzuki,M., Oda,E., Nakajima,T., Sekiya,S., and Oda,K. (1998) Induction of Sp1 in differentiating human embryonal carcinoma cells triggers transcription of the fibronectin gene Mol.Cell Biol. 18: 3010-3020.

45. Kornblihtt,A.R., Pesce,C.G., Alonso,C.R., Cramer,P., Srebrow,A., Werbajh,S., and Muro,A.F. (1996) The fibronectin gene as a model for splicing and transcription studies FASEB J. 10: 248-257.

46. Collins,T., Read,M.A., Neish,A.S., Whitley,M.Z., Thanos,D., and Maniatis,T. (1995) Transcriptional regulation of endothelial cell adhesion molecules: NF- kappa B and cytokine-inducible enhancers FASEB J. 9: 899-909.

47. Shu,H.B., Agranoff,A.B., Nabel,E.G., Leung,K., Duckett,C.S., Neish,A.S., Collins,T., and Nabel,G.J. (1993) Differential regulation of vascular cell adhesion molecule 1 gene expression by specific NF-kappa B subunits in endothelial and epithelial cells Mol.Cell Biol. 13: 6283-6289.

48. Ahmad,M., Theofanidis,P., and Medford,R.M. (1998) Role of activating protein-1 in the regulation of the vascular cell adhesion molecule-1 gene expression by tumor necrosis factor-alpha J.Biol.Chem. 273: 4616-4621.

49. Fleming,R.A., Arbuck,S.G., and Stewart,C.F. (1991) Interspecies differences in in vitro etoposide plasma protein binding Biochem.Pharmacol. 42: 2246-2249. 
50. Haim,N., Nemec,J., Roman,J., and Sinha,B.K. (1987) In vitro metabolism of etoposide (VP-16-213) by liver microsomes and irreversible binding of reactive intermediates to microsomal proteins Biochem.Pharmacol. 36: 527-536.

51. Ito,C.Y., Kazantsev,A.G., and Baldwin,A.S., Jr. (1994) Three NF-kappa B sites in the I kappa B-alpha promoter are required for induction of gene expression by TNF alpha Nucleic Acids Res. 22: 3787-3792.

52. Kaushansky,K., O'Rork,C., Shoemaker,S.G., and McCarty,J. (1996) The regulation of GM-CSF is dependent on a complex interplay of multiple nuclear proteins Mol.Immunol. 33: 461-470. 


\section{FIGURE LEGENDS}

Figure 1. VCAM-1 transcripts in bone marrow stromal cells treated with VP-16. (A) To determine if VCAM-1 mRNA expression was altered by VP-16 treatment, semiquantitative PCR was performed as described in Materials and Methods. Actin and VCAM-1 specific sequences were amplified from RNA isolated from untreated control stromal cells and stroma treated for $4-24$ hours with $100 \mu \mathrm{M}$ VP-16 as indicated. (B) To evaluate VCAM-1 message stability, stromal cells were treated with $100 \mu \mathrm{M}$ VP-16 in the presence of actinomycin-D as described in Materials and Methods. RNase protection was completed to quantitate VCAM-1 specific RNA in untreated control stromal cell layers in the presence of actinomycin-D, compared to those treated for up to 24 hours with both VP-16 and actinomycin-D. Values shown are relative to control values set to 1.0.

Figure 2. Cellular localization of NF-KB p65 and p50 subunits following treatment of bone marrow stromal cells with VP-16. The relative amount and cellular localization of p50 or p65 protein in stromal cells treated with VP-16 for 3 hours (p65) or 6 hours (p50) was determined by fluorescent microscopy as described in Materials and Methods. Following treatment, stromal cells were fixed in methanol:acetone and p65 or p50 protein detected by incubation with $200 \mu \mathrm{g} / \mathrm{mL}$ rabbit anti-human p50 or p65 (Santa Cruz Biotechnology, Inc.; Santa Cruz, CA). Data shown are representative of 3 stromal cell lines evaluated.

Figure 3. Nuclear p65 and p50 protein in stromal cells following treatment with VP-16. To quantitate changes in nuclear levels of p65 and p50 in stromal cells exposed to VP16, Western blot analysis of nuclear proteins was completed as described in Materials 
and Methods. Stromal cells were treated with $100 \mu \mathrm{M}$ VP-16 for 30 minutes to 3 hours as indicated, and nuclei isolated as previously described for protein analysis. Nuclear p65 (panel A) and nuclear p50 (panel B) were evaluated by Western blot analysis. A representative control (RAP 30) is shown for one experiment. Data from 4 independent experiments evaluating nuclear p65, and 5 independent experiments evaluating nuclear p50 expression are normalized to untreated control values are summarized in panel C.

Figure 4. NF-kB binding to its consensus sequence in VP-16 treated stromal cells. To determine if VP-16 exposure resulted in alterations of NF-kB binding to its consensus sequence, EMSA's were performed as described in Materials and Methods. Densitometric analysis was completed to quantitate relative band intensities.

Figure 5. I $\mathrm{K}-\mathrm{B} \alpha$ protein expression in stromal cells exposed to VP-16. (A) To evaluate total $1 \kappa-B \alpha$ protein levels in stromal cells following VP-16 exposure, confluent stromal cell layers were treated for 30 minutes to 3 hours and Western blot analysis completed. (B) Densitometric analysis of 3 representative experiments are shown (SEM). Reduced IKB- $\alpha$ protein was observed at all time points evaluated.

Figure 6. VCAM-1 expression in (E)-Capsaicin treated stromal cells. Confluent bone marrow stromal cells were exposed to a single 4 hour treatment of Capsaicin, or to 4 hour treatments on two consecutive days, and VCAM-1 ELISA completed at 24 and 48 hours respectively. Isotype matched control binding indicative of non-specific background was subtracted from each sample. Data from two independent stromal cell lines, P154 (solid bar) and P155 (hatched bar), are shown with SEM.

Figure 7. Nuclear p65 and p50, and VCAM-1 protein expression return to baseline levels following removal of chemotherapy. To determine if nuclear profiles of p65 and 
p50 returned to baseline following termination of VP-16 exposure, confluent stromal cell cultures were treated for 3 hours with $100 \mu \mathrm{M}$ VP-16, then thoroughly rinsed with media and allowed to recover for up to 72 hours as described in Materials and Methods. Subsequently, nuclear p65 and p50 protein was evaluated by Western blot analysis and densitometry completed (panel A). Values are shown with SEM. (B) Stromal cell VCAM-1 protein following removal of VP-16 from cultures was evaluated by ELISA as described in Materials and Methods. Confluent layers were treated for 24 hours, and allowed to recover for up to 60 hours in fresh medium. Isotype matched controls are shown for each sample. Values are shown with SEM. (C) VCAM-1 protein was evaluated by ELISA following up to 72 hours of VP-16 exposure, followed by $1-5$ days recovery in fresh medium as described in Materials and Methods. Values from two different human stromal cell lines, P154 (solid bar) and P155 (hatched bar) are shown with SEM. Isotype matched control antibody binding was subtracted from each value. 
Figure 1. VCAM-1 transcripts in bone marrow stromal cells treated with VP-16

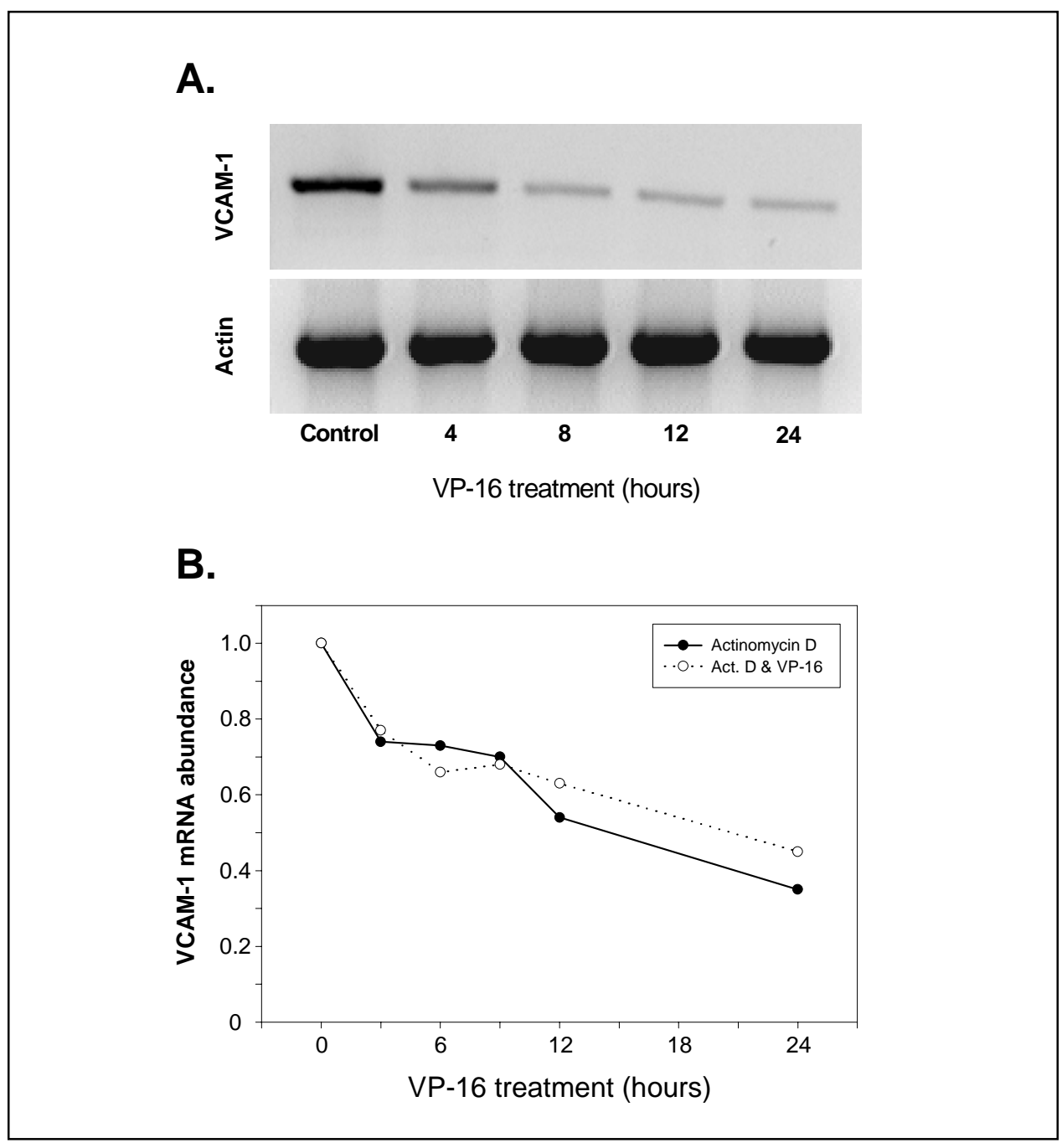


Figure 2. Cellular localization of NF-kB p65 and p50 subunits following treatment of bone marrow stromal cells with VP-16

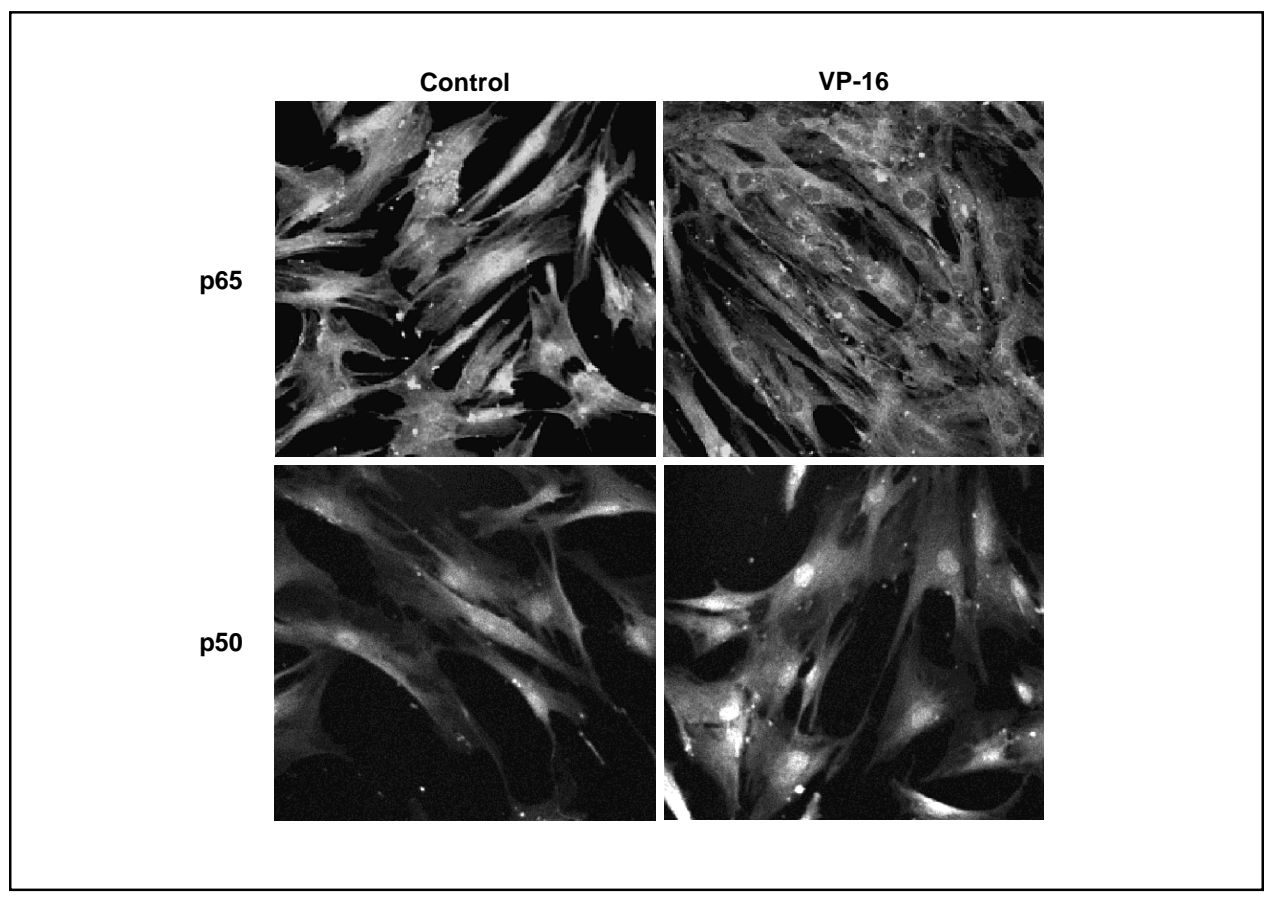


Figure 3. Nuclear p65 and p50 protein in stromal cells following treatment with VP-16

A.

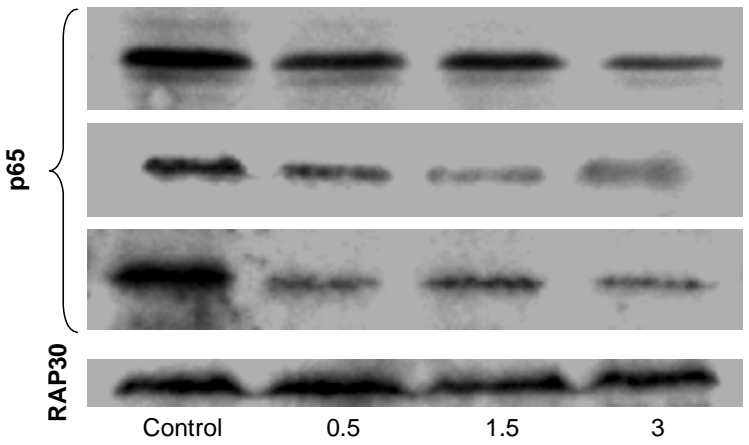

B.
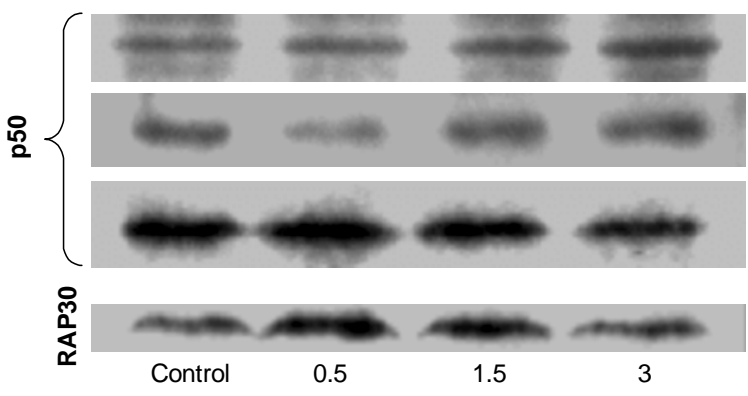

VP-16 treatment (hours)

C.

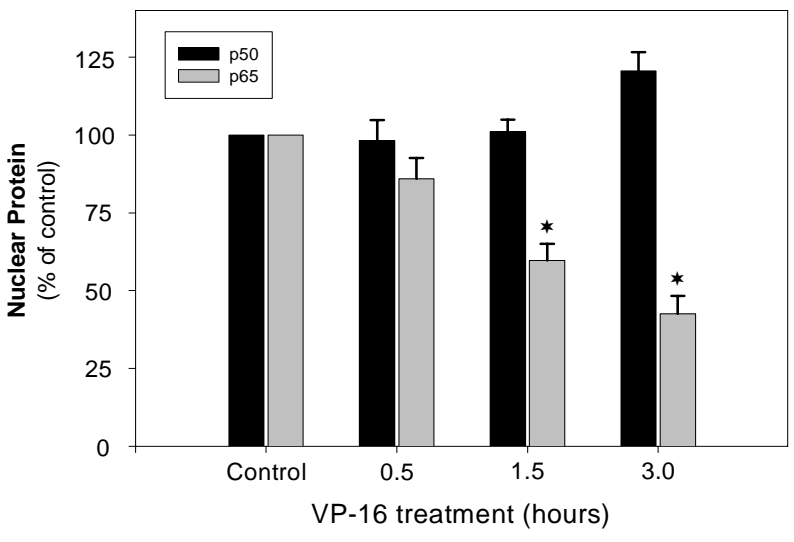


Figure 4. NF- $\mathrm{KB}$ binding to its consensus sequence in VP-16 treated stromal cells

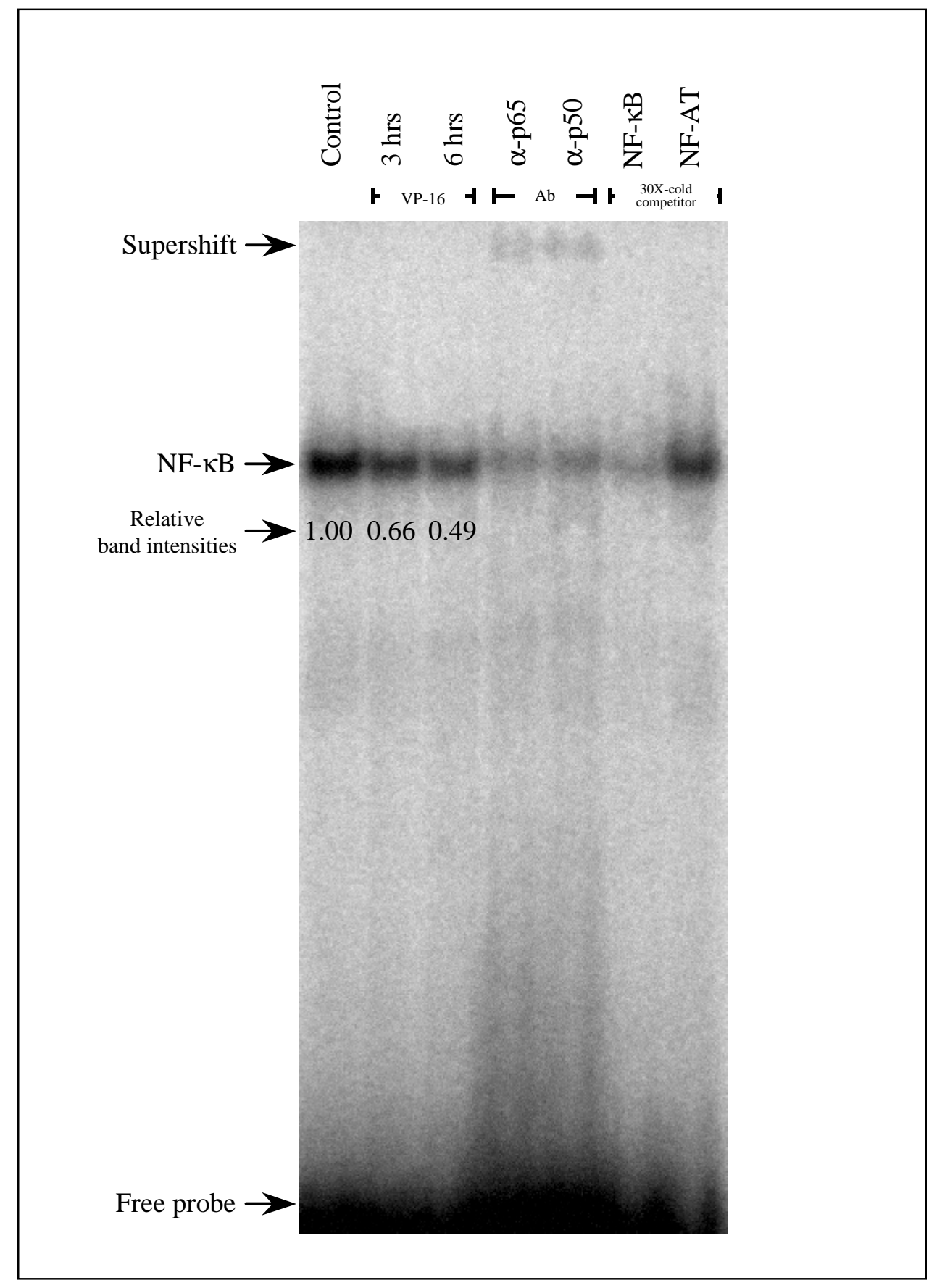


Figure 5. . I $\mathrm{k}-\mathrm{B} \alpha$ protein expression in stromal cells exposed to VP-16

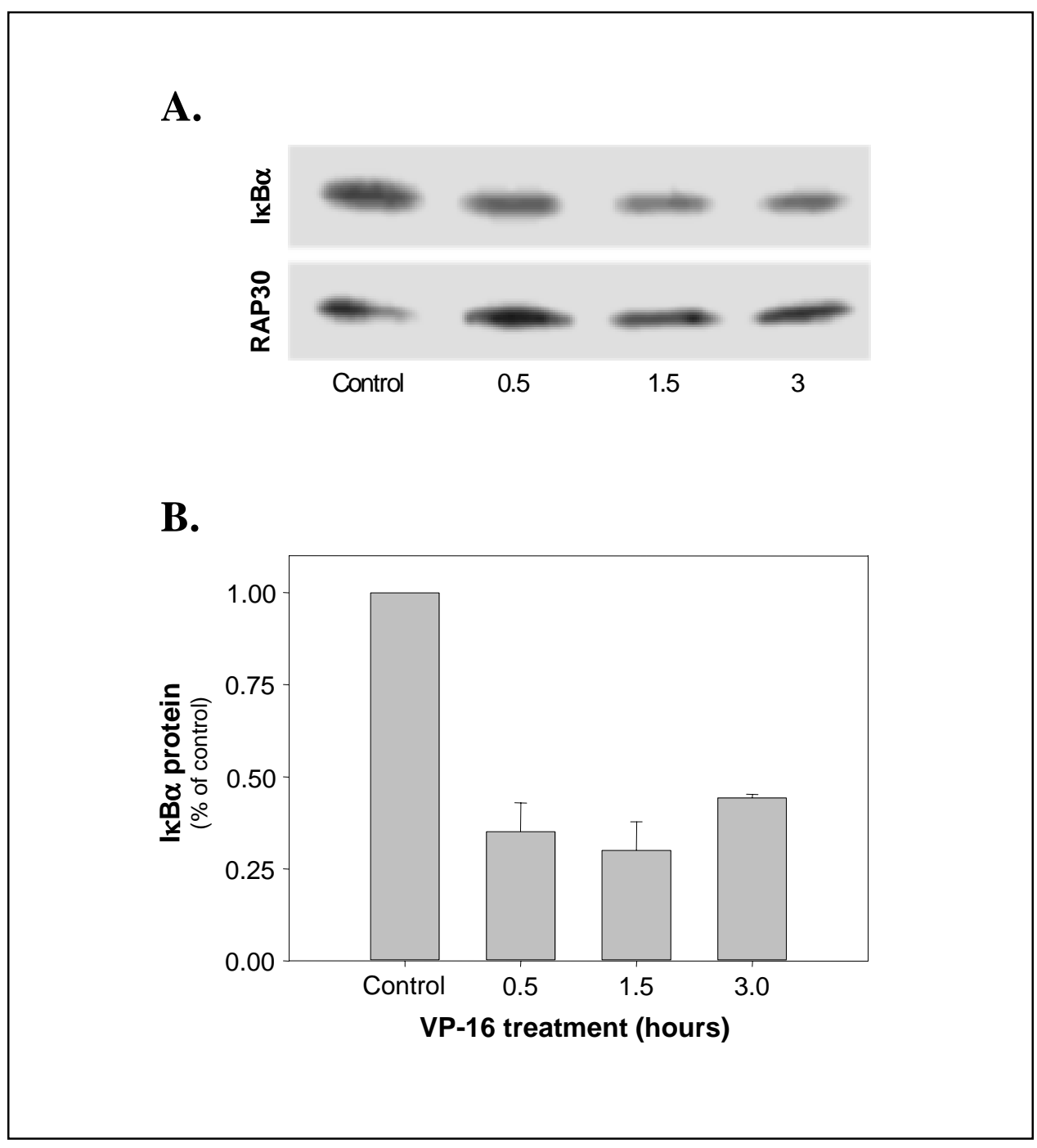


Figure 6. VCAM-1 expression in (E)-Capsaicin treated stromal cells

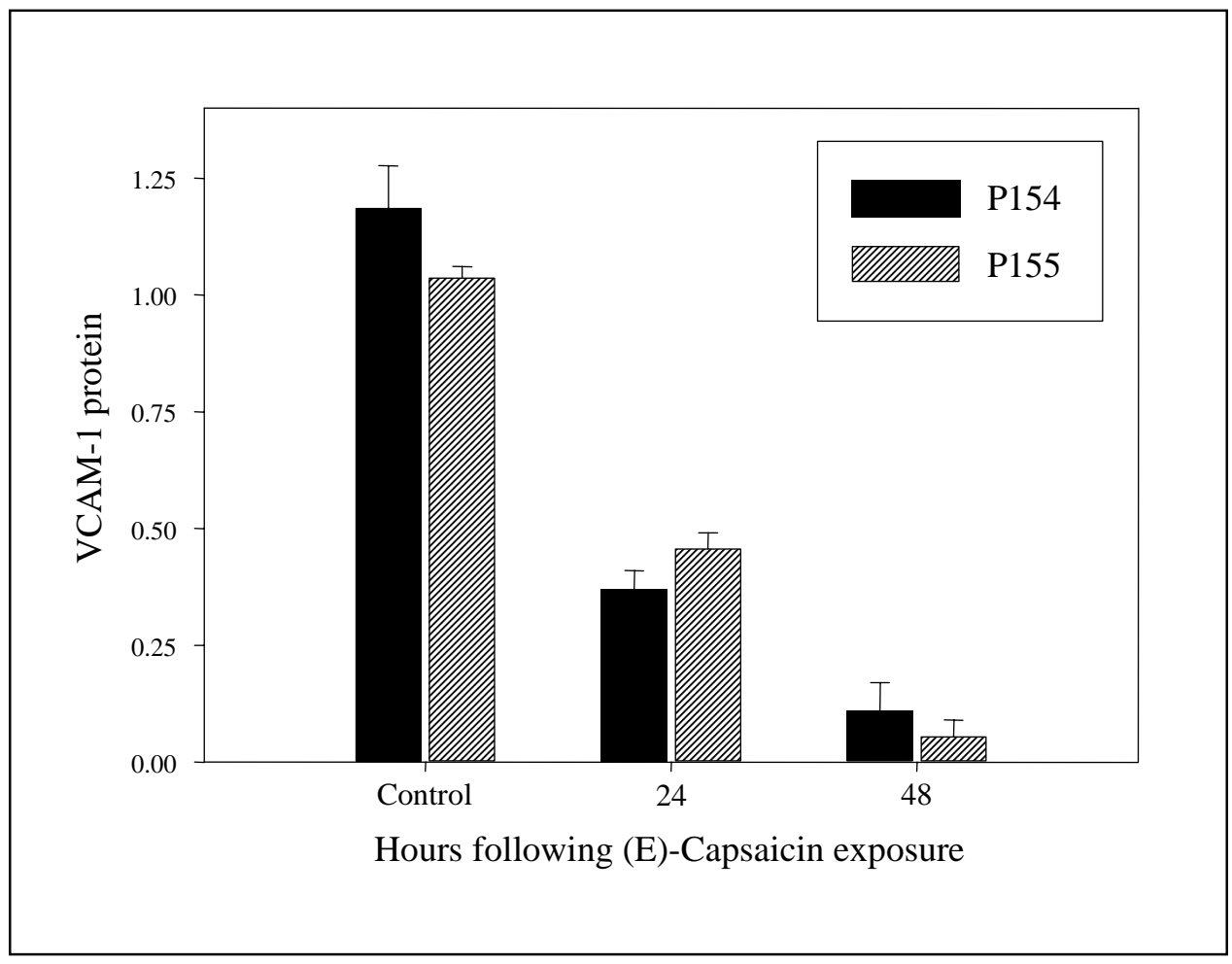


Figure 7. Nuclear $\mathrm{p} 65$ and $\mathrm{p} 50$, and VCAM-1 protein expression return to baseline levels following removal of chemotherapy

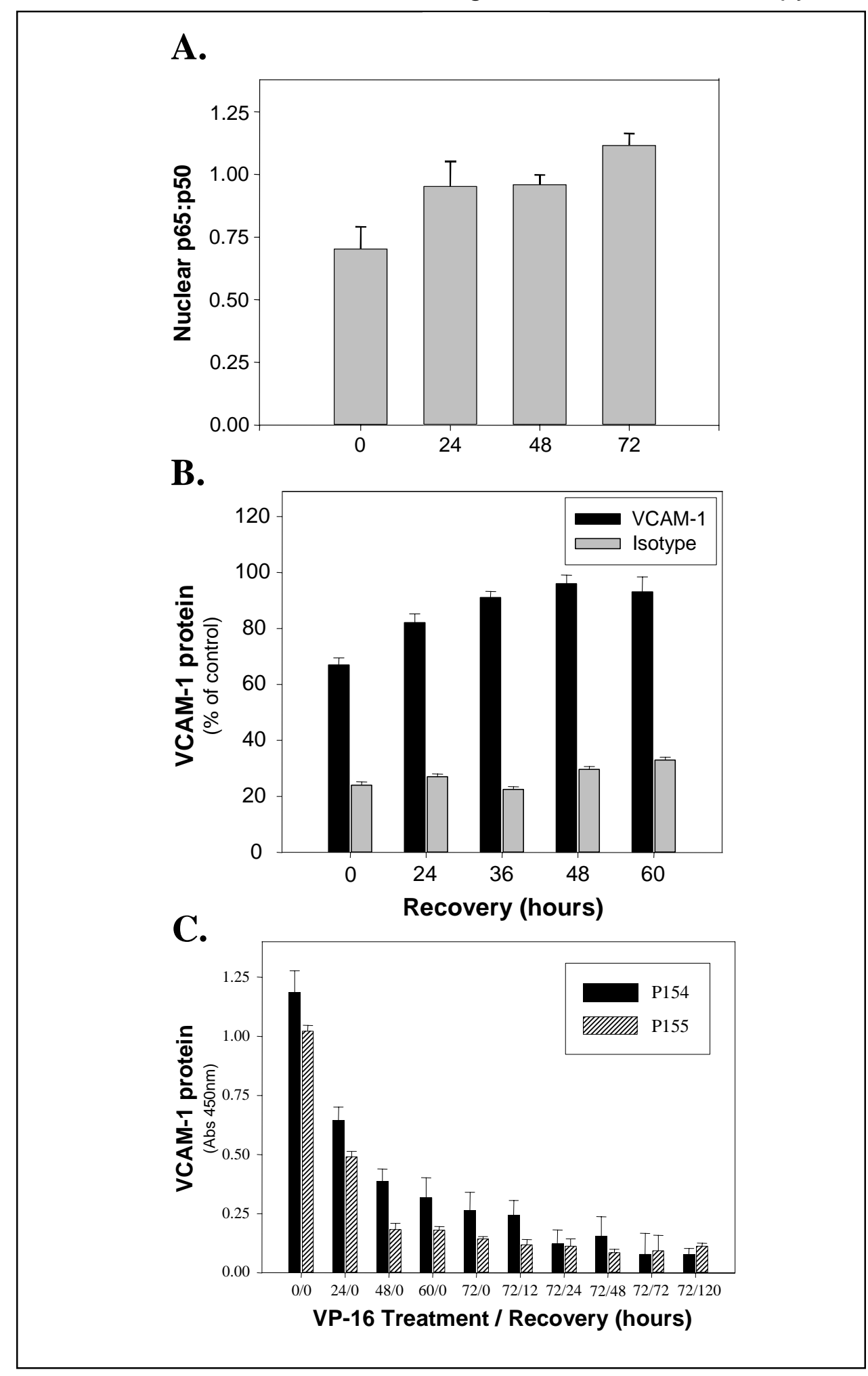




\title{
Chapter IV
}

\section{Characterization of Stromal Cell Lines Stably Transfected with Human VCAM-1}

\author{
Brett M. Hall ${ }^{1}$, James E. Fortney ${ }^{2}$, and Laura F. Gibson ${ }^{1,2,3}$
}

Departments of Microbiology, Immunology and Cell Biology ${ }^{1}$, Pediatrics ${ }^{2}$, and the Blood and Marrow Transplantation Program of the Mary Babb Randolph Cancer Center ${ }^{3}$. West Virginia University, Morgantown, WV 26506 


\begin{abstract}
VCAM-1 protein expression in the bone marrow microenvironment on fibroblastic stromal cells is critical for normal B-cell lymphopoiesis. Diminished interaction between VLA-4 on immature B-cells and VCAM-1 on stromal cells results in dysregulated Blymphopoiesis. In the current study, murine stromal cells were transfected with human VCAM-1 cDNA expressed from a constitutive promoter. Stromal cells transfected with human VCAM-1 cDNA or $\beta$-galactosidase support early B-cell expansion and survival equally well. However hVCAM-1 lines are quantitatively different from the $\beta$ galactosidase expressing vector control lines. In coculture with immature B-cells, increased numbers of proB cells adhere to hVCAM-1 expressing stromal cells compared to vector control cell lines. ProB cells on hVCAM-1 expressing stromal cells maintained a higher viability compared to vector contol cell lines. And, murine stromal cells maintain expression of human VCAM-1 following exposure to the chemotherapeutic agent etoposide (VP-16) while endogenous murine VCAM-1 decreased after treatment. These stromal cell lines will be useful in studies that evaluate the role of VCAM-1 maintenance following chemotherapy in hematopoietic restoration.
\end{abstract}




\section{INTRODUCTION}

The critical role of Vascular Cell Adhesion Molecule-1 (VCAM-1) in hematopoiesis has been well established through both in vitro and in vivo models (1-8). VCAM-1, a surface bound stromal cell adhesion molecule, is an essential component of stromal cell support of hematopoietic stem and progenitor cells (9-16). An essential role of VCAM- 1 is contributing to retention of VLA-4 positive hematopoietic progenitor cells in the bone marrow. Injection of anti-VCAM-1 antibody into mice disrupts stromal and hematopoietic progenitor cell associations and results in disrupted B-lymphopoiesis (16). In addition, hematopoietic progenitor cells are mobilized in primates following antiVLA-4 antibody treatment (11).

Bone marrow stromal cell VCAM-1 protein levels are altered by local marrow cytokine influences, with reduced VCAM-1 protein expression linked to alterations of immature B-cells adherence to bone marrow stromal cells. Disrupted adhesion leads to dysregulation of early B-cell development (17). Further studies on ex vivo expanded bone marrow stromal cells from patients receiving various conditioning regiments in preparation for bone marrow transplantation demonstrated reduced VCAM-1 protein expression and diminished capacity to support normal B-cell precursor growth in vitro (8). These observations suggest an essential role of VCAM-1 in the development of progenitor cells committed to the B cell lineage.

We have previously reported reductions of surface VCAM-1 protein following human or murine bone marrow stromal cell exposure to etoposide in vitro. (18). Subsequently, we demonstrated that reduced stromal cell VCAM-1 protein following exposure to etoposide was due to alterations in vcam-1 gene transcription reflected by 
reduced numbers of VCAM-1 transcripts (19). Two key studies, one ex vivo (8) and one in vitro (18), suggest that exposure to specific classes of chemotherapeutic drugs alter the functional capacity of stromal cells to support early B-cell development in a VCAM-1 specific manner. These studies support the premise that VCAM-1 dysregulation may contribute to the clinical observation of delayed B-cell reconstitution following dose escalated chemotherapy and bone marrow transplantation $(8 ; 20 ; 21)$. Together, these data suggest that stromal cells expressing VCAM-1 from a constitutive promoter have the potential to partially restore functional capacity of chemotherapy treated bone marrow to support immature B-cell development.

In this study, we generated and characterized murine stromal cell lines that constitutively express human VCAM-1 or $\beta$-galactosidase from the mammalian housekeeping gene promoter, EF1 $\alpha$. These cell lines maintain surface human VCAM-1 (or intracellular $\beta$-galactosidase) following etoposide exposure, while endogenous murine VCAM-1 is diminished. A higher percentage of pro-B cells were bound when cocultured with human VCAM-1 expressing lines as compared to $\beta$-galacatosidase vector control lines. In addition, IL-7 dependent pro-B cells maintained significantly higher viabilities on human VCAM-1 cell lines in the absence of IL-7 than when cocultured on vector control stromal cells. These observations suggest that maintenance of VCAM-1 expression on bone marrow stromal cells following high dose chemotherapy may facilitate B-cell recovery through enhanced interactions with immature B-cells. In addition, these data indicate that VLA-4 occupancy may delay the onset of apoptosis, which is characteristic of proB Cell IL-7 deprivation. 


\section{MATERIALS \& METHODS}

\section{Cell lines}

Stromal Cells:

The cloned murine stromal cell line, S-10 (22), was kindly provided by Dr. Kenneth Landreth (West Virginia University, WV) with the permission of Dr. Kenneth Dorshkind (University of California at Los Angeles, CA). S-10 stromal cell lines were maintained in Iscove's medium supplemented with 5\% Fetal Bovine Serum (Summit; Ft. Collins, CO) , 2mM L-Glutamine (GibcoBRL; Rockville, MD), 100U/ml Penicillin (Sigma; St. Louis, MO), $100 \mu \mathrm{g} / \mathrm{ml}$ Streptomycin (Sigma), $5 \times 10^{-5} \mathrm{M} \beta$-mercaptoethanol (Sigma).

Human stromal cells were initiated from consenting donor's bone marrow, with approval by the West Virginia University Institutional Review Board, as previously described (18). All stromal cell primary cultures were initiated from donors with no previous chemotherapy exposure. Human derived stromal cells were maintained in media identical to that of murine lines with the exception of FBS increased to $10 \%$.

\section{Pro-B cells:}

C1.92, a non-transformed murine fetal liver (d14) derived pro-B cell line (23), was kindly provided by Dr. Kenneth Landreth (West Virginia University, WV). C1.92 is stromal cell dependent and requires exogenous recombinant IL-7 (rIL-7) for sustained survival and proliferation.

\section{Human VCAM-1 and $\beta$-galactosidase transfected cell lines}

The murine S-10 cell line was stably transfected with pTRACER ${ }^{T M}$-EF/Bsd-LacZ (pTlacZ) (expression of $\beta$-galactosidase from EF-1 $\alpha$ promoter) or $\mathrm{pTRACER}{ }^{\mathrm{TM}}$-EF/BsdA-hVCAM-1 (pTaV) (expression of human VCAM-1 from EF-1 $\alpha$ promoter) (Invitrogen; 
Carlsbad, CA) (Figure 1). The pTaV vector was generated as follows: Human VCAM-1 (hVCAM-1) cDNA (Ingenius; Madison, WI) was excised from pCDM8 by restriction with Xho-I. The hVCAM-1 cDNA fragment was previously subcloned into the pIRES2-EGFP (pIE) (Clontech; Palo Alto, CA) multiple cloning site (MCS) at the Xho-I specific restriction site. The entire MCS of pIRES2-EGFP was then subcloned into the Nco-I site of pTRACER-EF/Bsd-A (pTa). The pIE MCS fragment was first circularized and then cut with Eco-RI. This fragment was then inserted into the pTa MCS Eco-R1 restriction site. The hVCAM-1 cDNA was transferred from the pIRES-EGFP-hVCAM-1 plasmid to the pTRACER-EF/Bsd-A-pIE-MCS plasmid via flanking Nhe-I (5') and Sma-I (3') restriction sites. Appropriate orientation was confirmed by subsequent restriction analysis. S-10pTlacZ or S-10pTaV transfected cells that demonstrated blasticidin resistance at $25 \mu \mathrm{g} / \mathrm{ml}$ were used to isolate approximately 50 clones by limiting dilution.

\section{$\beta$-galactosidase assay}

In situ $\beta$-gal staining assay was performed as outlined in the Life Technologies (Promega) "Guide to Eukaryotic Transfections with Cationic Lipid Reagents" booklet (http://www.lifetech.com/searchaction2.cfm?cfid=408984\&cftoken=44455543) Briefly, cells were fixed in 1X Dulbecco's PBS (D-PBS) containing $2 \%$ formaldehyde and $0.05 \%$ glutaraldehyde for 5 minutes, rinsed twice with $1 \mathrm{X}$ D-PBS, then stained overnight at $37^{\circ} \mathrm{C}$ in staining solution. Staining solution consisted of $1 \mathrm{X}$ D-PBS with $5 \mathrm{mM}$ potassium ferricyanide, $5 \mathrm{mM}$ potassium ferrocyanide, $2 \mathrm{mM} \mathrm{MgCl}$, and $1 \mathrm{mg} / \mathrm{ml}$ of X-gal (Promega; Madison, WI). Cells were then rinsed in D-PBS and qualitatively evaluated for $\beta$-gal staining. Cloned lines were scored from one to five based both on pace of 
color development and final color intensity. The two clones scoring the highest in $\beta$-gal expression were primarily used in the current study and are designated C5 and C54.

\section{Flow cytometry}

Confluent stromal cell monolayers were harvested by trypsinization. Each $55 \mathrm{~cm}^{2}$ plate was divided into two samples for VCAM-1 and matched isotype antibody staining. Samples were rinsed in $1 \mathrm{X}$ PBS/3\% BSA, centrifuged and resuspended with $1 \mu \mathrm{g}$ of mouse $\lg G_{1} \alpha$-human VCAM-1 (PharMingen; San Diego, CA) or rat $\lg \mathrm{G}_{\mathrm{a}} \alpha$-mouse VCAM-1 (PharMingen) in $200 \mu \mathrm{L}$ of $1 \mathrm{X} \mathrm{PBS} / 3 \%$ BSA. Matched isotype controls included nonimmune mouse IgG1 (Southern Biotechnology Associates, Inc.; Birmingham, AL) and rat IgG2a antibodies (PharMingen). Goat $\alpha$-mouse IgG1 - RPE (Southern Biotechnology Associates, Inc.) and goat $\alpha$-rat IgM/lgG - RPE (Southern Biotechnology Associates, Inc.), were used at $1 \mu \mathrm{g} / 200 \mu \mathrm{L}$ of $1 \mathrm{X}$ PBS with $3 \%$ BSA respectively for detection. Flow cytometric analysis was performed using FACScan and CellQuest v. 3.1f software (Becton Dickinson, San Jose, CA).

Enzyme-Linked Immunosorbent Assay (ELISA)

Confluent stromal cell layers were treated with up to $100 \mu \mathrm{M}$ VP-16 for 48 hours in 96well tissue culture dishes (Falcon; Franklin Lakes, NJ). Prior to ELISA assay, all wells were rinsed with isotonic phosphate buffered saline (1X PBS) and fixed for 20 minutes at room temperature in $2 \%$ paraformaldehyde. Cells were rinsed twice with $1 \mathrm{X}$ PBS and then incubated with $100 \mathrm{mM}$ glycine in PBS for 5 minutes. Further rinses were carried out using $1 \mathrm{X}$ PBS/0.05\% tween-20 (Sigma). Cells were rinsed twice and incubated with $0.2 \mu \mathrm{g} / 100 \mu \mathrm{l}$ of primary or isotype matched antibodies at $37^{\circ} \mathrm{C}$ for 1 hour (same antibodies as used for FACS analysis above). Following incubation, cells were 
rinsed five times with 1 X PBS $/ 0.05 \%$ tween-20 and $1 \mu \mathrm{g} / \mathrm{ml}$ of appropriate secondary antibody, sheep $\alpha$ mouse IgG - HRP (Amersham Pharmacia Biotech; Piscataway, NJ) or goat $\alpha$ rat IgG - HRP (Southern Biotechnology Associates, Inc.) was added. After 1 hour, cells were again rinsed five times and colorometric quantitation was carried out using the TMB Microwell Peroxidase Substrate System following the manufacturer's recommendation (Kirkegaard \& Perry Laboratories; Gaithersburg, MD). Wells were read at $450 \mathrm{~nm}$ using a $\mu$ Quant Universal Microplate Spectrophotometer (Bio-Tek Instruments, Inc.; Winooski, VT). The two clones scoring the highest in human VCAM-1 expression were primarily used in the current study and are designated V31 and V49.

\section{Coculture of pro-B cells on C54 and V49 stromal cells}

Four wells each of C54 and V49 were approximately $80 \%$ confluent at day 0 when $2 \times 10^{5} \mathrm{C} 1.92$ cells in $1 \mathrm{ml}$ of medium containing $25 \mathrm{U} / \mathrm{ml}$ recombinant mouse IL-7 (rlL-7) was added to each well. Established cocultures were harvested with trypsin after 1,2 , and 3 days of incubation. At day 2 , additional IL-7 in $1 \mathrm{ml}$ was added to each of the day 3 wells. C1.92 cells were counted based on easily distinguishable morphological differences. Viability was determined by trypan blue exclusion.

For analysis of C1.92 on C54 or V49 in the absence of the exogenous growth factor rlL-7, the experiments described above were repeated in medium alone. C1.92 cells were collected and rinsed at day 0 and resuspended in medium without rIL-7 prior to starting assays.

\section{Chemotherapeutic agents}

VP-16 (Sigma) was mixed at a stock concentration of $20 \mathrm{mg} / \mathrm{ml}(100 \mathrm{mg}$ VP-16, $650 \mathrm{mg}$ polyethylene glycol 300, $80 \mathrm{mg}$ Tween 80 (ultra pure), 30.5\% ethanol, $2 \mathrm{mg}$ citric 
acid, 30mg benzyl alcohol) and diluted to $100 \mu \mathrm{M}$ in culture medium immediately prior to

use. We have previously determined that matched vehicle doses do not impact on murine or human VCAM-1 surface expression (data not shown). $100 \mu \mathrm{M}$ VP-16 was chosen to approximate serum levels reported for patients on high dose therapy (24). VP-16 stock solutions were stored at $-80^{\circ} \mathrm{C}$ and diluted immediately prior to use.

\section{RNA isolation}

Total RNA was isolated from untreated confluent stromal cells using the S.N.A.P. Total RNA Isolation kit following the recommendation of the manufacturer (Invitrogen; Carlsbad, CA). Pelleted stromal cells were lysed by centrifugation through QIAshredder Spin Columns (QIAGEN Inc.; Santa Clarita, CA). RNA was DNase treated and quantitated at 260nm (GENESYS-10uv; Spectronic Unicam; Rochester, NY).

\section{Reverse Transcriptase - Polymerase Chain Reaction (RT-PCR)}

To evaluate human VCAM-1 and murine VCAM-1 RNA levels, "One-Step" RT-PCR (Qiagen Inc.; Valencia, CA) was completed using RNA isolated from untreated or VP-16 treated stromal cells. Murine specific VCAM-1 primers were: 5'-CAA CGA TCT CTG TAC ATC CC-3' and 5'-AGA GGC TGT ACA CTC TGC CT-3' (Stratagene; La Jolla, CA). Primers were used at $0.08 \mu \mathrm{g} /$ reaction to generate an amplicon of 839 base pairs (25). Human specific VCAM-1 primers were: 5'-CAT CCA CAA AGC TGC AAG AA-3' and 5'-GCC ACC ACT CAT CTC GAT TT-3' (Stratagene; La Jolla, CA). Human VCAM1 specific primers were used at $0.08 \mu \mathrm{g} /$ reaction to generate an amplicon of 563 base pairs (26). Reverse transcription (RT) was completed at $50^{\circ} \mathrm{C}$ for $30 \mathrm{~min}$ followed by an RT deactivation cycle at $95^{\circ} \mathrm{C}$ for $15 \mathrm{~min}$. PCR amplification consisted of 30 cycles at $94^{\circ}-30 \mathrm{sec}, 55^{\circ}-1 \mathrm{~min} / 15 \mathrm{sec}, 72^{\circ}-2 \mathrm{~min} / 15 \mathrm{sec}$ (Perkin-Elmer GeneAmp PCR System 
9600). Samples included $0.1 \mu \mathrm{g}$ of total RNA isolated from treated and untreated stromal cells as indicated above. As a negative control, samples that lacked RNA were included in all experiments.

\section{Chemotaxis assay}

Migration of the CXCR-4 $4^{+}$cell line C1.92 toward medium alone or toward SDF-1 across stromal cell layers of C54 or V49 was determined using $5 \mu \mathrm{m}$ pore $/ 6.5 \mathrm{~mm}$ diameter tissue culture treated transwells (Corning, Inc.; Corning, NY). Stromal cell layers were grown overnight on the transwell membranes to approximately $80 \%$ confluence. Stromal cells were rinsed with fresh medium and $350 \mu$ of Iscove's medium was placed in the bottom of each well. Stromal cells on transwell membranes were placed into each well and $1.5 \times 10^{5} \mathrm{CXCR}-4^{+} \mathrm{C} 1.92$ cells in $150 \mu$ I Iscove's medium were placed in the top chamber. C1.92 chemotaxis toward medium alone, $10 \mathrm{ng} / \mathrm{ml}$ or $100 \mathrm{ng} / \mathrm{ml}$ of recombinant human SDF-1 was measured. Transwells were incubated at $37^{\circ} \mathrm{C}$ for 3.0 hours. Cells migrating to the lower chamber were enumerated. C1.92 chemotaxis was determined as percent of total input cell number. Control samples included medium only in the lower chamber to evaluate spontaneous migration, and SDF-1 gradient wells containing $100 \mathrm{ng} / \mathrm{ml}$ recombinant human SDF-1 (rSDF-1) in the lower chamber. Control wells were evaluated both in the presence and absence of stromal cell transwell layers.

\section{Binding assay}

Pro-B cell binding to stromal cells on transwell filters was evaluated following completion of chemotaxis evaluation. Transwells, following completion of chemotaxis assays, were rinsed three times with fresh medium and then trypsinized to determine 
the percentage of bound $\mathrm{C} 1.92$ cells to the stromal cell/membrane layers. Control samples included medium only in the lower chamber to evaluate spontaneous migration, and SDF-1 gradient wells included up to $100 \mathrm{ng} / \mathrm{ml}$ recombinant human SDF1 (rSDF-1) in the lower chamber.

\section{Statistical analysis}

Statistical analysis was performed using One Way Analysis of Variance and Tukey Test to detect differences among means (SigmaStat Version 2.0 software, SPSS Inc.; Chicago, IL). All statistical comparisons represent treated samples as compared to control levels, or comparison of C54 to V49 stromal cells where specifically indicated.

\section{RESULTS}

Stable transfection of murine S-10 stromal cells with human VCAM-1 and $\beta$ galactosidase.

The S-10 murine stromal cell line was transfected with either pTaV or pTlacZ (see materials and methods). S-10pTlacZ $\left(\beta-\right.$ gal $\left.{ }^{+}\right)$lines were designated "C" (for vector Control line) followed by a corresponding clone number (e.g. C3, C5, C17, C27, C43, $\mathrm{C} 48, \mathrm{C} 54, \mathrm{C} 64$, and $\mathrm{C} 73)$. Nine $\beta$-gal ${ }^{+}$control cell lines were qualitatively graded for the kinetics and intensity of in situ $\beta$-gal staining (Table 1). C5 and C54 demonstrated the highest relative $\beta$-gal expression compared to other clones.

S-10pTaV (hVCAM-1 $1^{+}$) lines were designated "V" (for human VCAM-1 line) followed by a corresponding clone number (e.g. V13, V18, V31 and V49). V13 demonstrated a transformed phenotype suggested by loss of growth contact inhibition 
and was not used in further studies. The remaining three lines, V18, V31 and V49, maintained an S-10 phenotype with contact inhibition and expressed human VCAM-1 protein determined by FACS analysis (Figure 2a-c). The negative controls, vector control cell lines C5 and C54, were both found to be negative for human VCAM-1 expression (Figure 2d-e). C54 and V49 were predominately used in further experiments as they express the highest levels of $\beta$-galactosidase and human VCAM-1 respectively, and had similar surface levels of endogenous murine VCAM-1 (Figure 3a-b).

Control cell lines, C5 and C54, and hVCAM-1+ ${ }^{+}$cell lines, V18 and V49, were evaluated for expression of human and murine VCAM-1 message. Primary human stromal cell lines P160 and Ped300 as well as primary Balb/c murine stromal cells (parental strain of S-10) were included as human and murine control cell lines. All murine lines expressed mVCAM-1 message and only human control and hVCAM-1 ${ }^{+}$ murine lines expressed hVCAM-1 RNA (Figure 4).

C54 and V49 support expansion and survival of the stromal cell-dependent pro-B cell clone, C1.92 equally.

The $\beta-\mathrm{gal}^{+}$control cell line C54 and the human VCAM-1 ${ }^{+}$line V49 were compared for their ability to support pro-B cell expansion and survival. No statistical difference in the ability of C54 or V49 to support C1.92 survival ( $>95 \%$ at each time

point) or expansion ( $2 \times 10^{5}$ to $>5 \times 10^{6}$ by day three) was observed at any time point (Figure 5).

Chemotaxis across C54 stromal cell layers is elevated compared to V49 
In vitro chemotaxis of C1.92 was compared between stromal cell layers of C54 and V49 (see materials and methods). After three hours, chemotaxis across C54/membrane transwells was $11.2 \%, 13.8 \%$, and $20.2 \%$ toward medium, $10 \mathrm{ng} / \mathrm{ml}$, and 100ng/ml rSDF-1 respectively (Figure 6a). Chemotaxis across V49 stromal cell transwells was significantly lower at $1.4 \%, 4.5 \%$, and $18.2 \%$ toward medium and 10ng/ml rSDF-1 (Figure 6b). Controls included, C1.92 chemotaxis towards $100 \mathrm{ng} / \mathrm{ml}$ SDF-1 which was $53.04 \pm 5.45 \%$. Consistent with previous experiments, chemotaxis of C1.92 in the absence of SDF-1 was negligible unless stromal cell layers were present.

\section{C1.92 binding to V49 stromal cells is enhanced compared to the C54 vector control line.}

To determine whether differences in C1.92 adhesion to C54 and V49 exist, binding assays were performed (see materials and methods). Following chemotaxis assays, the transwell membranes were harvested and the number of stromal cell bound C1.92 cells measured. The percentage of $\mathrm{C} 1.92$ bound to the membrane/C54 was $16.2 \%$ and $7.0 \%$ in the medium and $100 \mathrm{ng} / \mathrm{ml}$ wells respectively, while $46.0 \%$ and $31.8 \%$ were observed in membrane/V49 wells (Figure $6 \mathrm{~b}$ ). Less than $1 \%$ of the pro-B cells were associated with the membrane in matched transwells lacking stromal cell layers.

Human VCAM-1 protein expression is maintained on V49 following exposure to $100 \mu M$ VP-16. 
Reduced VCAM-1 protein and no changes in fibronectin protein were observed when stromal cell lines C54 and V49 were exposed to VP-16 for up to 48 hours (Figure 7a). Additionally, human and murine VCAM-1 protein levels on C54 and V49 following exposure to $50 \mu \mathrm{M}$ and $100 \mu \mathrm{M}$ VP-16 were evaluated. Endogenous murine VCAM-1 protein decreased on both C5 and V49 cells following treatment, but human VCAM-1 protein was maintained on V49 following exposure (Figure 7b).

\section{V49 supports enhanced survival of the stromal cell and IL-7 dependent pro-B cell clone C1.92 in the absence of exogenous growth factor.}

No expansion of C1.92 cells was observed when cocultured with V49 in the absence of exogenous rlL-7. However, coculture with V49 stromal cells resulted in significantly higher maintenance of $\mathrm{C} 1.92$ viability compared to C54 cell cocultures (Figure 8). C1.92 cell viability on V49 at day 3 was $90.5 \%$ while $\mathrm{C} 1.92$ viability on C54 at day 3 was only $65.4 \%(P<0.001)$. Matched controls containing rlL-7 had $\mathrm{C} 1.92$ viabilities of $98.9 \%$ on V49 and $98.1 \%$ on C54 at day 3 . Unlike cocultures in the absence of rIL-7, those with added rIL-7 expanded significantly (Figures 5 and 8).

\section{DISCUSSION}

We have generated and characterized murine marrow stromal cell lines that constitutively express human VCAM-1 or $\beta$-galactosidase protein. These lines were derived from the previously characterized parental cell line S-10 (22). Both $\beta$ galactosidase and hVCAM-1 lines sustain vector specific gene expression for greater

than 6 months in culture in the absence of selective media (Figures 2 and 4), maintain 
marrow stromal cell phenotype including contact growth inhibition, and exhibit similar functional capacities in the support of the stromal cell dependent progenitor cell line C1.92 (Figure 5). Additionally, human VCAM-1 expressing lines demonstrated increased progenitor cell binding capacity (Figure 6b) and supported enhanced viability of pro-B cells in the absence of exogenous IL-7 (Figure 8).

Previously, Gibson, et al. has shown that human stromal cell VCAM-1 protein is diminished following exposure to $100 \mu \mathrm{M}$ VP-16 (18). In that study, no changes in another adhesion molecule, fibronectin, were observed (18). In additional studies, we demonstrated that down regulation of bone marrow stromal cell VCAM-1 protein correlated with VP-16 induced loss of NF-kB nuclear localization and reduced VCAM-1 gene expression (19). These data underlie the hypothesis that maintenance of VCAM-1 gene expression and protein levels could be maintained in cell lines expressing the VCAM-1 gene from a constitutive promoter that was not regulated by NF-kB. We now show that stromal cell lines that constitutively express hVCAM-1, from a non-NF-kB specific promoter, maintain baseline levels of protein expression following exposure to VP-16 (Figure 7b). Interestingly, high levels of VCAM-1 availability delayed the onset of apoptosis of the proB cell clone $\mathrm{C} 1.92$ in coculture in the absence of exogenous rlL-7 (Figure 8).

In the correct microenvironment, these cell lines may lead to new treatment strategies involving ablative chemotherapy and bone marrow transplantation. As chemotherapy doses escalate to achieve maximal tumor cell death, stromal cell damage is expected $(8 ; 27-31)$. Several recent studies have demonstrated that coinfusion or replacement of damaged cells with healthy stromal cells in conjunction with 
hematopoietic cells leads to enhanced hematopoietic recoveries following bone marrow transplantation $(32 ; 33)$. In the context of stromal cell replacement following ablative chemotherapy, stromal cells engineered to express specific hematopoietic growth factors or adhesion molecules may enhance stem cell maintenance and engraftment if established in correct microenvironments. Additionally, healthy stromal cells may enrich hematopoietic stem and progenitor cell homing, and restore robust B-cell development. As such, VCAM-1 engineered stromal cell lines may prove useful in therapeutic procedures during high-dose chemotherapy treatment strategies for advanced metastatic cancers.

Although there have been several studies that suggest higher levels of stromal cell VCAM-1 in concert with other stromal cell factors such as SCF and IL-6 correlate with enhanced support of hematopoiesis, upregulated VCAM-1 alone has not been evaluated $(17 ; 34)$. Other studies have demonstrated that diminished stromal cell VCAM-1 protein or blocking antibodies to VCAM-1 are associated with decreased stromal cell support of hematopoiesis and stem cell homing $(8 ; 11 ; 35-37)$. Unlike models of diminished VCAM-1 availability or enhanced VCAM-1 in conjunction with other stromal cell derived factors, our stromal cell lines will allow us to characterize the individual impact of enhanced stromal cell VCAM-1 in hematopoiesis and stem cell homing in vitro. These studies will establish a foundation for investigating the therapeutic potential of enhanced bone marrow VCAM-1 expression preceding bone marrow transplantation.

Furthermore, human VCAM-1 expressing murine stromal cell lines will enable us to determine the specific impact that reductions in VCAM-1 protein on chemotherapy 
pretreated stromal cells has on the ability of these lines to efficiently support hematopoiesis. Additionally, these cell lines may prove useful in assessment of immune system recognition of these lines in vivo (murine models) in the context of xenoprotein expression viability (i.e. hVCAM-1) in host murine derived cells lines. In contrast to enhanced hematopoietic recovery, evaluation of enhanced stromal cell VCAM-1 expression and its contribution to protection of leukemia cells in the bone marrow can now be further explored as well $(38 ; 39)$. 


\section{REFERENCES}

1. McGinnes,K., Quesniaux,V., Hitzler,J., and Paige,C. (1991): Human Blymphopoiesis is supported by bone marrow-derived stromal cells. Exp.Hematol., 19:294-303.

2. Sudo,T., Ito,M., Ogawa,Y., lizuka,M., Kodama,H., Kunisada,T., Hayashi,S., Ogawa,M., Sakai,K., and Nishikawa,S. (1989): Interleukin 7 production and function in stromal cell-dependent B cell development. J Exp.Med., 170:333-338.

3. Borghesi,L.A., Smithson,G., and Kincade,P.W. (1997): Stromal cell modulation of negative regulatory signals that influence apoptosis and proliferation of $B$ lineage lymphocytes. J Immunol., 159:4171-4179.

4. Dexter,T.M. (1982): Stromal cell associated haemopoiesis. J Cell Physiol Suppl, $1: 87-94$.

5. Ryan,D.H., Nuccie,B.L., Abboud,C.N., and Liesveld,J.L. (1990): Maturationdependent adhesion of human $B$ cell precursors to the bone marrow microenvironment. J Immunol., 145:477-484.

6. Ryan,D.H., Nuccie,B.L., Abboud,C.N., and Winslow,J.M. (1991): Vascular cell adhesion molecule-1 and the integrin VLA-4 mediate adhesion of human B cell precursors to cultured bone marrow adherent cells. J Clin.Invest, 88:995-1004.

7. Murti,K.G., Brown,P.S., Kumagai,M., and Campana,D. (1996): Molecular interactions between human B-cell progenitors and the bone marrow microenvironment. Exp.Cell Res., 226:47-58.

8. Dittel,B.N. and LeBien,T.W. (1995): Reduced expression of vascular cell adhesion molecule-1 on bone marrow stromal cells isolated from marrow transplant recipients correlates with a reduced capacity to support human B lymphopoiesis in vitro. Blood, 86:2833-2841.

9. Miyake,K., Medina,K., Ishihara,K., Kimoto,M., Auerbach,R., and Kincade,P.W. (1991): A VCAM-like adhesion molecule on murine bone marrow stromal cells mediates binding of lymphocyte precursors in culture. J Cell Biol., 114:557-565. 
10. Funk,P.E., Kincade,P.W., and Witte,P.L. (1994): Native associations of early hematopoietic stem cells and stromal cells isolated in bone marrow cell aggregates. Blood, 83:361-369.

11.Papayannopoulou,T. and Nakamoto,B. (1993): Peripheralization of hemopoietic progenitors in primates treated with anti-VLA4 integrin. Proc.Natl.Acad.Sci.U.S.A, 90:9374-9378.

12. Jacobsen,K., Kravitz,J., Kincade,P.W., and Osmond,D.G. (1996): Adhesion receptors on bone marrow stromal cells: in vivo expression of vascular cell adhesion molecule- 1 by reticular cells and sinusoidal endothelium in normal and gammairradiated mice. Blood, 87:73-82.

13. Oostendorp,R.A., Reisbach,G., Spitzer,E., Thalmeier,K., Dienemann,H., Mergenthaler,H.G., and Dormer,P. (1995): VLA-4 and VCAM-1 are the principal adhesion molecules involved in the interaction between blast colony-forming cells and bone marrow stromal cells. Br.J Haematol., 91:275-284.

14.Wang,M.W., Consoli,U., Lane,C.M., Durett,A., Lauppe,M.J., Champlin,R., Andreeff,M., and Deisseroth,A.B. (1998): Rescue from apoptosis in early (CD34selected) versus late (non-CD34- selected) human hematopoietic cells by very late antig. Cell Growth Differ., 9:105-112.

15. Simmons,P.J., Masinovsky,B., Longenecker,B.M., Berenson,R., Torok-Storb,B., and Gallatin,W.M. (1992): Vascular cell adhesion molecule-1 expressed by bone marrow stromal cells mediates the binding of hematopoietic progenitor cells. Blood, 80:388395.

16. Arroyo,A.G., Yang,J.T., Rayburn,H., and Hynes,R.O. (1999): Alpha4 integrins regulate the proliferation/differentiation balance of multilineage hematopoietic progenitors in vivo. Immunity., 11:555-566.

17. Dittel,B.N., McCarthy,J.B., Wayner,E.A., and LeBien,T.W. (1993): Regulation of human B-cell precursor adhesion to bone marrow stromal cells by cytokines that exert opposing effects on the expression of vascular cell adhesion molecule-1 (VCAM-1). Blood, 81:2272-2282.

18. Gibson,L.F., Fortney,J., Landreth,K.S., Piktel,D., Ericson,S.G., and Lynch,J.P. (1997): Disruption of bone marrow stromal cell function by etoposide. Biol.Blood Marrow Transplant., 3:122-132. 
19. Hall,B.M., Fortney,J.E., and Gibson,L.F. (2001): Alteration of nuclear factor-kappaB (NF-kappaB) expression in bone marrow stromal cells treated with etoposide. Biochem.Pharmacol., 61:1243-1252.

20.Lum,L.G. (1987): The kinetics of immune reconstitution after human marrow transplantation. Blood, 69:369-380.

21. Kagan,J.M., Champlin,R.E., and Saxon,A. (1989): B-cell dysfunction following human bone marrow transplantation: functional-phenotypic dissociation in the early posttransplant period. Blood, 74:777-785.

22. Collins,L.S. and Dorshkind,K. (1987): A stromal cell line from myeloid long-term bone marrow cultures can support myelopoiesis and B lymphopoiesis. $J$ Immunol., 138:1082-1087.

23. Gibson,L.F., Piktel,D., and Landreth,K.S. (1993): Insulin-like growth factor-1 potentiates expansion of interleukin-7- dependent pro-B cells. Blood, 82:3005-3011.

24. Herzig,R.H., Lynch,J., Christiansen,N.P., Fay,J.W., Davis,M.P., and Herzig,G.P. (1996): Dose-intensive chemotherapy with etoposide-cyclophosphamide for advanced breast cancer. North American Marrow Transplant Group. Semin.Oncol., 23:28-32.

25. Bowen,J.A. and Hunt,J.S. (1999): Expression of cell adhesion molecules in murine placentas and a placental cell line. Biol.Reprod., 60:428-434.

26. Pietersma,A., Tilly,B.C., Gaestel,M., de Jong,N., Lee,J.C., Koster,J.F., and Sluiter,W. (1997): p38 mitogen activated protein kinase regulates endothelial VCAM1 expression at the post-transcriptional level. Biochem.Biophys.Res.Commun., 230:44-48.

27. Galotto,M., Berisso,G., Delfino,L., Podesta,M., Ottaggio,L., Dallorso,S., Dufour,C., Ferrara,G.B., Abbondandolo,A., Dini,G., Bacigalupo,A., Cancedda,R., and Quarto,R. (1999): Stromal damage as consequence of high-dose chemo/radiotherapy in bone marrow transplant recipients. Exp.Hematol., 27:1460-1466.

28. Schwartz,G.N., Warren,M.K., Rothwell,S.W., Zujewski,J., Halverson,D.C., Cowan,K.H., Tolcher,A., O'Shaughnessy,J., and Gress,R.E. (1998): Postchemotherapy and cytokine pretreated marrow stromal cell layers suppress 
hematopoiesis from normal donor CD34+ cells. Bone Marrow Transplant., 22:457468.

29. Fried,W. and Barone,J. (1980): Residual marrow damage following therapy with cyclophosphamide. Exp.Hematol., 8:610-614.

30. Gardner,R.V. (1999): Long term hematopoietic damage after chemotherapy and cytokine. Front Biosci., 4:e47-e57

31. Migliaccio,A.R., Migliaccio,G., Johnson,G., Adamson,J.W., and Torok-Storb,B. (1990): Comparative analysis of hematopoietic growth factors released by stromal cells from normal donors or transplanted patients. Blood, 75:305-312.

32. Koc,O.N., Gerson,S.L., Cooper,B.W., Dyhouse,S.M., Haynesworth,S.E., Caplan,A.I., and Lazarus,H.M. (2000): Rapid hematopoietic recovery after co-infusion of autologous-blood stem cells and culture-expanded marrow mesenchymal stem cells in advanced breast cancer patients receiving high-dose chemotherapy. $J$ Clin.Oncol., 18:307-316.

33. Janczewska,S., Ziolkowska,A., Durlik,M., Cybulska,E., Olszewski,W.L., and Lukomska,B. (1999): Requirement of stromal cells in the bone marrow transplant for rapid lymphoid replenishment. Transplant.Proc., 31:696-699.

34. Yanai,N. and Obinata,M. (2001): Oncostatin $\mathrm{m}$ regulates mesenchymal cell differentiation and enhances hematopoietic supportive activity of bone marrow stromal cell lines. In Vitro Cell Dev.Biol.Anim, 37:698-704.

35. Koni,P.A., Joshi,S.K., Temann,U.A., Olson,D., Burkly,L., and Flavell,R.A. (2001): Conditional vascular cell adhesion molecule 1 deletion in mice: impaired lymphocyte migration to bone marrow. J Exp.Med., 193:741-754.

36. Kikuta,T., Shimazaki,C., Ashihara,E., Sudo,Y., Hirai,H., Sumikuma,T., Yamagata,N., Inaba,T., Fujita,N., Kina,T., and Nakagawa,M. (2000): Mobilization of hematopoietic primitive and committed progenitor cells into blood in mice by anti-vascular adhesion molecule-1 antibody alone or in combination with granulocyte colony-stimulating factor. Exp. Hematol., 28:311-317.

37. Levesque,J.P., Takamatsu,Y., Nilsson,S.K., Haylock,D.N., and Simmons,P.J. (2001): Vascular cell adhesion molecule-1 (CD106) is cleaved by neutrophil 
proteases in the bone marrow following hematopoietic progenitor cell mobilization by granulocyte colony-stimulating factor. Blood, 98:1289-1297.

38. Mudry,R.E., Fortney,J.E., York,T., Hall,B.M., and Gibson,L.F. (2000): Stromal cells regulate survival of $B$-lineage leukemic cells during chemotherapy. Blood, 96:19261932.

39. Fortney,J.E., Zhao,W., Wenger,S.L., and Gibson,L.F. (2001): Bone marrow stromal cells regulate caspase 3 activity in leukemic cells during chemotherapy. Leuk.Res., 25:901-907. 


\section{FIGURE LEGENDS}

Table 1. Qualitative expression of $\beta$-galactosidase in vector control cell lines ( $C 3, C 5$, C17, C27, C43, C48, C54, C64, and C73). $\beta$-gal assays were performed as described in the materials and methods. Each cell line was graded from one (lowest) to five (highest) based on both kinetics and final $\beta$-gal blue intensities.

Figure 1. Mammalian expression vector maps. $\beta$-galactosidase control expression vector: pTRACER ${ }^{\text {TM }}$-EF/Bsd-LacZ (pTlacZ) and human-VCAM-1 expression vector: pTRACER $^{\text {TM }}$-EF/Bsd-A-hVCAM-1 (pTaV) [Invitrogen; Carlsbad, CA]

Figure 2. Human VCAM-1 (hVCAM-1) expression on selected $\mathrm{hVCAM}-1^{+}$and $\beta-g \mathrm{l}^{+}$ cell lines. A human VCAM-1 specific monoclonal antibody was used to evaluate hVCAM-1 expression on hVCAM-1 lines (a) V18 (b) V31 (c) V49 and on vector control lines (d) C5 (e) C54. Expression of hVCAM-1 was observed on all hVCAM-1 lines (a-c) while no expression was detected on vector control lines (d-e). Isotype controls in each figure are solid.

Figure 3. Murine VCAM-1 (mVCAM-1) expression on representative cell lines, C54 and V49. A murine VCAM-1 specific monoclonal antibody was used to evaluate mVCAM-1 expression on the (a) $\beta-g \mathrm{gl}^{+}$cell line C54 and (b) the hVCAM-1 ${ }^{+}$cell line V49. Similar levels of murine VCAM-1 was observed on each cell line. 
Figure 4. Human and murine VCAM-1 RNA expression in multiple cell lines. RT-PCR analysis using human or murine specific primers demonstrated that all murine stromal cell lines (Balb/c primary, S-10, C5, C54, V18, and V49) express mVCAM-1 messenger RNA while only human (P160 primary and Ped300 primary) and hVCAM-1 murine cell lines (V18 and V49) express hVCAM-1 messenger RNA. No template (N.T.) lanes represent negative controls without RNA in the RT-PCR sample.

Figure 5. Expansion of the stromal cell-dependent pro-B cell line C1.92 on C54 or V49. Similar stromal cell capacity to support C1.92 expansion or survival (>95\% at each time point, D.N.S.) was observed between the vector control cell line C54 and hVCAM-1 ${ }^{+}$cell line V49. No statistical difference was found at any time point between C54 and V49 cocultures in total $\mathrm{C} 1.92$ cell number. $25 \mathrm{U} / \mathrm{ml}$ of rlL-7 was added to co-cultures at days 0 (all wells) and 2 (day 3 wells only). Data representative of 3 independent experiments.

Figure 6. Pro-B cell clone $\mathrm{C} 1.92$ (a) chemotaxis and (b) binding in modified chemotaxis assays with C54 or V49 established at approximately $80 \%$ confluence on transwell membranes. (a) Percent chemotaxis of C1.92 across C54 or V49 stromal cells grown on $5 \mu \mathrm{m}$ pore membranes. Enhanced migration/passage of $\mathrm{C} 1.92$ across the stromal cell:membrane layers was observed for C54 over V49 after 3 hours, and similar chemotaxis levels were seen when $100 \mathrm{ng} / \mathrm{ml}$ of rSDF-1 was in the lower chamber. (b) Percent of stromal cells bound to the stromal cell:membrane following chemotaxis assay ( 3 hours). After the chemotaxis assay, transwells were rinsed $3 x$ with fresh 
medium, the stromal cell:membranes were removed and all cells trypsin harvested. Increased numbers of $\mathrm{C} 1.92$ were found bound to the V49 over the C54 transwells.

Figure 7. Expression of VCAM-1 and fibronectin protein following exposure to $100 \mu \mathrm{M}$ VP-16. ELISA analysis was used to evaluate (a) mVCAM-1 and fibronectin protein on S-10 after 24 and 48 hours VP-16 exposure and (b) mVCAM-1 and hVCAM-1 protein levels of C54 and V49 following 48 hours of VP-16 treatment. While reductions of mVCAM-1 were observed in each line ((a) S-10, (b) C54 and V49), no reductions of fibronectin ((a) S-10) or hVCAM-1 ((b) V49) were found.

Figure 8. Expansion and survival of the stromal cell-dependent pro-B cell line C1.92 on C54 or V49 in the absence of rlL-7. Stromal cell capacity to support C1.92 survival in the absence of exogenous growth factors was enhanced when cocultured with hVCAM$1^{+}$cell line V49 as compared to C54. [ * - statistically significant from both (-)IL-7 groups $\left(\mathrm{P}=0.001\right.$ "viability" and $\mathrm{P}<0.001$ "viable cell number" $\|^{* *}$ - statistically significant from C54 (-)IL-7 (P=0.018 "viability") \|\|$^{\wedge}$ - statistically significant from both ()IL-7 groups ( $\mathrm{P}<0.001$ "viability" and $\mathrm{P}<0.001$ "viable cell number") \|\|$^{\wedge} \wedge$ - statistically significant from C54 (-)IL-7 ( $\mathrm{P}<0.001$ "viability")] 
Figure 1. Mammalian expression vector maps ( $\beta$-galactosidase and human VCAM-1)

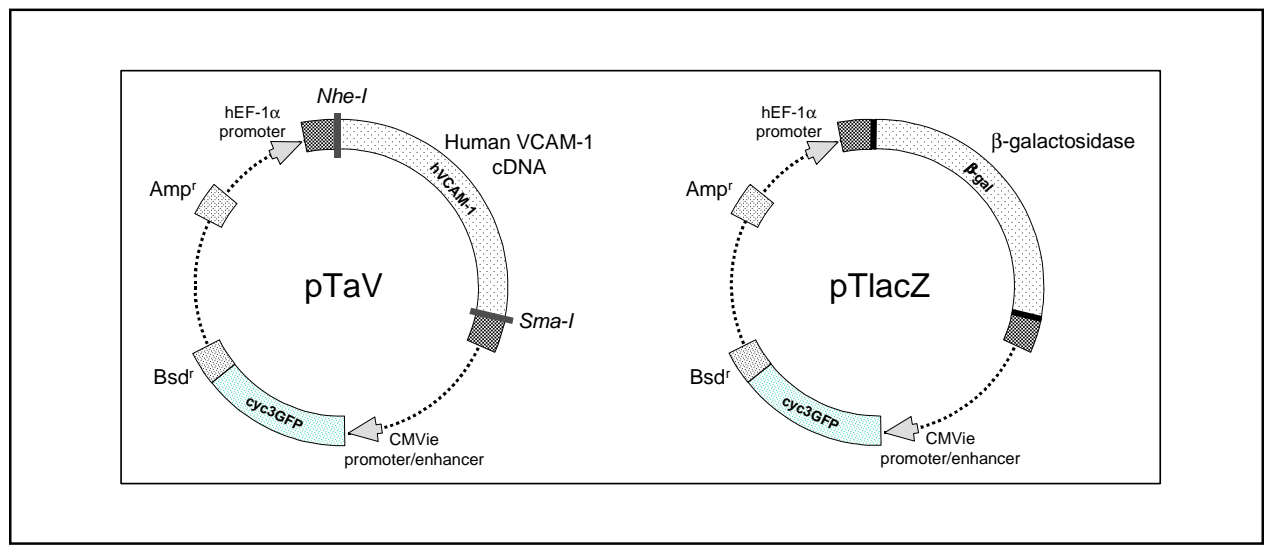


Table 1. Qualitative expression of $\beta$-galactosidase in vector control cell lines (C3, C5, C17, C27, C43, C48, C54, C64, and C73)

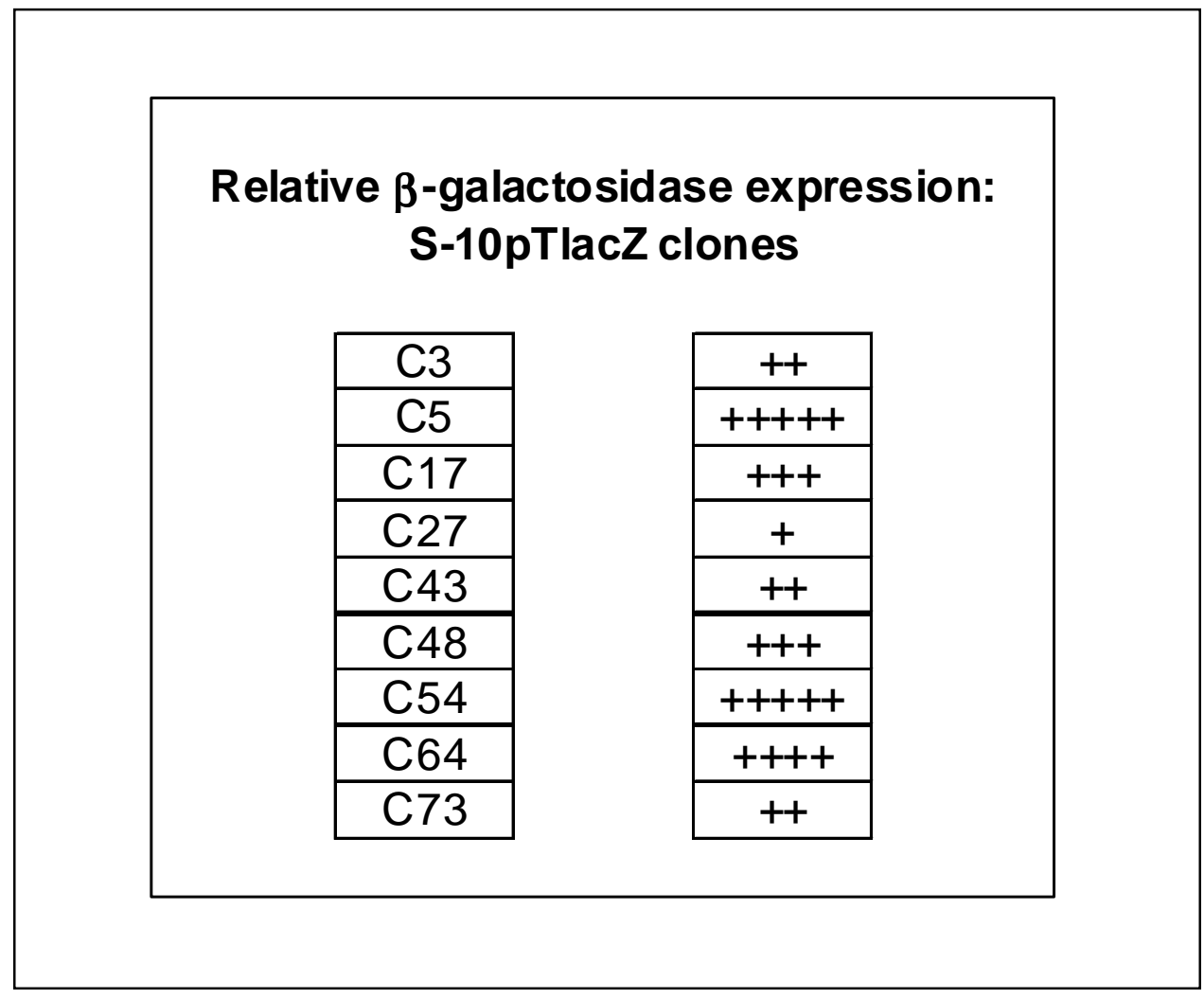


Figure 2. Human VCAM-1 (hVCAM-1) expression on selected hVCAM- $1^{+}$and $\beta-g a l^{+}$cell lines

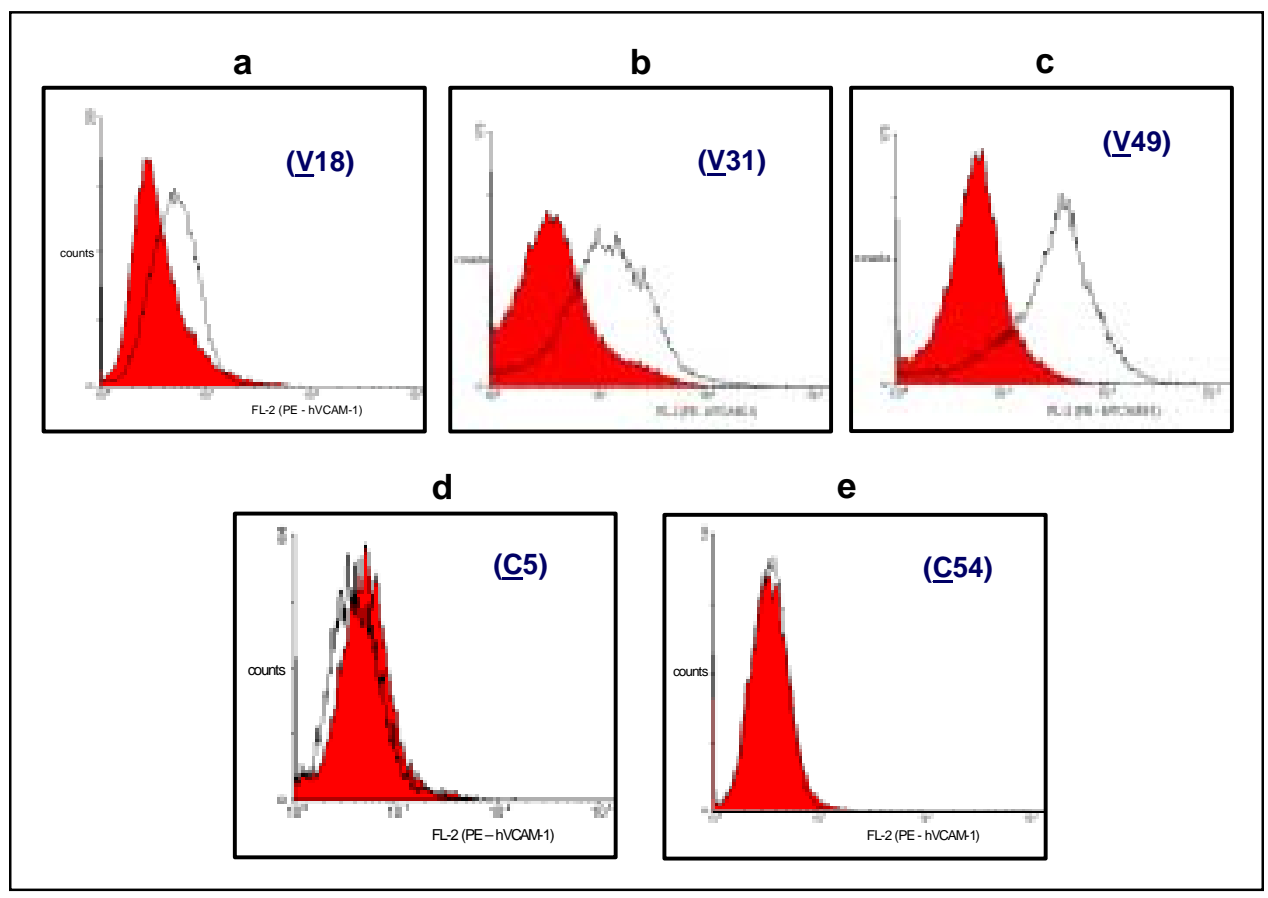


Figure 3. Murine VCAM-1 (mVCAM-1) expression on representative cell lines, C54 and V49

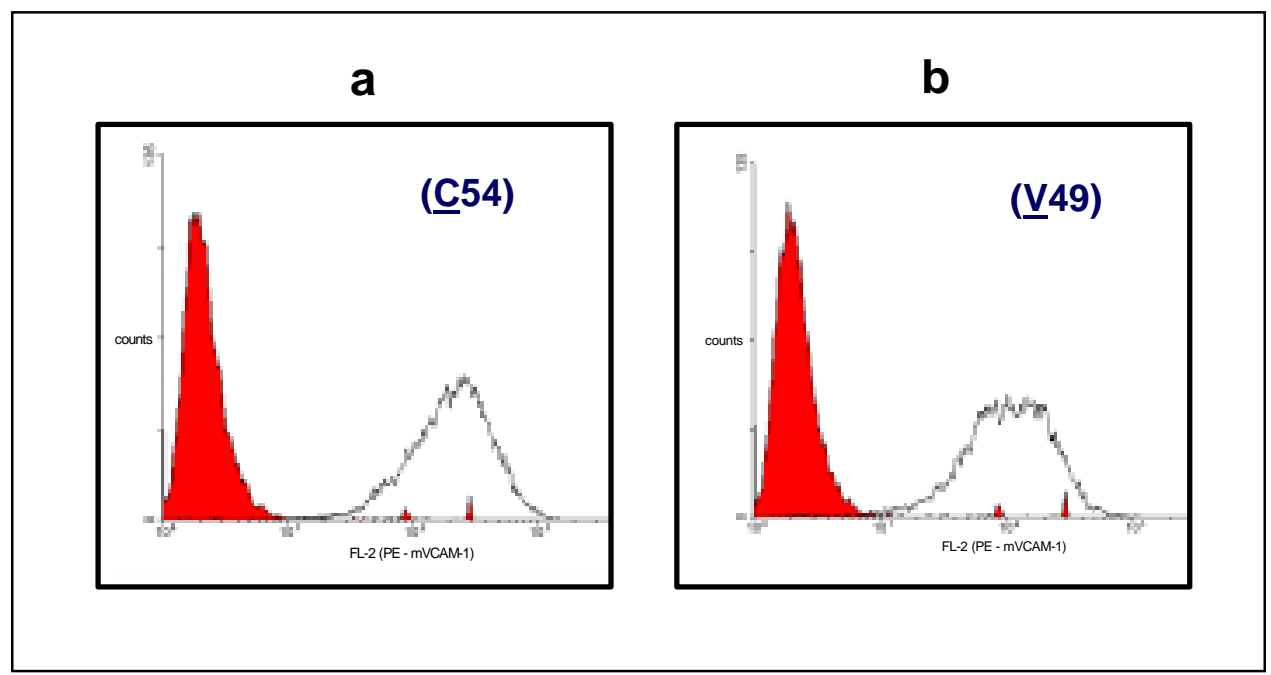


Figure 4. Human and murine VCAM-1 RNA expression in multiple cell lines

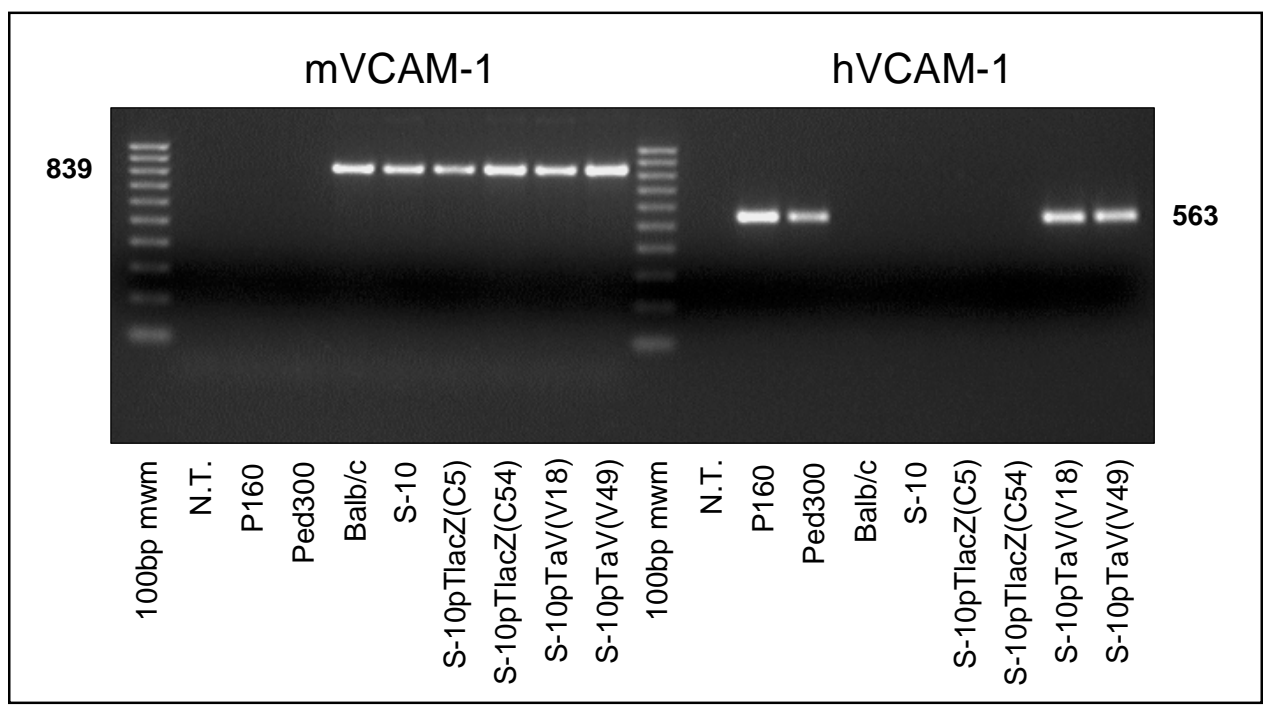


Figure 5. Expansion of the stromal cell-dependent pro-B cell line C1.92 on C54 or V49

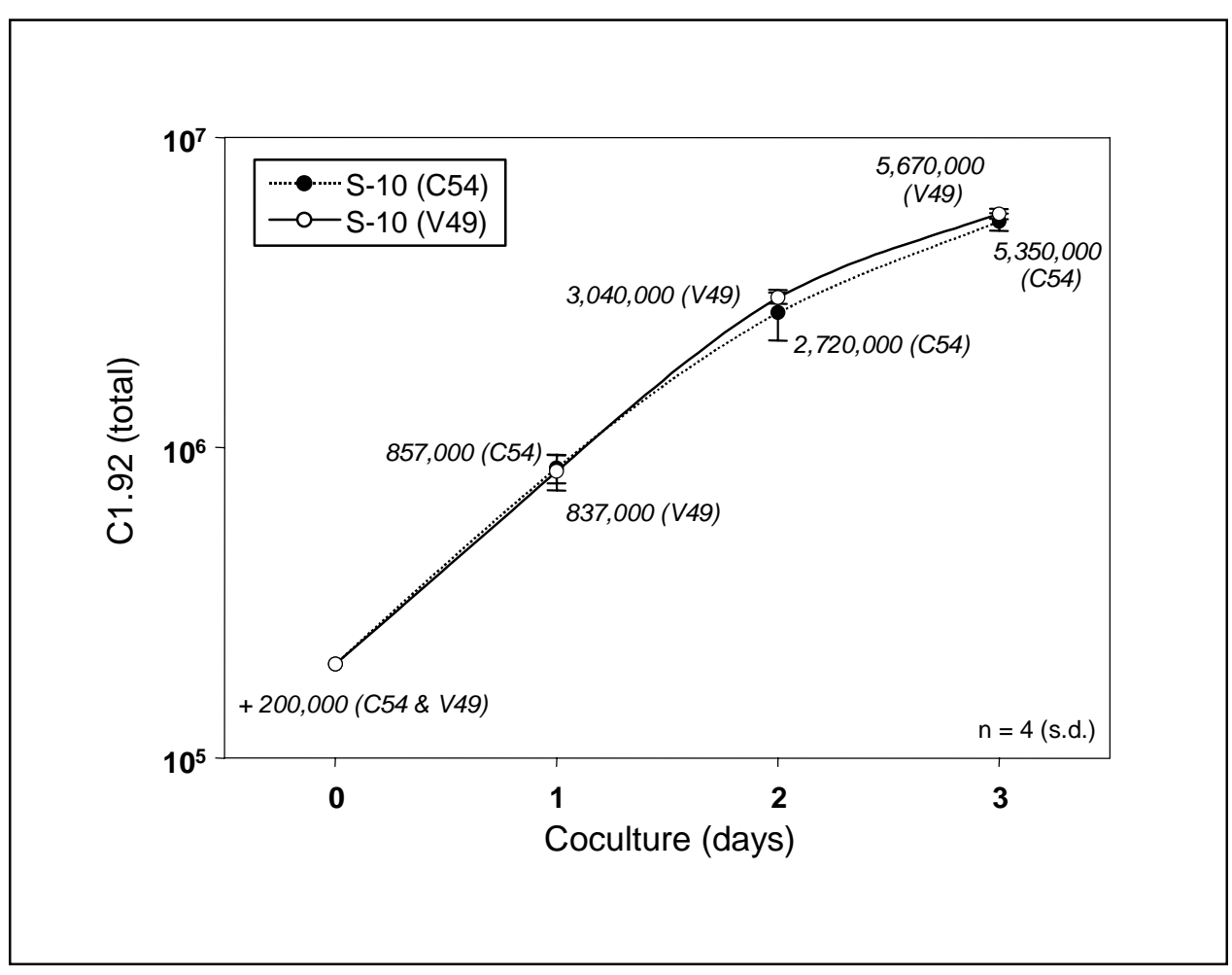


Figure 6. Pro-B cell clone $\mathrm{C} 1.92$ chemotaxis and binding associated with C54 and V49 stromal cell clones

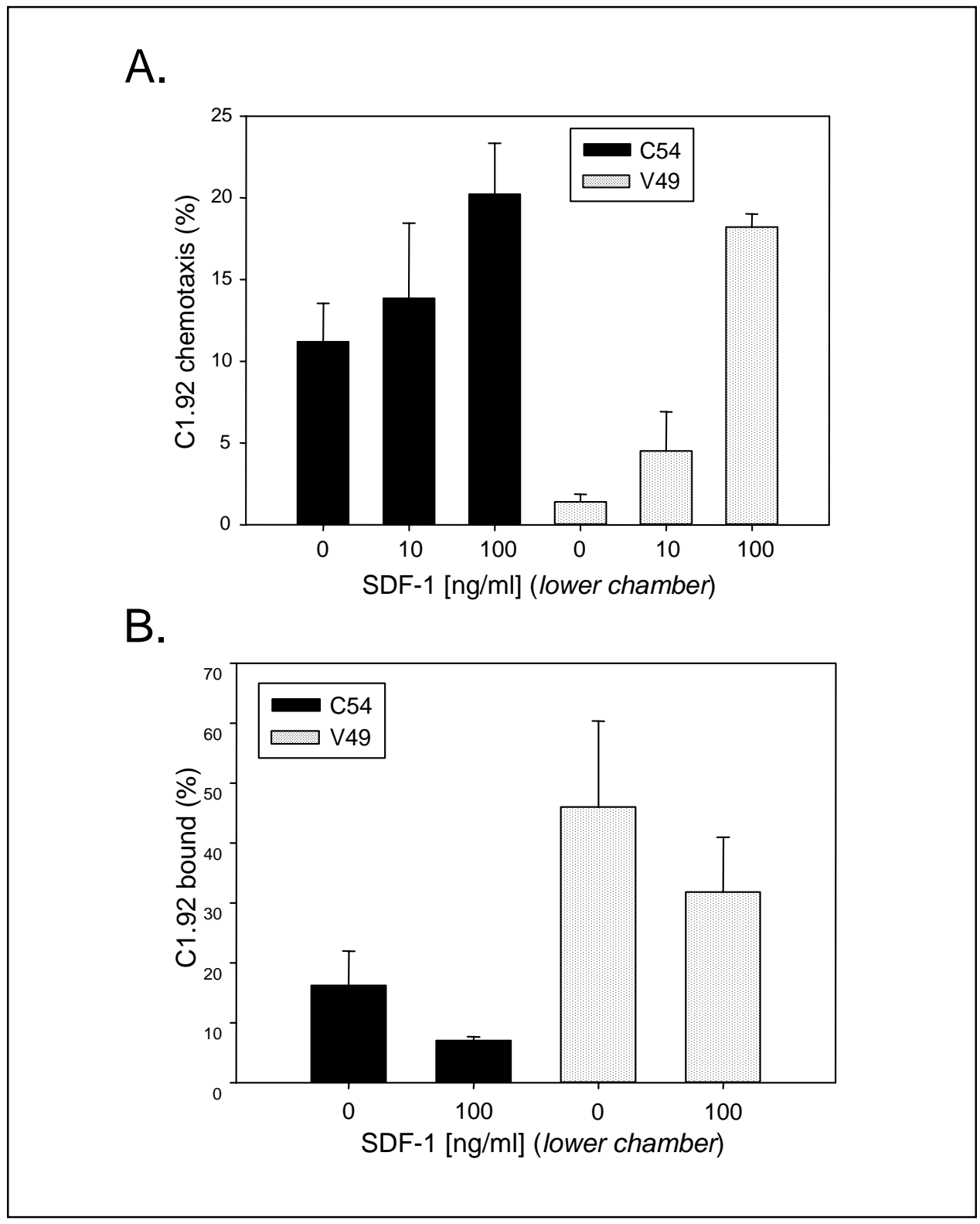


Figure 7. Expression of VCAM-1 and fibronectin protein following exposure to $100 \mu \mathrm{M}$ VP-16

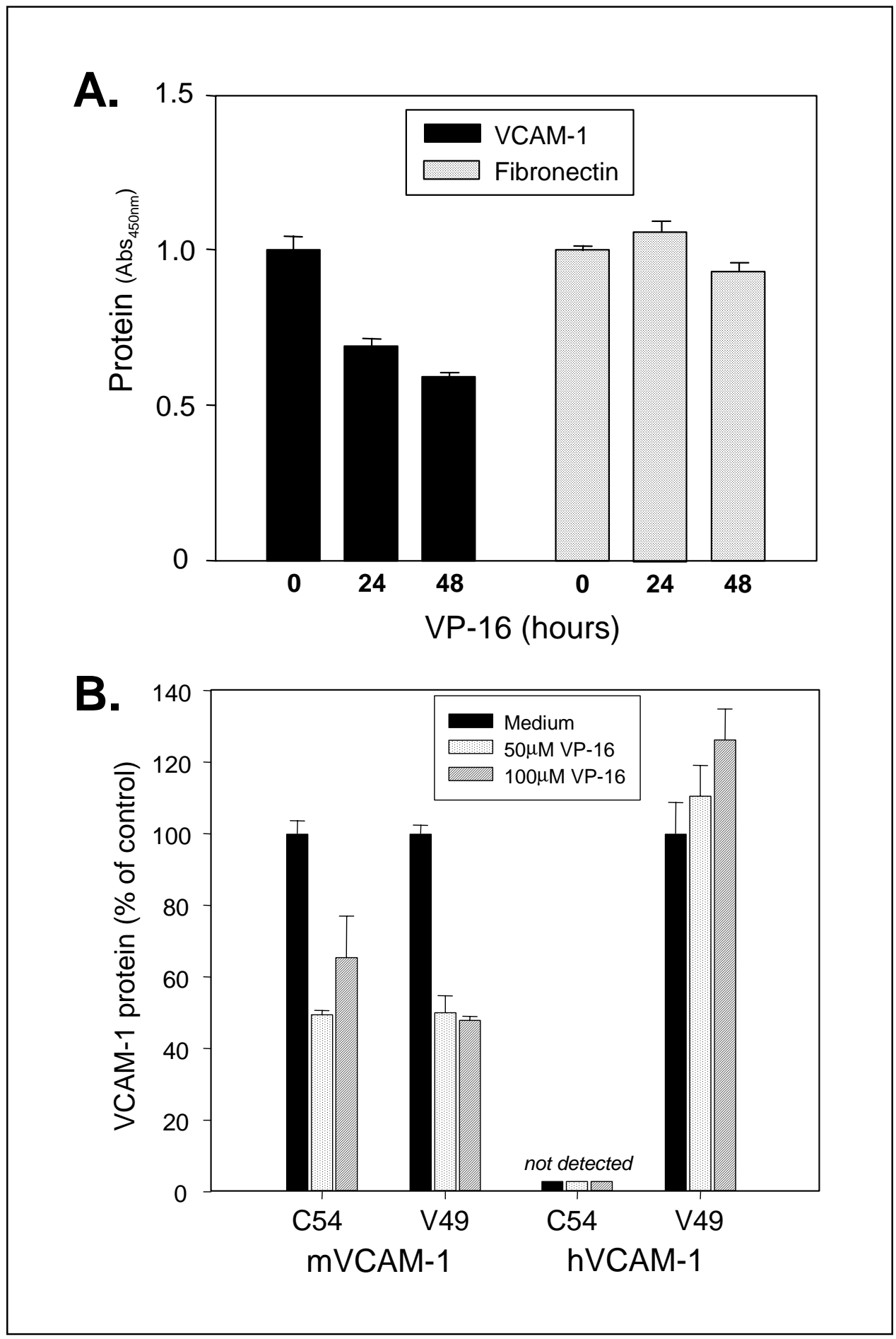


Figure 8. Expansion and survival of the stromal cell-dependent pro-B cell line C1.92 on C54 or V49 in the absence of rlL-7

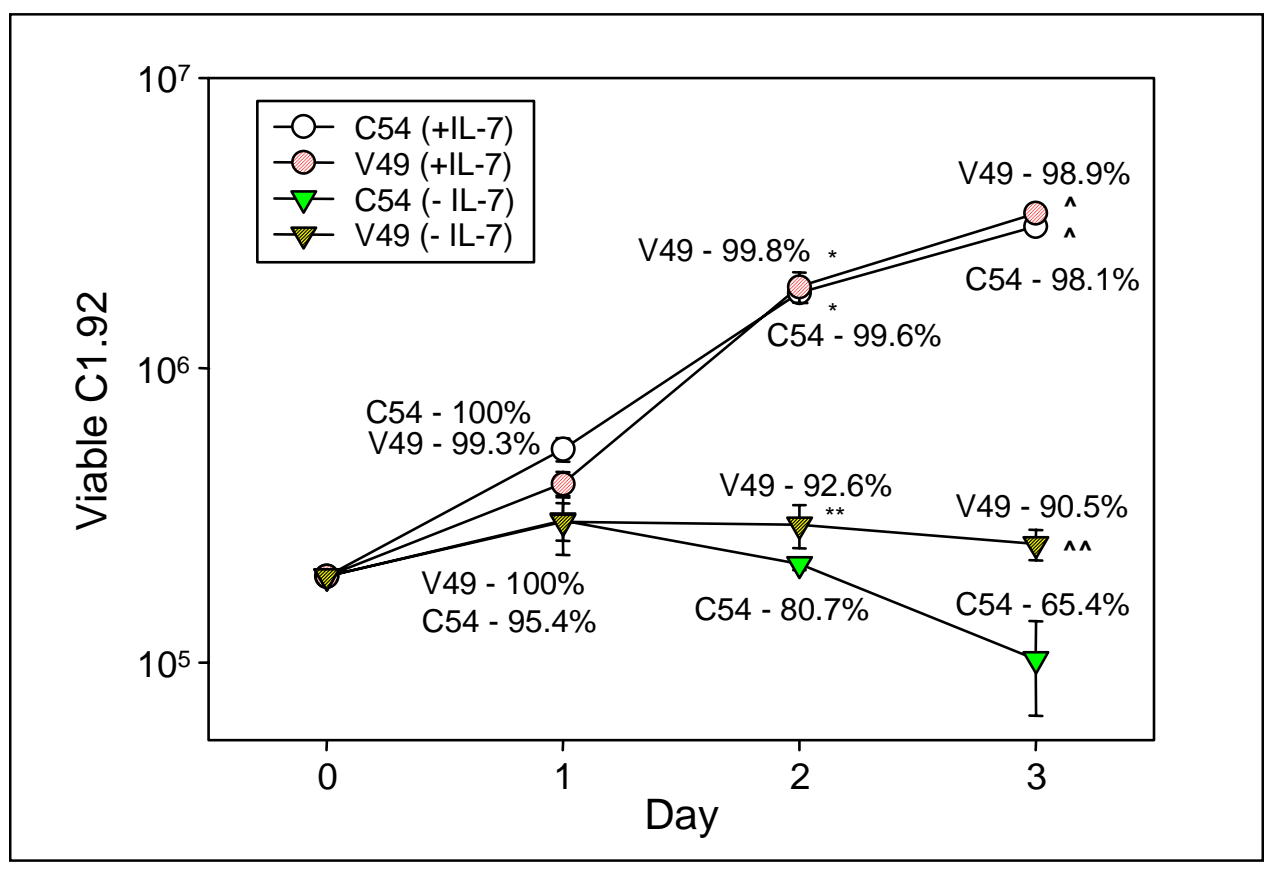




\title{
Chapter V
}

\author{
Discussion
}


The broad goal of this study was to evaluate how specific chemotherapeutic drugs affect the bone marrow microenvironment and its ability to support hematopoiesis. Hematological deficiencies following myelosuppressive chemotherapy or irradiation predispose patients to opportunistic pathogens and increase patient morbidity and mortality following bone marrow transplantation (BMT). Characterization of microenvironment damage following chemotherapy may lead to new preparative regimens that minimize bone marrow toxicity and support maximal hematopoietic recovery.

This study established that topoisomerase II inhibitors VP-16 and doxorubicin negatively impacted stromal cell SDF-1 protein production and contributed to functional deficits in stromal cell chemotactic signals (Chapter II). In addition, VP-16 exposure resulted in stromal cell molecular alterations that account for previous observations of reduced stromal cell VCAM-1 protein (Chapter III). Finally, established VCAM-1engineered stromal cell lines will allow us to further delineate the functional roles of altered VCAM-1 expression on stromal cells following chemotherapeutic exposures (Chapter IV).

Expression of stromal cell chemokines, adhesion molecules, and cytokines effect the ability of the microenvironment to support hematopoiesis. Previous work in our laboratory determined that human stromal cells exposed to VP-16 had reduced VCAM-1 protein (1). In addition, we observed that doxorubicin also disrupted stromal cell VCAM1 protein. In addition, VP-16 and doxorubicin reduced stromal cell SDF-1 production (Chapter II). Taken together, these observations support the premise that specific chemotherapeutic agents may blunt hematopoietic reconstitution by disrupting factors 
that underlie progenitor cell chemotaxis to, or retention within, appropriate stromal cell niches of the marrow microenvironment (Figure $1 \mathrm{a}-\mathrm{b})$.

Our model is based on functional in vitro evaluations of stromal cell damage following dose-escalated treatment with VP-16. Clinical treatment strategies commonly include various cocktails of chemotherapeutic agents alone or in conjunction with total body irradiation (2). Because complexities of multi-drug interactions with biological systems present challenges in defining precise damage to the bone marrow microenvironment in vivo, we narrowed our focus to the impact of single chemotherapeutic agents bone marrow stromal cells (3-11). VCAM-1 and SDF-1 support critical hematopoietic functions in stem cell maintenance, establishment of bone marrow hematopoiesis, B-cell development, hematopoietic cell bone marrow homing, and hematopoietic bone marrow retention (7;12-17), and VP-16 suppressed expression of these stromal cell proteins for extended periods of time (Chapter II and III).

Hematopoietic cell chemotaxis to, and retention within, the bone marrow relies on local and peripheral SDF-1 concentration gradients $(16 ; 18-25)$. We demonstrated that two independent topoisomerase II inhibitors, VP-16 and doxorubicin, functionally disrupted bone marrow stromal cell capacities to support efficient chemotaxis of immature hematopoietic cells by reducing stromal cell SDF-1 protein production. While a range of doses was tested for each drug, clinically relevant doses were chosen as the focus of our investigation. The functional ability of stromal cells to support chemotaxis of immature B-cells was markedly reduced by stromal cell exposure to either 
Figure 1. Model of hematopoietic delays associated with altered stromal cell function

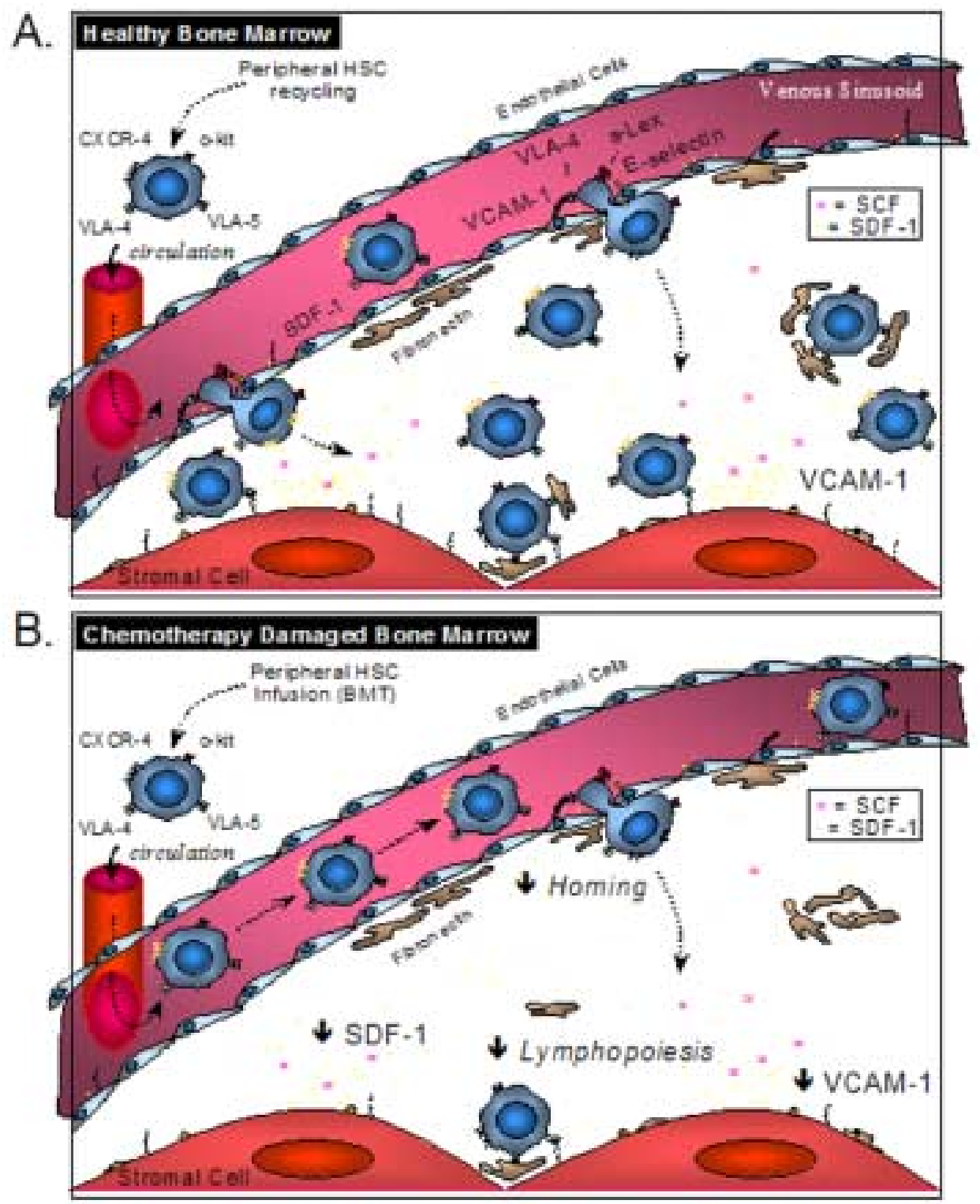


chemotherapeutic agent, consistent with the reduction of SDF-1 that was observed (Chapter II).

VP-16 is of particular interest as it is tolerated by patients at escalated doses, while doxorubicin use at high levels is limited by cardiac toxicities $(26 ; 27)$. Both topoisomerase II inhibitors decreased SDF-1 production by stromal cells, while cytosine arabinoside (Ara-C) or 4-hydroxycyclophosphamide (4-HC; the primary active metabolite of cyclophosphamide) treatment had no effect on SDF-1 levels. These observations suggested that reduction of stromal cell SDF-1 production may correlate with mechanisms of specific drugs or classes of drugs such as topoisomerase II inhibitors. These results may explain variable observations seen clinically in the ability of exogenous growth factors to facilitate lymphopoietic recovery (28-30).

Sustained deficits in hematopoietic recovery were noted following high dose chemotherapy and bone marrow transplantation in many studies (31-33). Consistent with delayed hematopoietic recovery following chemotherapy exposure, we observed sustained reductions of SDF-1 protein levels from chemotherapy treated stromal cells (Chapter II). This correlated with a functional impairment of chemotherapy treated stromal cells to support chemotaxis in vitro as well (Chapter II). Minimizing disruption of stromal cell production of SDF-1 following chemotherapy exposure would likely result in enhanced homing of hematopoietic stem cells to the bone marrow and shortened delays in hematopoietic recovery following bone marrow transplantation.

Previously, bone marrow stromal cells treated with VP-16 resulted in reduced stromal cell capacity to support survival and proliferation of lymphoid and myeloid progenitor cells. Diminished levels of VCAM-1 protein expression were also observed 
in that study (1). Because interaction of hematopoietic progenitor cells with VCAM-1 on stromal cells has been shown to be important for development of B cell progenitors (3437), we investigated the potential mechanism by which VP-16 exposure results in dysregulated VCAM-1 expression.

VP-16 exposure suppressed endogenous stromal cell VCAM-1 gene promoter activity through changes in nuclear NF-KB profiles resulting in diminished VCAM-1 RNA and protein. Recovery of p65 and p50 nuclear levels to baseline following brief exposure to VP-16 suggested an absence of permanent damage to stromal cells following short-term treatment (Chapter III). In addition, restoration of VCAM-1 protein following removal of drug occurred following a 24-hour VP-16 exposure but not following 72 hours (Chapter III). These observations suggested potential links between duration of drug exposure and severity of damage that may be as critical to microenvironment function as drug dose. Furthermore, the response of stromal cell NF-kB to specific chemotherapeutic agents may provide insight into mechanisms that contribute to a disrupted bone marrow microenvironment, and the delayed hematopoietic recovery that is associated with specific chemotherapeutic agents.

Stromal cell lines that constitutively express human VCAM-1 protein may be beneficial in restoration of bone marrow support of hematopoiesis following BMT (Figure 2). Our engineered stromal cell lines sustained vector specific gene expression following exposure to VP-16 and supported enhanced viability of pro-B cells in the absence of exogenous IL-7 (Chapter IV). These stromal cell lines may prove useful during bone marrow transplantation if stromal cells that over express VCAM-1 are coinfused with hematopoietic cells and engraft within the bone marrow (38-41). 
Figure 2. Corrective bone marrow environment following dose-escalated chemotherapy

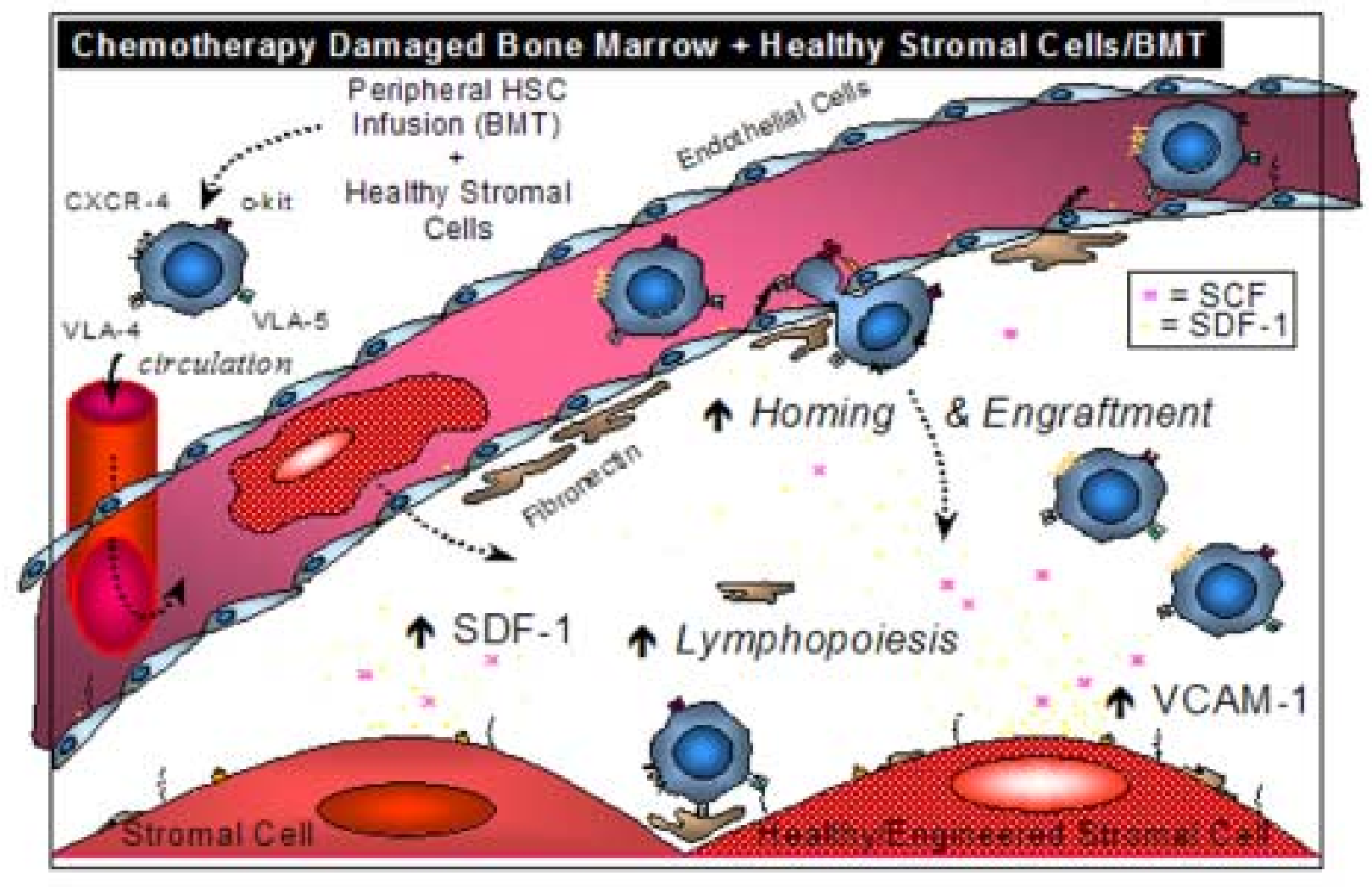


Constitutive VCAM-1 expressing stromal cells would maintain expression of VCAM-1, even in microenvironments containing residual cytotoxic compounds, and potentially restore and maintain baseline levels of B-lymphopoiesis (Figure 2).

Long-term engraftment of stromal cells has not been established. In fact, several studies have suggested that stromal cells have finite (<2 years) life spans following bone marrow engraftment $(42 ; 43)$. These studies suggest potential therapeutic uses of engineered stromal cells in enhancement of short-term B-lymphopoiesis following bone marrow transplantation with minimal long-term consequences.

As chemotherapy doses escalate to achieve maximal tumor cell death, stromal cell damage is inevitable $(12 ; 33 ; 44-47)$. Several recent studies have demonstrated that co-infusion or replacement of damaged cells with healthy stromal cells in conjunction with hematopoietic cells leads to enhanced hematopoietic recoveries following bone marrow transplantation $(38 ; 39)$. In the context of stromal cell replacement following ablative chemotherapy, stromal cells engineered to express specific hematopoietic growth factors or adhesion molecules may enhance stem cell maintenance and engraftment if established in correct microenvironments. Additionally, healthy stromal cells may enrich hematopoietic stem and progenitor cell homing, and restore robust Bcell development (Figure 2). As such, VCAM-1 engineered stromal cell lines may prove useful in therapeutic procedures during high-dose chemotherapy treatment strategies.

Restoration of hematopoiesis is often clinically defined as recovery of absolute numbers of neutrophils and platelets (2). However, this definition of hematopoietic recovery is incomplete and misleading. Hematopoietic recovery also encompasses restoration of $B$ and $T$ cell populations, bone marrow microenvironment cellularity, and 
functional competence of these cells. Several recent studies addressed the deficits of information on damage sustained to the functional capacity of bone marrow following ablative regiments of chemotherapy and irradiation $(2 ; 40 ; 45 ; 48 ; 49)$. Unfortunately, our understanding of the sustained damage and consequences of bone marrow microenvironmental toxicity remain incomplete (48).

Although bone marrow stromal cells demonstrate high radioresistance due to observed slow turnover rates in vivo $(50 ; 51)$, functional deficits of bone marrow stromal cells in osteogenic potential, proliferative capacity, and hematopoietic support $(1 ; 45 ; 47$ 49) are now being reported. With the reported success of high-dose chemotherapy in patients with various hematological and non-hematological cancers (52-54), it is essential to better define bone marrow microenvironmental damage following aggressive chemotherapy and bone marrow transplantation. A fundamental understanding of stromal cell damage is important for success in development of new treatment strategies, enhanced drug design, and other measures that minimize bone marrow microenvironment toxicity.

This study has focused on myelosupportive alterations of stromal cells following chemotherapy exposure. Another common consequence of stromal cell damage is dysregulation of bone mineral metabolism. Recent work has begun to characterize mechanisms contributing to diminished bone mineral density (BMD) and osteoporosis in patients following bone marrow transplantation $(55 ; 56)$. One group identified reduced capacities of bone marrow stromal cells to differentiate into osteoblasts when evaluated ex vivo from patients who had recently undergone bone marrow transplantation (57). Other studies documented enhanced bone mineral absorption in conjunction with 
diminished bone formation in patients following bone marrow transplantation (58-60). Although it is clear that altered stromal cell function contributes to these observations, mechanisms of stromal cell damage leading to alterations in bone mineral metabolism are poorly understood.

In conclusion, bone marrow stromal cells have been defined as a radioresistant population (50;51), but it is clear that they sustain widespread molecular and functional damage following preparative treatment regimens and bone marrow transplantation. Diminished self-renewal, hematopoietic support, and multipotential differentiation are three defined areas of stromal cell dysregulation following bone marrow transplantation. The efficacy of cytotoxic treatment strategies must consider the long-term damage sustained to bone marrow stromal cells, or alternatively, further progress in restoration of the bone marrow microenvironment through stromal cell transplantation for must be developed $(61 ; 62)$. 


\section{REFERENCES}

1. Gibson,L.F., Fortney,J., Landreth,K.S., Piktel,D., Ericson,S.G., and Lynch,J.P. (1997): Disruption of bone marrow stromal cell function by etoposide. Biol.Blood Marrow Transplant., 3:122-132.

2. Guillaume,T., Rubinstein,D.B., and Symann,M. (1998): Immune reconstitution and immunotherapy after autologous hematopoietic stem cell transplantation. Blood, 92:1471-1490.

3. Stoddart,A., Fleming,H.E., and Paige,C.J. (2001): The role of homotypic interactions in the differentiation of B cell precursors. Eur.J Immunol., 31:1160-1172.

4. LeBien,T.W. (1998): B-cell lymphopoiesis in mouse and man. Curr.Opin.Immunol., 10:188-195.

5. Tang,J., Nuccie,B.L., Ritterman,I., Liesveld,J.L., Abboud,C.N., and Ryan,D.H. (1997): TGF-beta down-regulates stromal IL-7 secretion and inhibits proliferation of human B cell precursors. J Immunol., 159:117-125.

6. Prieyl,J.A. and LeBien,T.W. (1996): Interleukin 7 independent development of human B cells. Proc.Natl.Acad.Sci.U.S.A, 93:10348-10353.

7. Funk,P.E., Stephan,R.P., and Witte,P.L. (1995): Vascular cell adhesion molecule 1positive reticular cells express interleukin-7 and stem cell factor in the bone marrow. Blood, 86:2661-2671.

8. Peault,B. (1995): In-vitro models of stroma-dependent lymphopoiesis. Semin.Immunol., 7:169-175.

9. Witte,P.L., Frantsve,L.M., Hergott,M., and Rahbe,S.M. (1993): Cytokine production and heterogeneity of primary stromal cells that support B lymphopoiesis. Eur.J Immunol., 23:1809-1817.

10. Billips,L.G., Petitte,D., and Landreth,K.S. (1990): Bone marrow stromal cell regulation of $B$ lymphopoiesis: interleukin-1 (IL-1) and IL-4 regulate stromal cell support of pre-B cell production in vitro. Blood, 75:611-619. 
11.Sudo,T., Ito,M., Ogawa,Y., lizuka,M., Kodama,H., Kunisada,T., Hayashi,S., Ogawa,M., Sakai,K., and Nishikawa,S. (1989): Interleukin 7 production and function in stromal cell-dependent B cell development. J Exp.Med., 170:333-338.

12. Dittel,B.N. and LeBien,T.W. (1995): Reduced expression of vascular cell adhesion molecule-1 on bone marrow stromal cells isolated from marrow transplant recipients correlates with a reduced capacity to support human B lymphopoiesis in vitro. Blood, 86:2833-2841.

13. Ryan,D.H. (1993): Adherence of normal and neoplastic human B cell precursors to the bone marrow microenvironment. Blood Cells, 19:225-241.

14. Kincade,P.W. (1992): Cell interaction molecules and cytokines which participate in B lymphopoiesis. Baillieres Clin.Haematol., 5:575-598.

15. Levesque,J.P., Takamatsu,Y., Nilsson,S.K., Haylock,D.N., and Simmons,P.J. (2001): Vascular cell adhesion molecule-1 (CD106) is cleaved by neutrophil proteases in the bone marrow following hematopoietic progenitor cell mobilization by granulocyte colony-stimulating factor. Blood, 98:1289-1297.

16. Egawa,T., Kawabata,K., Kawamoto,H., Amada,K., Okamoto,R., Fujii,N., Kishimoto,T., Katsura,Y., and Nagasawa,T. (2001): The earliest stages of B cell development require a chemokine stromal cell-derived factor/pre-B cell growthstimulating factor. Immunity., 15:323-334.

17. Nagasawa,T., Kikutani,H., and Kishimoto,T. (1994): Molecular cloning and structure of a pre-B-cell growth-stimulating factor. Proc.Natl.Acad.Sci.U.S.A, 91:2305-2309.

18. Nagasawa,T., Hirota,S., Tachibana,K., Takakura,N., Nishikawa,S., Kitamura,Y., Yoshida,N., Kikutani,H., and Kishimoto,T. (1996): Defects of B-cell lymphopoiesis and bone-marrow myelopoiesis in mice lacking the CXC chemokine PBSF/SDF-1. Nature, 382:635-638.

19.Zou,Y.R., Kottmann,A.H., Kuroda,M., Taniuchi,I., and Littman,D.R. (1998): Function of the chemokine receptor CXCR4 in haematopoiesis and in cerebellar development. Nature, 393:595-599.

20.Ma,Q., Jones,D., Borghesani,P.R., Segal,R.A., Nagasawa,T., Kishimoto,T., Bronson,R.T., and Springer,T.A. (1998): Impaired B-lymphopoiesis, myelopoiesis, 
and derailed cerebellar neuron migration in CXCR-4-deficient mice. Proc.Natl.Acad.Sci.U.S.A, 95:9448-9453.

21. Tashiro,K., Tada,H., Heilker,R., Shirozu,M., Nakano,T., and Honjo,T. (1993): Signal sequence trap: a cloning strategy for secreted proteins and type I membrane proteins. Science, 261:600-603.

22. Bleul,C.C., Fuhlbrigge,R.C., Casasnovas,J.M., Aiuti,A., and Springer,T.A. (1996): A highly efficacious lymphocyte chemoattractant, stromal cell-derived factor 1 (SDF-1). J Exp.Med., 184:1101-1109.

23. Prosper,F. and Verfaillie,C.M. (2001): Regulation of hematopoiesis through adhesion receptors. J Leukoc.Biol., 69:307-316.

24. Kim,C.H. and Broxmeyer,H.E. (1998): In vitro behavior of hematopoietic progenitor cells under the influence of chemoattractants: stromal cell-derived factor-1, steel factor, and the bone marrow environment. Blood, 91:100-110.

25. Voermans,C., Anthony,E.C., Mul,E., van der,S.E., and Hordijk,P. (2001): SDF-1induced actin polymerization and migration in human hematopoietic progenitor cells. Exp.Hematol., 29:1456-1464.

26. Legha,S.S., Benjamin,R.S., Mackay,B., Ewer,M., Wallace,S., Valdivieso,M., Rasmussen,S.L., Blumenschein,G.R., and Freireich,E.J. (1982): Reduction of doxorubicin cardiotoxicity by prolonged continuous intravenous infusion. Ann.Intern.Med., 96:133-139.

27. Haq,M.M., Legha,S.S., Choksi,J., Hortobagyi,G.N., Benjamin,R.S., Ewer,M., and Ali,M. (1985): Doxorubicin-induced congestive heart failure in adults. Cancer, 56:1361-1365.

28. Appasamy,P.M. (1999): Biological and clinical implications of interleukin-7 and lymphopoiesis. Cytokines Cell Mol.Ther., 5:25-39.

29. Komschlies,K.L., Grzegorzewski,K.J., and Wiltrout,R.H. (1995): Diverse immunological and hematological effects of interleukin 7: implications for clinical application. J Leukoc.Biol., 58:623-633. 
30. Mertsching,E., Meyer,V., Linares,J., Lombard-Platet,S., and Ceredig,R. (1998): Interleukin-7, a non-redundant potent cytokine whose over-expression massively perturbs B-lymphopoiesis. Int.Rev.Immunol., 16:285-308.

31.Thomas,M.R., Robinson,W.A., Mughal,T.I., Morton,N., and Glode,L.M. (1986): Recovery of blood and bone marrow stem cells following intense chemotherapy and autologous bone marrow transplantation. Oncology, 43:273-277.

32. del Canizo,C., Lopez,N., Caballero,D., Fernandez,E., Brufau,A., Vazquez,L., Mateos,V., Gutierrez,N., and San Miguel,J.F. (1999): Haematopoietic damage persists 1 year after autologous peripheral blood stem cell transplantation. Bone Marrow Transplant., 23:901-905.

33. Fried,W. and Barone,J. (1980): Residual marrow damage following therapy with cyclophosphamide. Exp. Hematol., 8:610-614.

34. Jacobsen,K., Kravitz,J., Kincade,P.W., and Osmond,D.G. (1996): Adhesion receptors on bone marrow stromal cells: in vivo expression of vascular cell adhesion molecule- 1 by reticular cells and sinusoidal endothelium in normal and gammairradiated mice. Blood, 87:73-82.

35. Kincade,P.W., Yamashita,Y., Borghesi,L., Medina,K., and Oritani,K. (1998): Blood cell precursors in context. Composition of the bone marrow microenvironment that supports B lymphopoiesis. Vox Sang., 74 Suppl 2:265-268.

36. Miyake,K., Medina,K., Ishihara,K., Kimoto,M., Auerbach,R., and Kincade,P.W. (1991): A VCAM-like adhesion molecule on murine bone marrow stromal cells mediates binding of lymphocyte precursors in culture. J Cell Biol., 114:557-565.

37. Miyake,K., Weissman,I.L., Greenberger,J.S., and Kincade,P.W. (1991): Evidence for a role of the integrin VLA-4 in lympho-hemopoiesis. J Exp.Med., 173:599-607.

38. Janczewska,S., Ziolkowska,A., Durlik,M., Cybulska,E., Olszewski,W.L., and Lukomska,B. (1999): Requirement of stromal cells in the bone marrow transplant for rapid lymphoid replenishment. Transplant.Proc., 31:696-699.

39. Koc,O.N., Gerson,S.L., Cooper,B.W., Dyhouse,S.M., Haynesworth,S.E., Caplan,A.I., and Lazarus,H.M. (2000): Rapid hematopoietic recovery after coinfusion of autologous-blood stem cells and culture-expanded marrow mesenchymal stem cells 
in advanced breast cancer patients receiving high-dose chemotherapy. $J$ Clin.Oncol., 18:307-316.

40. Mauch,P., Constine,L., Greenberger,J., Knospe,W., Sullivan,J., Liesveld,J.L., and Deeg,H.J. (1995): Hematopoietic stem cell compartment: acute and late effects of radiation therapy and chemotherapy. Int.J Radiat.Oncol.Biol.Phys., 31:1319-1339.

41. Dominici,M., Hofmann,T.J., and Horwitz,E.M. (2001): Bone marrow mesenchymal cells: biological properties and clinical applications. J Biol.Regul.Homeost.Agents, 15:28-37.

42. Horwitz,E.M., Prockop,D.J., Fitzpatrick,L.A., Koo,W.W., Gordon,P.L., Neel,M., Sussman,M., Orchard,P., Marx,J.C., Pyeritz,R.E., and Brenner,M.K. (1999): Transplantability and therapeutic effects of bone marrow-derived mesenchymal cells in children with osteogenesis imperfecta. Nat Med., 5:309-313.

43. Horwitz,E.M., Prockop,D.J., Gordon,P.L., Koo,W.W., Fitzpatrick,L.A., Neel,M.D., McCarville,M.E., Orchard,P.J., Pyeritz,R.E., and Brenner,M.K. (2001): Clinical responses to bone marrow transplantation in children with severe osteogenesis imperfecta. Blood, 97:1227-1231.

44. Gardner,R.V. (1999): Long term hematopoietic damage after chemotherapy and cytokine. Front Biosci., 4:e47-e57

45.Galotto,M., Berisso,G., Delfino,L., Podesta,M., Ottaggio,L., Dallorso,S., Dufour,C., Ferrara,G.B., Abbondandolo,A., Dini,G., Bacigalupo,A., Cancedda,R., and Quarto,R. (1999): Stromal damage as consequence of high-dose chemo/radiotherapy in bone marrow transplant recipients. Exp. Hematol., 27:1460-1466.

46. Schwartz,G.N., Warren,M.K., Rothwell,S.W., Zujewski,J., Halverson,D.C., Cowan,K.H., Tolcher,A., O'Shaughnessy,J., and Gress,R.E. (1998): Postchemotherapy and cytokine pretreated marrow stromal cell layers suppress hematopoiesis from normal donor CD34+ cells. Bone Marrow Transplant., 22:457468.

47. Migliaccio,A.R., Migliaccio,G., Johnson,G., Adamson,J.W., and Torok-Storb,B. (1990): Comparative analysis of hematopoietic growth factors released by stromal cells from normal donors or transplanted patients. Blood, 75:305-312. 
48. Banfi,A., Bianchi,G., Galotto,M., Cancedda,R., and Quarto,R. (2001): Bone marrow stromal damage after chemo/radiotherapy: occurrence, consequences and possibilities of treatment. Leuk.Lymphoma, 42:863-870.

49. Piersma,A.H., Ploemacher,R.E., and Brockbank,K.G. (1983): Radiation damage to femoral hemopoietic stroma measured by implant regeneration and quantitation of fibroblastic progenitors. Exp. Hematol., 11:884-890.

50. Patt,H.M. and Maloney,M.A. (1975): Bone marrow regeneration after local injury: a review. Exp.Hematol., 3:135-148.

51. Osmond DG (1964): Radioautographic Studies of Bone Marrow Lymphocytes in vivo and in Diffusion Chamber Cultures. Blood, 23:1-17.

52. Nademanee,A., $\quad$ O'Donnell,M.R., $\quad$ Snyder,D.S., Schmidt,G.M., $\quad$ Parker,P.M., Stein,A.S., Smith,E.P., Molina,A., Stepan,D.E., Somlo,G., and . (1995): High-dose chemotherapy with or without total body irradiation followed by autologous bone marrow and/or peripheral blood stem cell transplantation for patients with relapsed and refractory Hodgkin's disease: results in 85 patients with analysis of prognostic factors. Blood, 85:1381-1390.

53. Herzig,R.H., Lynch,J., Christiansen,N.P., Fay,J.W., Davis,M.P., and Herzig,G.P. (1996): Dose-intensive chemotherapy with etoposide-cyclophosphamide for advanced breast cancer. North American Marrow Transplant Group. Semin.Oncol., 23:28-32.

54. Nichols,C. and Maziarz,R. (1999): High dose chemotherapy--results of American studies. Int.J Cancer, 83:841-843.

55. Kang,M.I., Lee,W.Y., Oh,K.W., Han,J.H., Song,K.H., Cha,B.Y., Lee,K.W., Son,H.Y., Kang,S.K., and Kim,C.C. (2000): The short-term changes of bone mineral metabolism following bone marrow transplantation. Bone, 26:275-279.

56. Schimmer,A.D., Mah,K., Bordeleau,L., Cheung,A., Ali,V., Falconer,M., Trus,M., and Keating,A. (2001): Decreased bone mineral density is common after autologous blood or marrow transplantation. Bone Marrow Transplant., 28:387-391.

57.Lee,W.Y., Cho,S.W., Oh,E.S., Oh,K.W., Lee,J.M., Yoon,K.H., Kang,M.I., Cha,B.Y., Lee,K.W., Son,H.Y., Kang,S.K., and Kim,C.C. (2002): The effect of bone marrow 
transplantation on the osteoblastic differentiation of human bone marrow stromal cells. J.Clin.Endocrinol.Metab, 87:329-335.

58. Kananen,K., Volin,L., Tahtela,R., Laitinen,K., Ruutu,T., and Valimaki,M.J. (2002): Recovery of bone mass and normalization of bone turnover in long-term survivors of allogeneic bone marrow transplantation. Bone Marrow Transplant., 29:33-39.

59. Kauppila,M., Irjala,K., Koskinen,P., Pulkki,K., Sonninen,P., Viikari,J., and Remes,K. (1999): Bone mineral density after allogeneic bone marrow transplantation. Bone Marrow Transplant., 24:885-889.

60. Ebeling,P.R., Thomas,D.M., Erbas,B., Hopper,J.L., Szer,J., and Grigg,A.P. (1999): Mechanisms of bone loss following allogeneic and autologous hemopoietic stem cell transplantation. J.Bone Miner.Res., 14:342-350.

61. Van Damme,A., Vanden Driessche,T., Collen,D., and Chuah,M.K. (2002): Bone marrow stromal cells as targets for gene therapy. Curr.Gene Ther., 2:195-209.

62. Devine,S.M. (2002): Mesenchymal stem cells: will they have a role in the clinic? J.Cell Biochem.Suppl, Suppl 38:73-79. 
Date of Birth: June 11, 1968 (Toledo, OH)

Social Security Number: 288-64-8304

$\underline{\text { Home }}$

1551 St. Rt. 314 South

Mansfield, OH 44903

(419) 492-3222

we3halls@juno.com
Work

West Virginia University Health Sciences Center Box 9177

Morgantown, WV 26506

Phone: (304) 293-5820

FAX: (304) 293-4341

\section{EDUCATION EXPERIENCE}

Ph.D. (2002)

Department of Microbiology, Immunology and Cell Biology

West Virginia University

Health Sciences Center

Morgantown, WV 26506

B.S. (1997)

Department of Biochemistry

Ohio State University

Columbus, $\mathrm{OH} 43210$

RESEARCH EXPERIENCE

Rotations:

Laboratory of Laura Gibson, Ph.D.

Topic: Cellular localization changes of NF-kB in bone marrow stromal cells following exposure to etoposide.

Laboratory of Christopher Cuff, Ph.D.

Topic: Reovirus as a possible vaccine vector.

Laboratory of Wei-Shau Hu

Topic: The role of the Cys-His motif in the NC domain of MLV and SNV RNA during non-reciprocal recognition. 


\section{Doctoral Studies:}

Laboratory of Laura F. Gibson, Ph.D.

Topic: Bone marrow stromal cell VCAM-1 and SDF-1 expression following etoposide exposure.

Following aggressive chemotherapy and bone marrow transplantation, immune system reconstitution relies on both successful homing to and retention within the bone marrow microenvironment of donor hematopoietic cells. My work has focused on characterization of chemotherapy-induced bone marrow stromal cell damage with a specific focus on altered adhesion molecule and chemokine expression. The long-term goal of this work is the development of intervention strategies that minimize bone marrow microenvironment damage and enhance recovery times following bone marrow transplantation.

Laboratory techniques: ELISA, Western analysis, immunoprecipitation, bacterial culture, plasmid vector design and construction, cell line cloning, conventional and "Real-Time" RT-PCR, PCR primer design, tissue culture (human and murine), transient and stable transfection (mammalian cell lines), surface and intracellular FACS, electrophoretic mobility shift assay (EMSA), RNase protection assay (RPA), chloramphenicol acetyl transferase (CAT) reporting assay, $\beta$ galactosidase reporting assay, colony forming unit-fibroblast (CFU-F) assay, RNA/DNA isolation from tissue or cell culture, cellular nuclear extraction, immunofluorescent confocal microscopy, radioactivity training, animal care and handling training, polyacrylamide gel silver staining, in vivo (murine) techniques including: establishment of bone marrow stromal cell lines, cellular transplantation (via tail vein), spleen and bone marrow harvest, intraperitoneal and intravenous drug administration.

\section{PRESENTATIONS AND LECTURES}

1998 "HIV and AIDS (current research topics)"

Visiting Lecturer

Ohio State University; Mansfield, Ohio

1999 "The effects of chemotherapy on bone marrow stromal cell function"

VanLiere Research Convocation

West Virginia University; Morgantown, West Virginia

1999 "What is cancer?"

Visiting Lecturer

Ohio State University; Mansfield, Ohio

2000 "Two common laboratory techniques: Western analysis and ELISA" Visiting Lecturer

Ohio State University; Mansfield, Ohio 
$2001 \quad$ "Effects of high dose chemotherapy on the bone marrow microenvironment"

Department of Microbiology, Immunology and Cell Biology

Annual Student Seminar Series (1998-2001)

West Virginia University; Morgantown, West Virginia

\section{PUBLICATIONS}

Mudry RE, Fortney JE, York T, Hall BM, Gibson LF. (2000) Stromal cells regulate survival of B-lineage leukemic cells during chemotherapy. Blood 96(5):1926-32.

Hall BM, Fortney JE, Gibson LF. (2001) Alteration of nuclear factor-kB expression in bone marrow stromal cells treated with etoposide. Biochemical Pharmacology 61(10):1243-52.

Hall BM, Fortney JE, Gibson LF. (2002) Human bone marrow stromal cell SDF-1 production is reduced following exposure to etoposide or doxorubicin. Analytical Pharmacology (in press).

Fortney JE, Hall BM, Bartrug L, Gibson LF. (2002) Chemotherapy induces Bcl-2 cleavage in lymphoid leukemic cell lines. Leukemia and Lymphoma (in press).

\section{ABSTRACTS}

Mudry RE, Fortney JE, York T, Hall BM, Gibson LF. (2000) Stromal cells regulate survival of JM-1 leukemic cells during chemotherapy. American Association of Cancer Research Special Apoptosis Conference; Vancouver, Canada.

Hall BM, Fortney JE, Gibson L. (2002) Bone marrow stromal cell SDF-1 production is reduced following exposure to etoposide. FASEB meeting; New Orleans, Lousiania.

Mellad JA, Peister A, Gibson LF, Hall BM, Prockop DJ. (2002) Isolation, expansion and characterization of murine marrow stromal cells. Second Annual Conference on Mesenchymal and Nonhematopoietic Stem Cells; New Orleans, Louisiana.

TEACHING EXPERIENCE

1997-1998 Microbiology Graduate Teaching Assistant Medical Microbiology

1998-2002 Graduate Research Assistant Laboratory Based Teaching: 
Wei Zhao, MD (Dept. of Pediatrics Resident)

Theresa York, MD (Dept. of Pediatrics Resident)

Ryan Mudry (Dept. of Biology Honors Student) Jacob Barkley (Biology Undergraduate Student)

Lindsay Bartrug (Summer Research Fellowship Program)

Nathan Alfred (Summer Research Fellowship Program)

AWARDS AND ACTIVITIES

1986-1990

United State Air Force

Missile Systems Maintenance Specialist

Honorable Discharge: 1/2/90

1991-1992

Ohio State University Graduate Student Council

Mansfield Campus Representative

1992

Chemistry Department Scholarship

Ohio State University, Mansfield Campus

1993-1997

Huntington National Bank

Personal Banker

Investment Specialist

1998

VanLiere Research Convocation Seminar

$3^{\text {rd }}$ Place Award

$1998-2000$

West Virginia University

Department of Microbiology, Immunology and Cell Biology

Departmental Graduate Student Representative

2000-2002

West Virginia University

Graduate Student Council

Graduate Student Representative School of Medicine

Committee Vice-Chair

2000-2002 West Virginia University

Faculty Graduate Student Council

Graduate Student Council Representative 